University of Louisville

ThinkIR: The University of Louisville's Institutional Repository

Electronic Theses and Dissertations

$5-2007$

\title{
Instructor perceptions of student learning in secondary and postsecondary algebra classes.
}

Jane Ann Houseman Jones 1940-

University of Louisville

Follow this and additional works at: https://ir.library.louisville.edu/etd

\section{Recommended Citation}

Jones, Jane Ann Houseman 1940-, "Instructor perceptions of student learning in secondary and postsecondary algebra classes." (2007). Electronic Theses and Dissertations. Paper 706.

https://doi.org/10.18297/etd/706

This Doctoral Dissertation is brought to you for free and open access by ThinkIR: The University of Louisville's Institutional Repository. It has been accepted for inclusion in Electronic Theses and Dissertations by an authorized administrator of ThinkIR: The University of Louisville's Institutional Repository. This title appears here courtesy of the author, who has retained all other copyrights. For more information, please contact thinkir@louisville.edu. 
INSTRUCTOR PERCEPTIONS OF STUDENT LEARNING IN SECONDARY AND POSTSECONDARY ALGEBRA CLASSES

\author{
By \\ Jane Ann Housman Jones \\ B.A., Hanover College, 1962 \\ M.A.T., University of Louisville, 1979

\begin{abstract}
A Dissertation
Submitted to the Faculty of the

Graduate School of the University of Louisville

in Partial Fulfillment of the Requirements

for the Degree of
\end{abstract} \\ Doctor of Philosophy \\ Department of Teaching and Learning \\ University of Louisville \\ Louisville, Kentucky
}

May, 2007 

Copyright 2007 by Jane H. Jones

All rights reserved 


\title{
INSTRUCTOR PERCEPTIONS OF STUDENT LEARNING IN SECONDARY AND POSTSECONDARY ALGEBRA CLASSES
}

\author{
By \\ Jane Ann Housman Jones \\ B.A., Hanover College, 1962 \\ M.A.T. University of Louisville, 1979
}

A Dissertation Approved on

December 7, 2006

By the following Dissertation committee:

Robert N. Ronau, Dissertation Director

Joseph Petrosko

Richard M. Davitt

William S. Bush

Namok Choi 


\title{
DEDICATION
}

This dissertation is dedicated to my husband

\author{
Richard Quentin Jones \\ and my sons \\ Brian Christopher Jones \\ and \\ Gregory Scott Jones
}

for their support and encouragement these past six years. 


\section{ACKNOWLEDGMENTS}

I would like to thank my dissertation chair, Dr. Robert Ronau, for his guidance and support. I would never have completed this dissertation without his persistence and patience with my inconsistencies and procrastinations and his not accepting any excuses for not completing the work. I would also like to thank the other members of my committee, Dr. William Bush, Dr. Richard Davitt, Dr. Namok Choi, and Dr. Joseph Petrosko for their advice and encouragement throughout the past six years and Dr. Karen Karp for her support in the early years of my program. I would also like to thank my husband, Richard, who spent many hours alone without complaint. Thanks also to my sons and their wives, Brian, Kellie, Greg, and Jennifer, who have provided so much encouragement and support, especially during these past difficult months. Finally, I want to thank my parents, the late Elizabeth and Walter Housman, who encouraged and supported my academic goals from my earliest school years. 


\section{ABSTRACT \\ INSTRUCTOR PERCEPTIONS OF STUDENT LEARNING IN SECONDARY AND POSTSECONDARY ALGEBRA CLASSES}

Jane H. Jones

May 12, 2007

The purpose of this study was to investigate various secondary to postsecondary mathematics transition issues for students. Making successful transitions from high school to postsecondary study has become necessary if our nation's young people are to obtain and hold good-paying jobs in the workplace. Knowledge of algebra is the critical gatekeeper for success in completing high school and postsecondary training. Nationwide $22 \%$ of entering freshmen at degree-granting institutions are under-prepared for college mathematics and must enroll in developmental mathematics classes that repeat the content of high school mathematics courses.

Researchers have documented disconnects between secondary and postsecondary mathematics' expectations and assessments. Reform initiatives, many of which are working in isolation from each other, have been undertaken at both the secondary and postsecondary level, but little research has been conducted to determine whether there are differences in instructor beliefs at the secondary and postsecondary level that may impact the transitions for students in mathematics. 
A researcher-developed survey was administered to a random sample of high school, two-year community and technical college, and four-year college and university mathematics instructors in Kentucky to determine how well they believed students were mastering American Diploma Project algebra benchmarks in high school, non-creditbearing, and credit-bearing college algebra classes.

Findings indicated there are differences in high school and four-year college and university and high school and two-year community college instructors' perceptions of perceived algebra learning in high school classes and in credit-bearing college algebra classes, with high school teachers consistently rating mastery of algebra topics higher than the college instructors.

Research indicates that instructor perceptions have an impact on instruction and on student learning. Differences in instructor perceptions of student learning in key transition algebra classes may affect the quality of instruction, and consequently equity for all students may be in jeopardy. Significant three-way dialogue between high school, community college, and four-year college and university instructors is needed in order to mediate differences in instructor beliefs and find ways to enable students to make successful transitions from high school to college mathematics. 
TABLE OF CONTENTS

\section{PAGE}

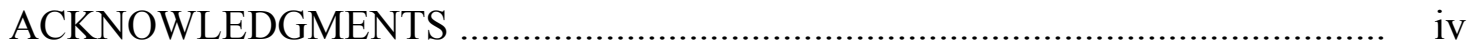

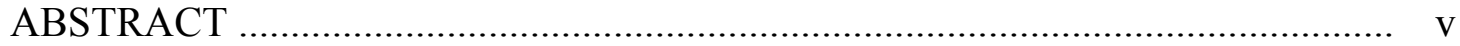

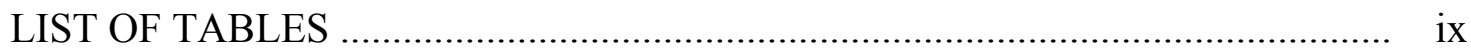

\section{CHAPTER}

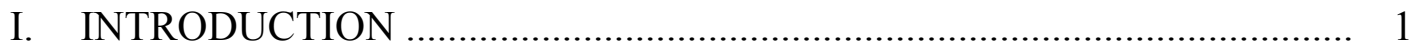

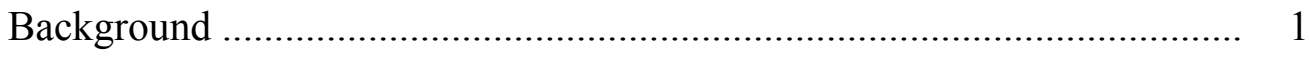

Misalignments Between Secondary and Postsecondary Expectations ......... 6

Initiatives Designed to Improve Transitions ................................................ 9

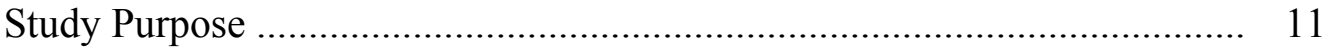

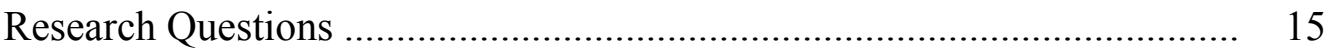

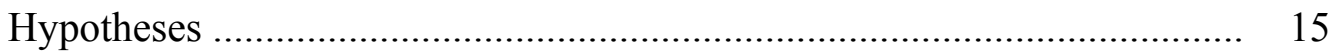

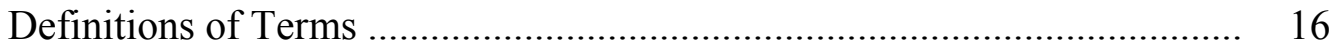

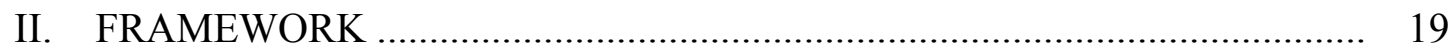

Growth of Mathematics Education in the United States .............................. 19

Current Status of Mathematics Education ............................................... 63

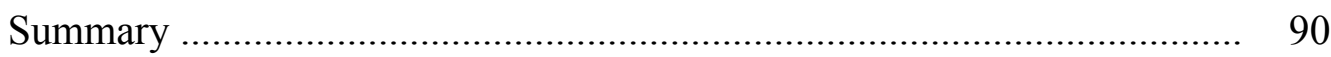

Purpose of this Study ......................................................................... 92

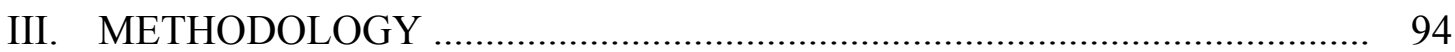

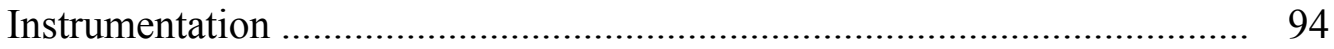




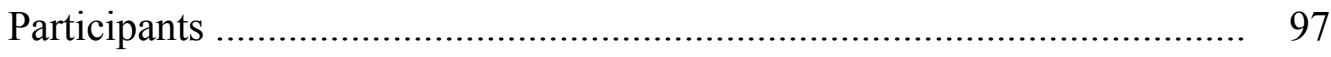

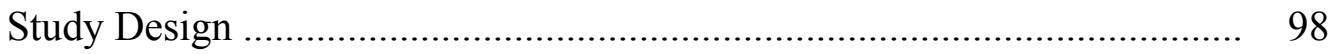

Variables ............................................................................... 99

Pilot Study ................................................................................ 104

Statistical Analysis .................................................................... 114

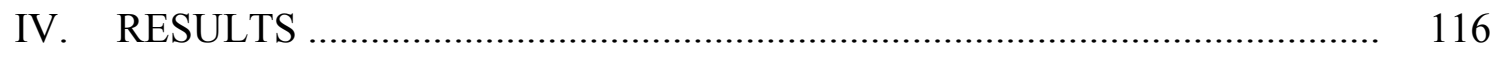

Study Participants ...................................................................... 117

Descriptive Statistics ............................................................... 117

Reliability Analysis ................................................................ 125

Data Analysis ........................................................................ 126

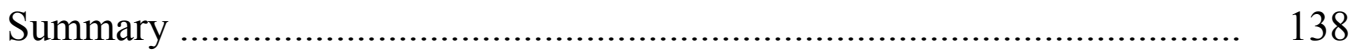

V. DISCUSSION AND IMPLICATIONS ............................................. 142

Discussion ................................................................................... 143

Limitations .............................................................................. 154

Implications ….......................................................................... 155

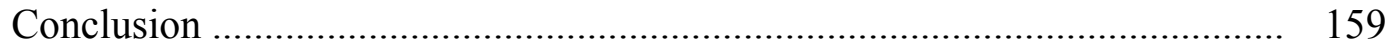

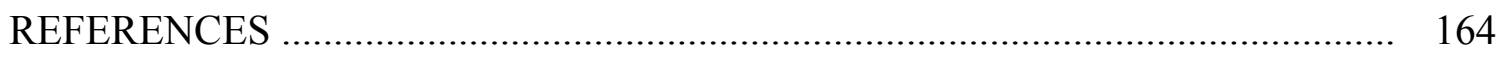

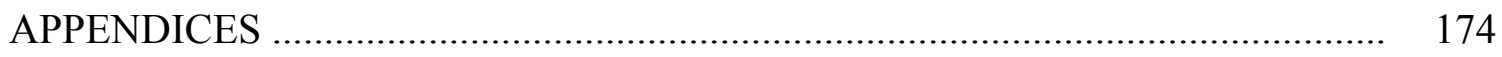

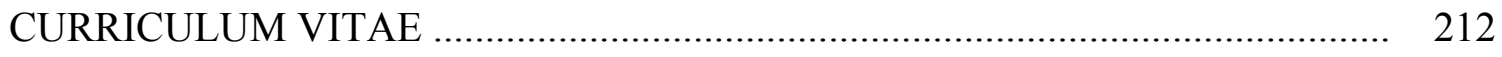




\section{LIST OF TABLES}

\section{TABLE}

1. Sub-Dependent Variables ..................................................................... 103

2. Number of Participants in Key Variable Categories: Pilot .......................... 106

3. High School Mean Algebra Learning Scores and Std. Deviations:

Pilot Test - Retest ............................................................................ 108

4. Non-Credit Bearing College Mean Algebra Learning Scores and Std.

Deviations: Pilot Test - Retest .................................................................... 109

5. Credit Bearing College Mean Algebra Learning Scores and Std.

Deviations: Pilot Test - Retest ........................................................... 110

6. Cronbach Alphas for Algebra Content in Each Classroom Setting - Pilot

Test

7. Descriptive Statistics for Study Participants ............................................... 119

8. Educational Background of Study Participants ...................................... 121

9. Number of Years Teaching at Institutional Level ...................................... 122

10. Mathematics Courses Taught by Participants in the Last Five Years ............ 123

11. Reliability Analysis - Cronbach Alpha Values ........................................ 126

12. Results of Tukey Post Hoc Analysis of Algebra Learning ........................... 128

13. Results of Tukey Post Hoc Analysis of Algebra Category Means, Standard Deviations, and Mean Differences: High School Classes 
14. Results of Tukey Post Hoc Analysis of Algebra Category Means, Standard Deviations, and Mean Differences: Non-Credit-Bearing College Algebra

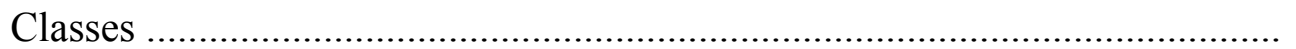

15. Results of Tukey Post Hoc Analysis of Algebra Category Means, Standard Deviations, and Mean Differences: Credit-Bearing College Algebra Classes 


\section{CHAPTER I}

\section{INTRODUCTION}

The purpose of this study was to investigate the secondary to postsecondary transition issues of high school graduates who struggle in their entry level college mathematics classes. Thompson (1984) found that teacher beliefs about students impact instructional practice, but little is known about instructor beliefs regarding how well students learn content that is critical for successful transitions from secondary to postsecondary mathematics. A researcher-developed survey was used to investigate instructors' perceptions of student learning in algebra classes in secondary and postsecondary institutions in order to determine whether there are differences in beliefs about how well students learn the same content in different institutional settings.

\section{Background}

Educating the populace in mathematics is essential for our increasingly technological society. "To function in today's society, mathematical literacy is as essential as verbal literacy" (National Research Council, 1989, p. 7). We have moved into a technological age, and mathematics is the language of science and technology. The growth of technology and easy availability of information, much of it numerical, requires that citizens have a command of methods to analyze and interpret this information. The study of mathematics can also help develop critical thinking skills such as the ability to 
distinguish evidence from anecdotal information, to understand chance, to recognize nonsense, and to value proof (National Research Council, 1989).

Our age is dominated by computers and data, not factory assembly lines. As society has become more complex, literacy has become more sophisticated. Plain old 'rithmetic, the original third $\mathrm{R}$, is clearly no longer sufficient for today's world. Scarcely any issue facing society can be resolved without recourse to sophisticated quantitative analysis and argumentation (Steen, 2004, p. 3).

White collar workers need some mathematical prowess and blue-collar workers need to be able to read manuals and use some algebra (Goldin, 2002).

Improved numerical literacy is also important for daily functioning in life. Citizens make decisions about family finances dealing with health insurance and retirement plans. They read meaning into numbers, assess risks, create budgets, and make informed projections concerning their financial future. People need to understand political arguments dealing with data and read and understand graphs and data that appear in the media (Steen, 2004).

Over the course of history, the mathematics knowledge that citizens of the United States need to possess has changed. During this history, educators have differed in their beliefs about the mathematics students need to know in order to be prepared for college study and the workplace. The primary role of secondary schools as they evolved in the 19th century was as preparatory schools for college; algebra and geometry were offered to fulfill college entrance requirements. Only $5.1 \%$ of the total school population was enrolled in high school in 1910 (Latimer, 1958 as cited in Kliebard \& Franklin, 2003), and algebra was taught as a mental discipline with little attention given to mathematics as a tool for solving practical problems (Osborne \& Crosswhite, 1970). 
In the 20th century, the purposes of a secondary education changed. The greater use of science by industry, the diffusion of critical inventions such as small electric motors, the internal combustion engine and new chemical processes, the rise of big business, and retailing growth increased the demand for skilled and educated labor among the mass of workers (Goldin, 2002). More students who were not college bound began to attend high school, and they expected schools to prepare them for a useful life. Mathematics courses in high schools were designed around topics such as installment purchasing, lending money, investing, and calculating taxes (Kliebard \& Franklin, 2003). Two or three distinct mathematics tracks in high school developed, with only college bound students enrolling in algebra and geometry.

Curricula in four year colleges and universities focused on preparing students for mathematics courses beyond calculus, and there was an expectation that newly enrolled students would be prepared for college level mathematics. During the first half of the 20th century, students leaving high school under-prepared for college level mathematics were expected to remediate deficiencies in their academic preparation by enrolling in two-year junior or community colleges (Cohen \& Brawer, 2003).

After the launch of Sputnik in 1957, the nation's attention was focused on the need for its citizens to have stronger backgrounds in science and mathematics. University research groups developed new secondary mathematics curricula that emphasized mathematical reasoning and problem solving rather than the rigorous paper and pencil manipulative algebra taught in high schools at the beginning of the 20th century. Increasing numbers of students enrolled in postsecondary institutions to meet the demands of a society needing highly skilled, educated workers. Financial incentives from 
the federal government encouraged many colleges to enroll large numbers of students, some of whom were not fully prepared for college level courses. Remedial mathematics and language arts classes grew in number in all postsecondary institutions along with increasing student enrollment (Cohen \& Brawer, 2003).

A report from the National Commission on Excellence in Education in 1983, A Nation at Risk, stated that "the educational foundations of our society are presently being eroded by a rising tide of mediocrity that threatens our very future as a Nation and a people" (para. 2). In mathematics, the report noted that average SAT mathematics scores dropped nearly 40 points from 1963 to 1980, and between 1975 and 1980, remedial mathematics courses in public four-year colleges increased by $72 \%$, constituting $2 \%$ of all mathematics courses taught in those institutions.

Recommendations from the National Commission on Excellence in Education to strengthen student knowledge of mathematics included requiring four years of mathematics in high school. Two sequences of mathematics instruction were recommended; a traditional sequence of mathematics was recommended for college bound students, and an equally demanding but different curriculum was recommended for those not planning on immediately attending a postsecondary institution. Six years later, the National Council of Teachers of Mathematics (NCTM), in their 1989 document Curriculum and Evaluation Standards for School Mathematics, recommended two tiers of training in secondary mathematics, one for non-college bound and the other for college bound students.

Differences in curricular recommendations for college versus non-college bound students faded rapidly, however, and by the end of the 20th century, mathematics 
educators, university mathematicians, the business community, and federal and state policy groups were recommending rigorous instruction in mathematics for all Kindergarten to Grade 12 students (National Council of Teachers of Mathematics, 2000; Achieve, Inc., 2004; Conley, 2003).

"Because access to postsecondary education and training is the threshold requirement for career success and social inclusion, it plays the crucial leadership role in preparing youth for adulthood and for sustaining lifelong learning" (Carnevale \& Desrochers, 2003, p. 1). Using data from the Bureau of Labor Statistics and the National Educational Longitudinal Survey, Carnevale and Desrochers determined that over the next ten years $62 \%$ of the projected jobs in our society that are well paid skilled jobs and highly paid professional jobs with good salaries and opportunities for advancement require some education beyond high school (Achieve, Inc. 2004). Society as a whole may be the greatest loser if students are unable to complete college level work.

There is considerable evidence that the nation cannot afford to disenfranchise even a small portion of the population who have the potential of succeeding in college from at least participating in some form of postsecondary education. The increasingly knowledge-based economy, particularly in a global marketplace, compels the nation to increase the number of people who have skills for job requirements that were not needed, or even thought of, a couple of decades ago (McCabe \& Day, 1998 as cited in Phipps, 1998, p. 18).

Ensuring that students are prepared to be successful in completing postsecondary education results in increased tax revenues, greater productivity, increased consumption of consumer goods, decreased reliance on government financial support, and increased workforce flexibility due to increased wage earning and improved work skills. Evidence indicates that persons with a postsecondary education commit fewer crimes, are more 
involved in the community, display a greater appreciation of a diverse society, and are more able to adapt to and use technology (Phipps, 1998).

\section{Misalignments Between Secondary and Postsecondary Expectations}

Students in nearly every postsecondary program of study, including two-year technical and associate degree programs, must successfully complete a credit-bearing college level mathematics course, but student placement in college mathematics varies considerably among institutions. Today most colleges and universities expect students to have completed at least two years of algebra and a year of geometry in high school before being admitted to college, but there is no national standard for admission. Each college and university sets its own requirements, basing entry on a number of factors, including pre-admissions test scores and high school academic programs (Greene, Parsad, \& Lewis, 2003). "There has never been a standard of admission to all colleges in the United States. Educational Testing Service and ACT programs offer uniform examinations across the country, but each college is free to admit students regardless of where they place on those examinations" (Cohen \& Brawer, 2003, p. 260).

Once admitted to a college or university, criteria for placement in college mathematics classes vary among institutions. Sixty-one percent of all institutions require all entering students to take a test to determine their placement in mathematics. Another $25 \%$ require students who meet various criteria such as a score below a specified cutoff level on the SAT or ACT to take a mathematics placement test (Greene, Parsad, \& Lewis, 2003).

Kirst, Venezia, and Antonio (2004) concluded there is little uniformity among placement tests given to students entering postsecondary institutions. They cite a study by 
the Southern Regional Education Board in 1998 that found postsecondary institutions in the southeastern United States administered nearly 125 combinations of 75 different placement tests. On each of these tests, students are tested on different content with a range of standards.

Differences in the content and format between assessments used at the Kindergarten to Grade 12 exit and college entrance levels point to great variance in expectations regarding what students need to know and be able to do to graduate from high school and enter college. [As an example], approximately $33 \%$ of the items on any state high school-level assessment were framed within realistic situations, and as many as $92 \%$ of the items were contextualized. In contrast, the placement tests and college entrance exams assessed examinees primarily with abstract questions (Kirst, Venezia, \& Antonio, 2004, p. 288).

Even students who attend a community college with open-admissions policies learn that the college has a set of placement standards that are higher than the standards set for high school graduation. Students who are determined to need remediation in mathematics based on institutional criteria are required to enroll in remedial mathematics courses that usually cover beginning and intermediate algebra content for which students may receive institutional credit but not college credit (National Center for Education Statistics, 2003; Achieve, Inc., 2004; Lutzer, Maxwell, \& Rodi, 2002).

Steen (2004) states that a common general education requirement in college mathematics is a course titled college algebra, with content similar to that defined by Charles Eliot and the Committee of Ten in 1890. In fall 2000, combined credit-bearing college algebra enrollment in two- and four-year colleges was approximately 400,000, with another 100,000 enrolled in a combined college algebra and trigonometry course. This number has increased about $73 \%$ since 1980 , while enrollment in mainstream calculus has remained approximately stable (Small, 2006; Lutzer, Maxwell, \& Rodi, 2002). 
Successful achievement in mathematics eludes many students, however, and as a result they have difficulty making smooth transitions from high school to college mathematics. Numerous articles in the press inform the public that students are underprepared for college mathematics. In a press release on August 16, 2005, ACT, Inc. stated that "just 41\% of [high school] graduates scored a 22 or higher on the ACT Math Test in [2004 to 2005], indicating they have a high probability of succeeding in college algebra" (ACT, Inc., 2005). The Louisville-Courier Journal reported on October 7, 2006 that nearly $44 \%$ of first-year, full-time college students in Kentucky needed to take a remedial mathematics class in 2004 (Kentucky Council on Postsecondary Education, 2006), despite the fact that mathematics requirements for high school graduation in Kentucky increased over the past two decades.

The National Center for Education Statistics reported that in fall 2000, $22 \%$ of entering freshmen at degree-granting institutions enrolled in remedial mathematics courses (2004).

Moreover, remediation is most heavily concentrated in colleges with high minority enrollments: in these institutions, $35 \%$ of entering students require some remediation in mathematics. Not surprisingly, students who require extensive remediation graduate at significantly lower rates than other students. In fact, those needing three or more remedial courses graduate at one-third the rate of students who enter college fully prepared (Somerville as cited in Steen, 2004, p. 53).

Students who are unable to complete the mathematics requirement often find the door to a college degree closed.

Successful achievement in mathematics eludes many students who are enrolled in the most commonly taken credit-bearing course, college algebra. College algebra has a reputation nationally for failing an unusually high percentage of students. The number of students who received a D, F, or withdraw may be as high as $40 \%$ to $50 \%$ (Herriott, 
2006). Even when an applied or survey mathematics course can be substituted for college algebra to meet the general education requirement, success in the course requires some knowledge of algebra.

Stanford University researchers Kirst, Venzeia, and Antonio (2004), in a six-year study of the transition issues for college-bound students entitled the Bridge Project, found that curricula between secondary and postsecondary institutions were disconnected. The researchers found that secondary teachers teach a set of standards and skills specified by state and district criteria that are assessed on statewide tests, and new testing burdens do not allow teachers sufficient time to focus on other needs such as helping students prepare for college. Additionally, the Stanford researchers found that state standards and skills do not meet the demands required by college entrance requirements. Postsecondary institutions are generally unaware of Kindergarten to Grade 12 standards and assessments, and Kindergarten to Grade 12 educators are usually unaware of specific postsecondary admission and placement policies. Postsecondary officials are wary of Kindergarten to Grade 12 assessments because they are politically volatile (Kirst, Venezia, \& Antonio, 2004).

Initiatives Designed to Improve Transitions

Numerous programs have been initiated to attain the goal of rigorous mathematics instruction for all students. The NCTM, representing Kindergarten to Grade 12 teachers, university mathematicians, and mathematics educators, has undertaken major reform initiatives in Kindergarten to Grade 12 mathematics since the 1980s. In 1989, the NCTM published Curriculum and Evaluation Standards for School Mathematics, a curriculum framework for mathematics that emphasized problem solving, reasoning, and 
communication, with a de-emphasis, but not elimination, of the focus on symbolic manipulation skills that had characterized school mathematics in the past. Eleven years later, the NCTM (2000) updated and refined its standards for school mathematics and published Principles and Standards for School Mathematics. A common foundation in mathematics was recommended for all students.

Two initiatives, Standards for Success and the American Diploma Project (ADP), have focused on defining mathematics benchmarks, along with other content areas, that high school students should master in order to make successful transitions to postsecondary programs. The ADP is sponsored by a coalition of representatives from universities, the business community, state governments, and political trusts. The project acknowledges the importance of problem solving but places a strong emphasis on rigorous content for all students (Achieve, Inc., 2004). The Standards for Success project, sponsored by the Pew Charitable Trusts and the Association of American Universities, has also developed rigorous mathematics standards for high school curricula (Conley, 2003).

Reform efforts also have been initiated by two professional mathematics organizations representing postsecondary institutions. The American Mathematical Association of Two-Year Colleges (AMATYC) described standards and made recommendations for two-year colleges and lower-division mathematics programs below the level of calculus in their initiative entitled Crossroads in Mathematics: Standards for Introductory College Mathematics Before Calculus (1995). The AMATYC engaged in their reform effort because they believed the needs of two-year colleges were not being addressed by either the NCTM or university reform efforts in calculus. In order to 
achieve their vision for mathematics education in two-year colleges, the AMATYC recommended dialogue between two-year college and Pre-Kindergarten to Grade 12 educators and between two-year and four-year college educators, with the goal of ensuring smooth transitions for all students between levels. This stance is unique among postsecondary based reform efforts. Reform efforts of the AMATYC continued with their release of a new document, Beyond Crossroads: Implementing Mathematics Standards in the First Two Years of College, in November, 2006 that updates and extends the recommendations made in 1995.

The Committee for Undergraduate Programs in Mathematics (CUPM) of the Mathematical Association of America (MAA) has focused on reform in undergraduate mathematics programs. The CUPM Curriculum Guide 2004 makes recommendations for changes in the undergraduate mathematics program that address the varying needs of non-mathematics majors, students planning to become teachers in Kindergarten to Grade 12 institutions, students planning mathematics intensive careers, and mathematics majors (Mathematical Association of America, 2004).

\section{Study Purpose}

The findings of the Bridge Project researchers and the differences in emphasis of each of the reform initiatives are indicators that mathematics educators in secondary, two-year college, and four-year college and university settings have different expectations regarding the mathematics preparation needed by secondary students. Discussions between

traditionalists and reformers continue to emphasize conflicting belief/value systems with respect to content, pedagogy, and assessment. Both sides have valid points, but a lack of coherence has led to confusion about what is important at many levels. The consequences for incoming freshmen college students, we think, 
are dire; they no longer know what to expect! (Lundin, Oursland, Lundgren, \& Reilly, 2005, p. 18).

One point of agreement between all groups is that knowledge of algebra is the gatekeeper to postsecondary degrees and good paying jobs in the workplace (RAND Mathematics Study Panel, 2003; Usiskin, 2005). Every state requires secondary students to have completed at least one course in algebra for high school graduation; postsecondary institutions expect students to have completed at least two years of algebra in high school, and nearly every postsecondary program of study requires students to complete a general education mathematics course that for the majority of students is either college algebra or a course that requires algebra as pre-requisite knowledge (Lutzer, Maxwell, \& Rodi, 2002; Steen, 2004).

The RAND Mathematics Study Panel (2003) recommended that algebra be a priority research focus in mathematics education because little is known about what is happening in algebra classrooms and how policy decisions affect equity and shape student learning. The literature on teachers' beliefs about mathematics teaching and learning in secondary and postsecondary institutions is limited. Kiernan (1992) noted that very little literature exists on algebra teachers' beliefs and cognitions. Most of the studies that do exist focus on teaching specific algebraic content. Hart (1999) found that noticeably absent from the literature is work on the beliefs of postsecondary mathematics faculty, how those beliefs impact instruction, or how teaching is changed in response to reforms. However, teachers' conceptions of mathematics teaching likely reflect their views, though tacit, of students' mathematical knowledge (Thompson, 1992).

The purpose of this study was to examine instructors' perceptions of how well they believe students are learning algebra content that one mathematics reform initiative, 
the American Diploma Project (ADP), has defined as the knowledge students should know for success in postsecondary programs and workplace readiness. The ADP algebra benchmarks were chosen because they were formulated and validated by mathematicians, mathematics educators, and representatives from business in five partner states, including Kentucky, over a two year period; 26 states currently are members of the ADP network (Achieve, Inc, 2004, 2006).

A survey instrument was developed for the study and administered to secondary and postsecondary mathematics instructors in Kentucky. The instrument used a Likerttype scale $(1=$ Not At All; $2=$ Very Little; $3=$ Some; $4=$ Well; and $5=$ Very well $)$ to capture instructor perceptions regarding how well they believe students are learning algebra in high school, non-credit-bearing or remedial college algebra classes, and creditbearing college algebra classes. The independent variable was the mathematics instructor's teaching position with three levels -- high school, two-year community and technical college, and four-year college and university.

The three main dependent variables were composite mean algebra perceived learning scores calculated from instructor perceptions of student learning across the ADP benchmark algebra topics in high school classes, non-credit-bearing or remedial college algebra classes, and credit-bearing college algebra classes. The ADP divided algebra content into five categories: (1) algebraic expressions; (2) functions; (3) equations and inequalities; (4) graphing; and (5) problem solving with modeling. Mathematical reasoning was defined separately from algebra but was included as a sixth category for this study. Several algebra topics were listed under each of the six content categories. Composite mean algebra learning scores were calculated for each algebra content 
category in the three classroom settings to form 18 sub-dependent variables. The study compared instructor perceptions as determined by the composite mean algebra learning scores using a three-group multivariate analysis of variance (MANOVA) as specified by Stevens (2002). Demographic information collected included teaching position, primary appointment, employment status, gender, educational background, and teaching experience.

Many students have difficulty making smooth transitions from high school to postsecondary institutions. For many of these students, under-preparedness in mathematics is a major reason why the transitions are difficult. Research has demonstrated a disconnected curricula alignment and expectations between secondary and postsecondary institutions that impacts student transitions from one educational setting to another. While many groups are working at finding solutions to the transition issues, little is known about instructor beliefs and their impact on the transitions. This study investigated perceptions of student learning in three key transition algebra classes in order to determine if there are differences in instructors' perceptions of student learning, and thus a potential disconnect in instruction, that may impact transitions for students. The results of this study added to the knowledge base regarding transitions for students in high school and college mathematics and had implications for dialogue between secondary, two-year college, and four-year college and university mathematics instructors. 


\section{Research Questions}

The study addressed the following three research questions:

1. Do high school, two-year community and technical college, and four-year college and university mathematics instructors differ in their perceptions of how well students typically learn algebra content in high school classes?

2. Do high school, two-year community and technical college, and four-year college and university mathematics instructors differ in their perceptions of how well students typically learn algebra content in non-credit -earing or remedial college algebra classes?

3. Do high school, two-year community and technical college, and four-year college and university mathematics instructors differ in their perceptions of how well students typically learn algebra content in credit-bearing college algebra classes?

The above research questions are formally stated as null hypotheses in the section that follows.

\section{Hypotheses}

H-1: There is no difference in high school, two-year community and technical college, and four-year college and university mathematics instructors' perceptions of how well they perceive students typically learn algebra in high school classes.

H-2: There is no difference in high school, two-year community and technical college, and four-year college and university mathematics instructors' perceptions of how well students typically learn algebra in non-credit-bearing or remedial college algebra classes.

H-3: There is no difference in high school, two-year community and technical college, 
and four-year college and university mathematics instructors' perceptions of how well they perceive students typically learn algebra in credit-bearing college algebra classes.

\section{Definitions of Terms}

The terms defined below clarify reader understanding of this study.

1. Academic mathematics: For purposes of this discussion, academic mathematics is a secondary mathematics sequence intended to prepare students for college mathematics. At a minimum, the courses in the sequence are Algebra 1, Geometry, and Algebra 2.

2. Calculus: The mathematics course that is required for students planning to major in college mathematics or who are planning majors in mathematics intensive areas such as the sciences or engineering.

3. College general education mathematics: Credit bearing postsecondary mathematics courses that meet institutional mathematics requirements for students majoring in non-mathematics intensive postsecondary programs.

4. Community college: A postsecondary institution whose purpose is to offer course work comparable to the first two years of college and/or to provide academic remediation for students who are determined to not be ready for college level work. Many community colleges also offer associate degrees or certificates attesting to a person's readiness for a variety of skilled workplace positions.

5. College preparatory mathematics: A secondary mathematics course sequence that includes Algebra 1, Geometry, and Algebra 2. 
6. Developmental mathematics: Postsecondary mathematics classes whose purpose is to remediate the mathematics knowledge of under-prepared students. These courses often carry institutional credit but do not count as a credit bearing course to be applied toward graduation or technical certification.

7. Developmental students: Students who are determined to be not ready for college level mathematics by scoring below criterion levels on postsecondary entrance examinations or by not scoring at a specified level of proficiency on a postsecondary placement test.

8. Four-year college: Any postsecondary institution offering a Bachelor of Science or Bachelor of Arts degree in a variety of academic areas. A four-year college, unlike a university, would not offer programs for advanced degrees.

9. Inductive learning: A process in which students formulate some of their own methods for performing mathematical procedures by looking for patterns and using hands-on models.

10. Junior college: A two-year postsecondary institution whose purpose is to offer course work comparable to the first two years of college and/or to provide academic remediation for students who are determined to be not ready for college level work.

11. Precalculus mathematics: In general, precalculus mathematics is any mathematics course that is a pre-requisite for a course in calculus. Courses usually titled Precalculus are normally taken between Algebra 2 and Calculus. Content may include topics such as trigonometry, functions, advanced algebraic manipulation techniques, probability, matrices, and an introduction to limits. 
12. Remedial mathematics: This term is used interchangeably with developmental mathematics.

13. University: Any postsecondary institution offering advanced degrees, masters, doctorate, or first-professional, in addition to bachelor's degrees. Faculty responsibilities include conducting research and publishing the results of that research in scholarly journals in addition to teaching.

14. Synthetic learning: A process in which students learn mathematical procedures by following a model presented by the instructor or by following procedural steps presented in a textbook.

15. Transitions: The ease with which students are able to leave one level of mathematics instruction and achieve success at the next level.

16. Two-year college: A postsecondary institution whose purpose is to offer course work comparable to the first two years of college and/or to provide academic remediation for students who are determined to be not ready for college level work. Many two-year colleges also offer associate degrees or certificates attesting to a person's readiness for a variety of skilled workplace positions.

17. Under-prepared students: This term is used interchangeably with developmental students.

18. Vocational mathematics: Secondary mathematics courses that prepare students for immediate entry into the workplace. Content usually focuses on bookkeeping, tax preparation, and computation needed in the workplace. 


\section{CHAPTER II}

\section{FRAMEWORK}

The framework for investigating the secondary to postsecondary transition issues for students in mathematics begins with a review of the historical development of curricular issues in mathematics in the United States and the effects these issues had on the development of our country's educational institutions, the growth of professional mathematics organizations, the increasing involvement of federal and state governments in setting educational policies, and late 20th century reform efforts. Indicators of student under-preparedness in mathematics at the beginning of the 21 st century, reasons being posited as to why students have difficulty making smooth transitions from secondary to postsecondary study in mathematics, current initiatives for improving mathematics achievement of students at key transition levels, and the role of teacher beliefs about students and classroom instruction will be reviewed.

Growth of Mathematics Education in the United States

\section{Mathematics education in the developing nation}

Throughout the history of school mathematics in the United States, mathematicians, business leaders, mathematics educators, and other citizens have expressed concerns about students' weak mathematical knowledge after completing their formal schooling (Jones \& Coxford, 1970). 
The National Council of Teachers of Mathematics (NCTM) undertook researching the history of mathematics education in the United States in 1966 for the Thirty-second Yearbook under the editorial leadership of Jones and Coxford from the University of Michigan. Additional writers were invited to contribute to the project, resulting in the publication of A History of Mathematics Education in the United States and Canada in 1970. The two underlying themes of this historical review were: (1) What are the goals of mathematics education? and (2) How can mathematics education in both content and instruction be adapted to the varied needs, capacities, and interests of students? Jones and Coxford wrote about the mathematics in evolving schools from colonial times until the mid 1960s, Osborne and Crosswhite discussed the forces and issues relating to curriculum and instruction in grades 7 to 12 from 1890 to the mid1960s, and Garrett and Davis discussed changes in school mathematics from World War II until about 1970.

In 1993, the Board of Directors of the NCTM voted to publish an additional history of school mathematics as part of their professional reference series. The Board's goal was not only to have the new history serve as a companion to the 1970 yearbook but also to stand alone as a complete history of school mathematics through the 20th century. The editorial panel invited a number of historians and mathematics educators to submit chapters for the book. In 2003 A History of School Mathematics, including the historical research of 53 authors and 64 designated consultants under the editorial leadership of Stanic and Kilpatrick from the University of Georgia, was published in two volumes. Among the contributors were: Cohen, who researched the development of early numeracy in America; Michalowicz and Howard, who researched mathematics textbooks 
during the 19th century; Parshall, who discussed the historical background leading to the development of the university research community; Donoghue, who discussed the emergence of mathematics education as a profession; Kliebard and Franklin, who discussed the growth of vocational mathematics in the early 20th century; Gates, who wrote about the establishment and growth of the NCTM; Usiskin, who wrote a personal reflection on the development of the University of Chicago School Mathematics Project; Lappan and Wanko, who discussed the changing roles of the federal government in mathematics education; Long, who summarized the role of state governments; Seeley, who summarized the effects of textbooks on mathematics education in the United States; and Clements, who discussed some of the issues in mathematics education from the perspective of an Australian educator.

Rudolph (1990) reviewed the literature pertaining to the development of postsecondary education in the United States. The overriding question in his research was "How and why and with what consequences have the American colleges and universities developed as they have?" (1990, p. xxvi). Within that context, Rudolph also discussed the development of primary and secondary schools as they were influenced by the requirements of postsecondary institutions.

The development of an elementary, secondary, and postsecondary educational system evolved with the changing needs of a growing country from colonial times until the late 19th century. Underlying this growth from the 17th century onward was "the belief that education is necessary for the welfare of society" (Jones \& Coxford, 1970, p. 17). The mathematics content taught in schools was driven by a physical world that required knowledge of arithmetic. 
Primary schools. The earliest pre-college schools in the American colonies were established to teach only reading and writing. The youngest students were age five to six up to the early teen years. Arithmetic might be taught to males 12 to 14 who were planning to engage in commerce; topics typically included whole numbers, fractions, and decimals. Students of the 17th and 18th centuries rarely possessed an arithmetic book, although instructors had textbooks that were usually imported from England. Problems in arithmetic textbooks focused on the mathematics required for weights and measures, bookkeeping, navigation, and surveying. Students typically copied computational rules with examples from the teachers' texts. The majority of organized schools were located in New England; young children in other areas of the colonies were taught at home by parents if they were able to do so (Jones \& Coxford, 1970; Rudolph, 1990).

After the American Revolution, the move to a decimal currency eliminated complex computations with English and colonial currencies, and the study of arithmetic became entrenched as a core subject in primary schools for all young children. In the early 19th century arithmetic texts abounded; most presented arithmetic as it had been taught during the colonial period, with students being expected to memorize sets of rules for computation. Knowledge of arithmetic became important for all citizens in order to manage household and business transactions. With more children attending school and with arithmetic being taught at a younger age than before the American Revolution, there was widespread dissatisfaction with teaching arithmetic as a set of rules to be memorized (Jones \& Coxford, 1970; Cohen, 2003).

The beginnings of the debate on the best approach to teaching arithmetic began in the years after 1821 when William Colburn wrote and published a text for children from 
ages four to eight that supported an inductive approach to learning arithmetic and broke the tradition of memorizing a set of rules with examples. A backlash against Colburn's inductive method appeared in the 1830 s with merchants complaining that students were coming out of school with a poor understanding of arithmetic. The arguments for inductive learning versus synthetic learning of arithmetic persisted throughout the 19th century, and some textbooks of the time reflected inductive methods for developing reasoning skills while others supported a rules-based approach to arithmetic. By the end of the 19th century, the inductive methods of Colburn had faded from popularity; however, his insistence that young children could learn arithmetic was instrumental in entrenching arithmetic as a subject to be learned in the early years of school by all young boys and girls during the 19th century (Jones \& Coxford, 1970; Cohen, 2003). Texts of all types during the 19th century, regardless of their approach to teaching mathematics, reflected "the emerging commerce of a growing continent" (Michalowicz \& Howard, 2003, p. 104). Problems in arithmetic textbooks reflected the business transactions of the times, although toward the end of the century, problems in history, science, and factory production appeared.

Colleges and universities. Colleges founded in the United States prior to the Revolutionary War did not require students to know any mathematics. "[The colleges] were shaped by aristocratic elements of colonial society ... and failed to establish themselves as popular institutions affecting the lives of the people" (Rudolph, 1990, p. 18-19). Even knowledge of arithmetic was not a requirement for entrance into college (Cohen, 2003). Arithmetic, geometry, and a little algebra, might be taught in the fourth year of college with the intention of developing mental discipline and logical thinking 
during the colonial and early Federalist periods (Rudolph, 1990). Typical of the period, an early mathematics textbook intended for college level students devoted 396 pages to arithmetic and only 33 pages to algebra (Jones \& Coxford, 1970).

Harvard was the first college to require algebra for admittance in 1820, and geometry was added as a requirement after the Civil War. Other Eastern colleges followed Harvard's lead in requiring algebra and geometry for admission by the mid1800s. College mathematics curricula in the 18th and early 19th centuries reflected the need for mathematics in the sciences, and mathematics was often taught along with the sciences. Content included advanced algebra, geometry, and trigonometry (Parshall, 2003; Jones \& Coxford, 1970).

Private colleges were founded outside the original colonies in the 1800s as part of the missionary movement in the development of the West. States established public colleges on land the federal government gave to each new state. State colleges were slower to require algebra for admission. Whether public or private, a college diploma in the early 19th century meant that the holder could manage people, think on his feet, and conduct business; a diploma was not necessarily an indication of scholarship. The classical curriculum that was taught in these early colleges only gradually included modern languages, science, and mathematics in response to a growing need for citizens to have some technical knowledge. Mathematics courses were focused on applications suitable for preparing students for scientific study and included arithmetic, algebra, geometry, and trigonometry (Rudolph, 1990).

Since there were few public secondary institutions outside the Northeast, aspiring college students in the 1800s were directed into college programs through an attached 
preparatory department that offered the algebra and geometry needed for college work. In order to increase enrollment, admissions standards were lowered or dropped altogether.

Some colleges had of necessity found themselves in the preparatory business at the very beginning. Insisting upon erecting colleges that neither need nor intelligence justified, college governing boards often had the choice of giving up or of taking any student who came along and starting with him at whatever point his ignorance required. (Rudolph, 1990, p. 282)

The number of state universities increased in the Midwest and West where frontier democracy and materialism supported practical-oriented, popular institutions providing a unified free education. This growth was given additional impetus with the passage of the Morrill Federal Land Grant Act of 1862, which established land grant colleges whose mission was to provide an agricultural or mechanical education. The federal government provided funding and land for these colleges in each state, but the land grant colleges struggled to develop curricula and establish their niche in American life. The curricula varied across the colleges, and many people did not understand why one needed to attend college to be a farmer. However, at some point during this time, colleges discovered a new purpose; "going to college was a way of making more money than if you did not" (Rudolph, 1990, p. 65). A college degree became a personal investment as opposed to the social investment of the 18th and early 19th centuries. As the colleges evolved, it became obvious that scientific agriculture enabled the farmer to enjoy higher living standards, and "ingrained in the land-grant idea was the concept of collegiate education for everyone at public expense" (Rudolph, 1990, p. 260).

The private colleges of the east and the more developed state colleges began offering courses in graduate study by the mid-19th century and evolved into universities. The focus of college curricula, including mathematics, changed with the founding of 
Johns Hopkins University in 1876. Its first president, Daniel Gilman, envisioned the American university to be more like the scholarly institutions of Europe. Gilman developed Johns Hopkins as a faculty-centered institution.

The institution in Baltimore, however, saw the faculty, its needs, and its work, as so central to its purpose that Gilman insisted that the faculty be given only students who were sufficiently well prepared to provide the faculty with challenging and rewarding stimulation. Nothing could have been more remote from the spirit of the old-time college, where the teachers were theoretically busily engaged in stimulating the students. (Rudoph, 1990, p. 271-272)

Gilman, along with Charles Eliot who was revamping Harvard in a similar vein at about this same time, did not address the methodology of teaching at the college level. Nor did they concern themselves with student affairs or educational guidance. Gilman redefined the American university in the world of the intellect (Rudolph, 1990).

Gilman understood the utility of pure scientific research, and he believed that a number of inventions of the time, including the steam locomotive, telegraph, and electric lighting were the result of applied mathematics. British research algebraist, J. J. Sylvester, was hired to develop a graduate program in mathematics. He instituted a research level graduate program in mathematics at Johns Hopkins that included courses such as number theory, determinants, quaternions, synthetic and algebraic geometry, various function theories, and matrix theory. Calculus was a necessary prerequisite for taking these higher level research mathematics courses, and it remains so today. Sylvester's students, and others who studied under Felix Klein in Europe, became leaders in establishing mathematics research departments in American universities during the late 19th century (Parshall, 2003). Calculus, preceded by algebra, was the gateway course to higher mathematics. The tendency for American mathematical research to be focused on 
the foundations of mathematics rather than on applied mathematics continued into the 20th century (Jones \& Coxford, 1970).

Secondary schools. The earliest secondary schools were privately incorporated academies for mostly male children of wealth (Rudolph, 1990). Public secondary schools did not appear in the Northeast until the 1820s and were well established throughout the northern states by 1875 . The earliest secondary schools were attended primarily by male students, but some schools were established for females. Since arithmetic was taught to young children in primary schools, male secondary students studied algebra and geometry (Jones \& Coxford, 1970). A few young women also learned algebra and geometry well enough to teach the subjects to students at secondary levels toward the end of the 19th century (Cohen, 2003).

Public secondary schools grew in size and importance along with the universities after the Civil War. Because secondary institutions were generally private academies, an early task for the state universities was to provide a bridge between the free public elementary schools and the universities. With the growth of the scholarly movement after the Civil War, universities began to establish admissions standards. In 1870 the University of Michigan was a leader in admitting only students from certain Michigan public schools that the university certified as offering appropriate collegiate preparation. The action encouraged schools to extend their responsibilities and "it was a device that unleashed the high school movement in the Middle West and that enabled the state universities to cultivate scholarly aspirations" (Rudolph, 1990, p. 283). Thus the state universities were able to reshape loosely organized combined elementary-secondary 
schools into distinct elementary schools and high schools (Rudolph, 1990; Osborne \& Crosswhite, 1970).

At the end of the 19th century, curricular content in secondary schools focused on mathematics as a mental discipline with little attention given to mathematics as a tool for solving practical problems. Algebra was studied primarily to fulfill college entrance requirements. Algebraic techniques such as factoring, roots, powers, and fundamental operations with rational expressions received most of the attention in textbooks -- with equation solving, functions, and graphs receiving less coverage. Manipulative skills were emphasized and the content was abstract; there was little standardization of what was meant by algebra or geometry from school system to school system (Osborne \& Crosswhite, 1970).

Enrollment in academic mathematics that focused on algebra and geometry in high school continued to grow between 1890 and 1910, but only a small percentage of the total school population was actually enrolled in high school. By 1910, 5.1\% of the total school population was enrolled in high school, and $89.7 \%$ of those students took academic mathematics (Latimer, 1958 as cited in Kliebard \& Franklin, 2003).

By $1890,41 \%$ of college students were graduates of the public high school, and the college-preparatory departments in colleges and universities were phasing out. High schools were closer to the people than the colleges and universities had been, and new subjects in the sciences and modern languages were offered. Former college-level work was pushed down into secondary schools and was incorporated into the requirements for college admission (Rudolph, 1990). School systems, colleges, and universities were now 
strong enough to look beyond themselves to questions of school effectiveness (Osborne \& Crosswhite, 1970).

Teacher preparation. By the late-19th century, teachers in primary and secondary schools were required to have some professional training. Spurred by the growth of mathematics departments in research universities and the growth of secondary schools, interest in formal preparation for secondary mathematics teachers grew. During the 1890s, several universities established programs to prepare their students to teach secondary mathematics. Course preparation varied with the institution but included some advanced mathematics courses beyond the calculus and training in mathematical pedagogy for high school (Jones \& Coxford, 1970).

Rise of professional organizations. The American Mathematical Society was organized in 1888 by a group of university mathematicians, and the membership was encouraged to form groups of mathematics teachers within established teacher organizations. At the turn of the century, mathematics teacher organizations in New England, the Middle States along the Atlantic coast, and Central States centered at Chicago were formed. These three regional organizations played an important role in establishing the foundations for mathematics education, but they did not agree on how mathematics should be taught in secondary schools. The two East Coast associations, heavily influenced by the research universities of the East, preferred to emphasize pure mathematics rather than applied mathematics. The central states, under the leadership of E. H. Moore of the University of Chicago, favored a laboratory method of teaching using "graphical depiction and physical models to lead the student from concrete experience to abstract generalization" (Donoghue, 2003, p. 168). 
Dissatisfaction with secondary education practices was so great that a number of committees were formed by professional organizations between 1890 and 1920 to investigate problems in the schools. The National Education Association formed the Committee of Ten, a group consisting of primarily university presidents and chaired by Charles W. Eliot of Harvard, in 1892. In mathematics the committee recommended that high school students complete a year of algebra, a year of geometry, another year of algebra and geometry combined, and trigonometry and higher algebra in the senior year, courses that had been in the college curriculum during most of the 19th century (Osborne \& Crosswhite, 1970). This curriculum is sometimes referred to as academic mathematics and is still required for admission into many postsecondary institutions. In the college tradition, mathematics was considered a subject that built logical reasoning and helped to develop the intellect.

Following the report from the Committee of Ten, the National Education Association formed a committee in 1895 to determine college entrance requirements. Known as the College Entrance Requirements Committee, the committee sought assistance from the American Mathematical Association, an organization of university mathematicians, and recommended that all students take mathematics throughout the four years of high school with an emphasis on algebra and geometry. The College Entrance Examination Board was founded in 1900 by the Association of Colleges and Secondary Schools of the Middle States and Maryland. Working closely with school accrediting agencies and using the recommendations from the National Education Association groups, high school courses in algebra, geometry, and trigonometry were recommended for college admission (Osborne \& Crosswhite, 1970). 


\section{Mathematics education from 1900 - 1950}

The changing role of mathematics in secondary schools. At the turn of the century, the workplace was changing. The greater use of science by industry, the diffusion of critical inventions such as small electric motors, the internal combustion engine, new chemical processes, the rise of big business, and retailing growth increased the demand for skilled and educated labor among the mass of workers (Goldin, 2002). More students who were not college-bound began to attend high school, and they expected schools to prepare them for a useful life. Leading psychologists and business leaders questioned the advisability of all students receiving an academic mathematics education (Osborne \& Crosswhite, 1970). Industrialization brought a new urgency for schools to prepare students for immediate entry into the workplace. Curriculum in all content areas began to focus on preparing students for the trades and for consumerism. Mathematics was increasingly valued for its immediate use in society and not as an intellectual endeavor, and vocational schools providing industrial education for high school age students were established.

In 1918 the Commission on the Reorganization of Secondary Education, organized by the National Education Association, issued its Cardinal Principles report. This report attested to a "growing belief on the part of educators and the general public as well that academic preparation subjects were largely irrelevant to a majority of high school students, particularly students not destined to go to college" (Kliebard \& Franklin, 2003, p. 409). The commission called for the reorganization of subjects taught in high schools, and in response, the National Education Association formed a committee consisting only of educators and no mathematicians. "The significant questions were 
what should be taught, how much of it, to whom, how, and why" (Osborne \& Crosswhite, 1970, p. 193). The resulting report, The Problem of Mathematics in Secondary Education, issued in 1920, called for three mathematics tracks in high school. Algebra and geometry were still recommended for college-bound students, and two tracks of practical mathematics were recommended for all non-college-bound students (Osborne \& Crosswhite, 1970). Osborne and Crosswhite noted that the mathematics education community did not welcome the report. One of the criticisms stated by D. E. Smith, who had written the first textbook for mathematics educators in the United States in 1900, was that the committee was not representative of the teaching of mathematics or mathematics as a science.

Gates (2003) writes that amidst the background of controversy surrounding what mathematics should be taught and how it should be taught in secondary schools, the NCTM was founded in 1920 by 127 mathematics teachers attending a spring meeting of the National Education Association. The action was a response to the various groups of educational reformers, from the college level and from school principals and superintendents, trying to promote changes in the mathematics being taught in schools in the early 20th century. The vision of the first president, C. M. Austin, was to "give mathematics and the teaching of mathematics their proper place in the educational world" (Austin, 1921 as cited in Gates, 2003, p. 738).

Concerns regarding student preparation for college and the content of collegelevel mathematics for all students had already resulted in the founding of the Mathematics Association of America (MAA) in 1915, with the undergraduate mathematics curriculum as its major concern. Among the goals of the MAA was 
providing "organized activity in the large field between the fields of secondary school mathematics and the field of pure research and forming a medium of communication for exchange of ideas between teachers and others interested in collegiate mathematics" (Jones, 1972, p. 20). Almost from the beginning, however, secondary mathematics teachers were encouraged to join the MAA, and an ongoing focus of the Association has been a strong interest in improving high school mathematics teaching and the preparation of high school mathematics teachers (Jones, 1972). Since its inception about 30 regional sections of the MAA have been organized. Section outreach programs to high schools include contests for high school students, sending lecturers to high schools, and meeting sessions on secondary mathematics content (Montague, 1972).

The School Science and Mathematics Association was founded in 1902 as the Central Association of Science and Mathematics Teachers. From the onset, the organization published the journal, School Science and Mathematics, which has focused on methods of connecting mathematics and science. The mission of the School Science and Mathematics Association is to improve instruction in mathematics and science in Kindergarten to Grade 16 by focusing on issues relating to teacher preparation, research, curriculum, and instruction (School Science and Mathematics Association, 2005).

Growth of the two-year community college. In a move away from advocating academic mathematics for all students, typical high school mathematics courses developed in the 1920 s were designed around topics such as installment purchasing, lending money, investing, and calculating taxes. (Kliebard \& Franklin, 2003). The Depression accelerated the development of two or three distinct mathematics tracks in high school as more non-college-bound students stayed in high school because there were 
no jobs. Algebra and geometry were offered for college-bound students who were generally from the privileged sectors of society. Non-college-bound students were directed into practical or consumer mathematics courses with little thought given to the possibility that work place skills might change or that people might work at several different occupations during their lifetime (Willoughby, 2000).

A new type of education institution, the community college, developed during the 1920s in response to a growing need for students to have access to some training beyond public high schools that was relatively inexpensive and close to home. Cohen and Brawer (2003) describe the functions of the community college and provide an interpretive analysis of those functions in The American Community College. They state that community colleges, which were established as a bridge between secondary school and the four year college and university, were formed because "the public perceived schooling as an avenue of upward mobility and a contributor to the community's wealth" (p. 2).

Community colleges were initially called junior colleges, offering two years of instruction beyond high school level work, and course offerings were expected to be the same as those a student might find in the first two years of work at a four-year college or university. Some were public local institutions, often opening in high school facilities, and the source of much local pride, while others were private institutions. Because statewide systems of education or a national education agenda hardly existed, community colleges allowed students to continue their formal education close to home for two years beyond high school before going to the workplace or going further from home to pursue higher learning. Community colleges filled the needs of high school graduates who 
wanted additional schooling, businesses that supported instruction that would provide for a trained workforce, and community leaders who saw the college as an avenue to prestige. (Pedersen, 1987, 1988, 2000; Frye; 1992; Gallagher, 1994; and Dougherty, 1994 as cited in Cohen \& Brawer, 2003) have documented the influence of leaders in local communities establishing community colleges.

Cohen and Brawer (2003) hypothesize that junior or community colleges were established at a time when society had reached a developmental state in which education at every level was perceived to be the solution to society's problems. Prior to the late 1800 s, the family and workplace took on most of the responsibility for educating young people and schools increased in number only as population increased. But the seeds of the value of education for everyone were established in earliest colonial times, and this philosophy permeated the growth of elementary schools, high school schools, colleges, and two-year junior or community colleges over the decades.

Many of the public community colleges developed organizationally as extensions of secondary schools. While most tried to provide an academic curriculum as preparation for the university, many began offering vocational or job training programs designed to meet the workplace needs of the community. State legislation authorizing the establishment of public community colleges nearly always promoted a variety of educational goals including academic transfer preparation, vocational-technical education, continuing education, developmental education, and community service. The number of private two-year colleges peaked in 1956, and by 1998 approximately $86 \%$ of two-year colleges were public institutions offering a wide variety of postsecondary training options as authorized by state legislatures (Cohen and Brawer, 2003). 
Mathematics education becomes a national issue. Garret and Davis (2003) state that during World War II American soldiers with both high school and college training were ill-prepared for the mathematics they needed for leadership roles in the armed forces. College students studying research level mathematics were unable to apply their mathematics knowledge to military needs. High school students in the academic tracks were equally unprepared, and those taking workplace mathematics lacked higher level mathematics skills needed for military applications.

Following the war, the GI Bill enabled many veterans to attend college who would not otherwise have been able to do so. In its peak year of 1947, veterans accounted for $49 \%$ of college enrollment. Over the active period of the World War II GI Bill (19441956), nearly half of the veteran population participated in some form of postsecondary training (Veterans Administration, 2005). College attendance was no longer limited to those with financial means, but thousands of these veterans were under-prepared for college level work (Payne \& Lyman, 1998 as cited in Phipps, 1998).

The needs of society and business changed rapidly after World War II, and there was an impetus for changing mathematics instruction in high school. The NCTM appointed a Commission on Postwar Plans to make recommendations for high school mathematics curricula. The Commission's reports, issued during the late 1940s, included recommendations that all students take mathematics, but their recommendations reflected a belief that not all students could learn high level mathematics. Three learning levels of mathematics were recommended. One level prescribed a traditional academic curriculum with algebra and geometry courses for college-bound students. A second level would be for those entering the work force, and a third level was intended for those who needed 
life survival skills (Osborne \& Crosswhite, 1970). The Commission's expressed belief that the majority of students should not study anything so advanced as first-year algebra was common in the public (Willoughby, 2000).

Parents often accept - and sometimes even expect—-their children's poor performance in mathematics....Adults who determine policy in mathematics education often measure the mathematical needs of today's students by their own meager and outdated mathematical accomplishments. From the faulty premise that most students 'can't do math' and the fact that many adults who never learned mathematics have succeeded without it, they rationalize that official expectations should be limited to minimal basic levels. The result is a spiral of lowered expectations in which poor performance in mathematics has become socially acceptable (National Research Council, 1989, p. 9).

Reform Efforts from 1950 - 1980

Early initiatives to improve mathematics achievement. Osborne and Crosswhite (1970) identify the University of Illinois Committee on School Mathematics, a group representing university mathematicians, as the first major curriculum development of the 1950s, and Lappan and Wanko (2003) identify the project as having the most influence on secondary mathematics. The committee's organization was triggered by the mathematical needs of students entering college. Several aspects of its work, including financial support from government education agencies and private foundations, the development of curriculum materials, and teacher training in the use of the materials, became characteristic of many of the projects that followed. The underlying philosophy of the University of Illinois Committee on School Mathematics was that students should understand the mathematics being studied by actively engaging in developing mathematical ideas and procedures. Program content included a more integrated mathematics 
curriculum with algebra being taught throughout a four-year secondary program and with less emphasis on solid geometry and trigonometry as separate courses.

The College Entrance Examination Board appointed a Commission on Mathematics in 1955 to explore changes in mathematics since 1900 and make recommendations for college-bound students. The committee represented university mathematicians, high school teachers, and college and university mathematics educators. While many of their recommendations were restricted to college-bound students and called for high school preparation for calculus and analytic geometry at college entry (Herrera \& Owens, 2001), the committee also recommended that new topics such as logic, modern algebra, probability, and statistics be included in the high school curriculum (Fey \& Graeber, 2004; Willoughby, 2000). Osborne and Crosswhite (1970) state that the recommendations for college entrance by the College Entrance Examination Board Commission impacted the curricular work of other committees in this era.

The launch of Sputnik in 1957 added to the perception that the United States was lagging technologically and helped to focus the movement to change mathematics curriculum and instruction that was already in progress. Lappan and Wanko (2003), in describing the changing roles of the federal government in education policies after 1957, state that the United States initially gave parents, states, and local communities the right to determine and control the education of children. Despite calls from the public and the education community for improved technology training in mathematics and science after World War II, there was no formal structure for the implementation of a national education agenda. After the launch of Sputnik in 1957, President Eisenhower committed himself to federal funding for education, which resulted in the passage of the National 
Defense Education Act in 1958. One of the major provisions of the National Defense Education Act was to fund science, mathematics and foreign language instruction.

Educating poor and immigrant children was becoming more of an issue. States and local communities had initially provided support for educating poor and minority children, but the government was under increasing pressure by the mid-1960s to provide support for the education of under-served children. The Elementary and Secondary Education Act of 1965 "changed the face of school funding in ways that had far-reaching influence on schools and school programs" with the hope that program funds would help erase the achievement gap between minority and poor children and those who were more financially advantaged (Lappan \& Wanko, 2003, p. 914).

The National Science Foundation (NSF) was established in 1950 by Congress with the purpose of promoting basic research and education in the sciences (Jones \& Coxford, 1970). Lappan and Wanko (2003) state that in the aftermath of Sputnik the activities of the NSF increased dramatically. Several curriculum projects were funded by the NSF to produce materials for teaching high school mathematics during the period from 1960 to 1970. The University of Illinois Committee on School Mathematics project, which had been started in 1952, was still in progress and eventually received funding from the NSF. The largest program funded by the NSF was the School Mathematics Study Group, which wrote a high school curriculum in 1958 that came to be known as the new math movement. The committee, composed of mathematics leaders in high school and college mathematics, regarded mathematics as a rich content that is continuously changing. While their curriculum was not widely adopted, their efforts served to turn the focus of mathematics curriculum toward the understanding of mathematical concepts as 
opposed to mere computational competence (Garrett \& Davis, 2003). Their work also influenced curricular mathematics materials for middle grades and elementary school students with a focus on building students' conceptual understanding of mathematics.

Usiskin (2003), from the University of Chicago, was one of the developers and researchers in the School Mathematics Study Group program. In a personal reflection on the program, he states that despite careful field testing and assessments showing that students using this new curriculum were doing well at learning mathematics, a few mathematicians were very vocal about their opposition to the new math. Parents were concerned because they couldn't understand the mathematics their children were doing. This factor along with the lack of wide-spread distribution of the curriculum and teacher training materials brought the end of the new math movement.

Clements (2003) states that the University of Illinois Committee on School Mathematics and School Mathematics Study Group projects both stressed unifying concepts such as sets, functions, and algebraic structures in their curriculums and were to some degree identified as models for mathematics curriculum development in countries outside the United States.

Deep within the collective psyche of communities across the United States in the 1950s was the idea that those young adolescents who were 'bright' should study first-year algebra, and then second-year algebra and geometry. All, or at least most, of the other students should enroll in lower-level mathematics courses in grade 9 (p. 1523).

An analysis of programs of the 1960s indicates that traditional algebra, geometry, and trigonometry courses remained the mainstay of the secondary mathematics curriculum for college-bound students. 
The role of state government in education. Long (2003), in describing the role of state government in mathematics education, states that constitutionally education is the responsibility of the states. Some states set policies for all the school districts in the state; other states have a few state initiatives with considerable local school independence. At a minimum, state governments regulate the certification of teachers and monitor the quality of course offerings.

Each state developed varying teacher standards and mathematics content for Kindergarten to Grade 12 prior to World War I; after that war, many states attempted to establish more stringent guidelines for teacher preparation and to provide courses of study, especially in rural areas, although enforcement lagged during the Depression. There was new faith in the power of government after the Depression and World War II. New state constitutions and new laws enacted by legislatures increased the responsibilities of the states for education, and state departments of education grew both in size and budget. One year of mathematics was typically required for high school students. Prior to 1940 , general mathematics or arithmetic was the norm for all but college-bound students. After World War II, a year of algebra was mentioned in many state programs of study, and algebra was always listed for college-bound students. States also increased requirements for teacher certification, with a college major in the content area required for secondary teachers, and elementary teachers being required to have some college work (Long, 2003).

State Departments of Education grew in size and responsibility with the passage of major education acts by the federal government during the 1950s. The funds allocated for education by the federal government went to the states for administration and 
program supervision. States began hiring content area specialists to provide content specific assistance to districts, but when student performance in mathematics dropped during the 1970s, state Departments of Education took much of the blame. During this time, the major state-level initiative was the implementation of basic-skills testing. Long (2003) observes that a plus side to the testing was that the curriculum became more focused; however, a negative effect was that the content being tested became the curriculum.

National testing systems. Cohen and Brawer (2003) note that accurate data on the literacy of the American population is difficult to compile because school systems are so varied and the United States never has had a uniform system of educational evaluation. However, by the 1970s, four measures of educational attainment were in place.

The National Assessment of Educational Progress (NAEP) was established in 1969 to determine what American students should know and be able to do in major academic subjects. NAEP is a project of the National Center for Education Statistics in the United States Department of Education, and the assessments are given in mathematics at grades 4, 8, and 12. Scores are reported at three achievement levels: (1) the basic level indicates partial mastery of prerequisite knowledge and skills; (2) the proficient level indicates solid academic performance at the grade assessed; and (3) the advanced level indicates superior performance (National Center for Education Statistics, 2001).

The Trends in International Mathematics and Science Study (TIMSS) has been periodically administered to students in grades $3,4,7,8$, and the final year of secondary school since 1959. Students who participate in the assessment in their final year of secondary school have generally taken calculus, trigonometry, or higher levels of algebra, 
although the definition of advanced mathematics courses varies between countries. Test questions cover equations and functions, calculus, and geometry (TIMSS International Study Center, 1998).

In order to determine who is or is not prepared for college level work, various preadmissions tests were developed. The most prevalent of these were the ACT and SAT tests. The first Scholastic Aptitude Test (SAT) was administered by the College Entrance Examination Board to approximately 8,000 high school students in 1926. The mission of the College Board is to prepare, inspire, and connect students to college and opportunity. The SAT focuses on identifying the most able students for admission to the more selective universities in the United States. The first several SAT tests had only free response questions requiring arithmetic and number series completion problems. Mathematics questions from 1930-35 were free-response and required some knowledge of algebra and geometry. There were no mathematics questions from 1928-29 and 193641. The traditional multiple-choice questions requiring knowledge of algebra and geometry first appeared in 1942 (Lawrence, Rigol, VanEssen, \& Jackson, 2003).

The American College Testing (ACT) Program was initiated in 1959 as an independent non-profit organization to help students make better decisions about which colleges to attend and to provide pre-admissions information to colleges about prospective students. The ACT examination includes multiple choice skills tests in English, mathematics, science, and reasoning. Mathematics content includes questions from pre-algebra, elementary algebra, intermediate algebra, coordinate geometry, plane geometry, and trigonometry (ACT, Inc., 2005). 
Decline in student mathematics achievement. NAEP scores for seventeen year olds in Grade 12 show that mathematics scores declined between 1969 and 1982 (National Center for Education Statistics, 2001b as cited in Cohen \& Brawer, 2003, p. 256). SAT mathematics scores dropped steadily from 516 in 1967 to 492 in 1981 (College Board, 1994 as cited in Cohen \& Brawer, 2003, p. 256). With this drop in high school achievement, larger numbers of students were under-prepared for postsecondary education. "Of all postsecondary educational structures in America, the public community colleges bore the brunt of the poor preparation of students in the 20th century" (Cohen \& Brawer, 2003, p. 260). During the 1950s and 1960s sizeable groups of students were entering postsecondary institutions and were reasonably well-prepared for college level work. During the 1970s, however, the college age population declined. Concurrently, the availability of financial aid and open admissions requirements at fouryear institutions meant that more able students enrolled in four-year colleges, causing less well-prepared students to opt for community colleges. The community college had always been accommodating to less well-prepared students by steering them into programs in which they might be successful, but the problems associated with admitting under-prepared students hit community colleges with full force by the 1970s (Cohen \& Brawer, 2003).

Along with less selective colleges and universities, community colleges met student needs for refresher or remedial mathematics by creating a series of courses that essentially repeated the content of high school academic mathematics. These courses typically covered computational skills and several levels of algebra. The lowest levels of 
these remedial courses did not bear college credit, and students took these classes to remediate deficiencies in core mathematics knowledge (Cohen \& Brawer, 2003).

\section{Late 20th Century Reform Efforts}

In Kindergarten to Grade 12 mathematics, the new mathematics movement faded and there was a strong back to the basics movement as mathematics scores declined on assessments such as NAEP and the SAT during the 1970s. Computation and algebraic manipulation received renewed emphasis in Kindergarten to Grade 12 schools and dominated the content of textbooks marketed during the 1980s. Concurrently, however, new and innovative programs influenced by the School Mathematics Study Group program were being developed and tested on a small scale. These new programs demonstrated that all children could learn much more mathematics, including higher order thinking skills, than previously believed (Willoughby, 2000).

One of these projects was the Rational Number Project, funded by the NSF from 1979 to 2002, at the University of Minnesota, Northern Illinois University, and Northwestern University. Researchers Behr, Lesh, Post, \& Silver (1983) state that the goals of the project were (a) to describe the development of the systems of relations and operations that children use to make judgments involving rational numbers, and (b) to describe the role that various representational systems play in the use of rational number concepts. Between 1979 and 1983, 18 fourth and fifth grade children were observed, interviewed, and tested frequently over a 16 week period of theory-based instruction. Approximately 1600 second through eighth grade children were tested using a battery of tests and interviews, and young adults having difficulties working with fractions were remediated using materials from other components of the study. Their findings 
determined that developing understanding and computation skills with rational numbers involved several types of learning experiences beyond traditional algorithmic approaches and added to a growing awareness that mathematics instruction in Kindergarten to Grade 12 schools needed to be changed (Post, Behr, Lesh, \& Wachsmuth, 2002). The study continued until 2002 with each new phase building on previous findings.

Calls for reforming mathematics curriculum and instruction. By the mid-1970s, with continued discussion about problems with mathematics learning and various efforts being attempted to improve mathematics instruction, the leadership of the NCTM felt that a carefully reasoned sense of direction for the future of mathematics instruction was missing. The NCTM (1981) undertook an extensive survey of mathematics instructors at all levels from Kindergarten to Grade 16 mathematics including Kindergarten to Grade 12 teachers, university mathematicians, university mathematics educators, and mathematics education consultants. One component of the project, Priorities for Reform in School Mathematics, was a survey of preferences for alternative content topics, instructional methodologies, use of calculators, and content appropriate for particular groups of students. Nine content strands were considered: whole numbers; fractions and decimals; ratio, proportion, and percent; measurement; algebra; geometry; probability and statistics; computer literacy; and problem solving. A second component of the study assessed priorities for curriculum change or for methods of addressing problems in mathematics education. Nine groups were surveyed: subscribers to the Arithmetic Teacher, a journal for elementary teachers; subscribers to the Mathematics Teacher, a journal for secondary school teachers; junior college mathematics teachers; college teachers of mathematics; supervisors of mathematics; mathematics teacher educators; 
principals of Kindergarten to Grade 12 schools; presidents of school boards; and presidents of parent-teacher organizations. Over 10,000 preferences surveys were distributed in 1978 to 1979 with an average return rate of $29 \%$, followed by 3,750 priorities surveys in 1979 with an average return rate of 34\%. Despite the limitations of the low return rates, the results were deemed representative of persons with a high interest in school mathematics.

A summary of the project's results, An Agenda for Action: Recommendations for School Mathematics, was published in 1981 and defined a vision for mathematics that set the direction for mathematics reform into the 21 st century. Unlike the report of the PostWar committee on mathematics that had recommended three levels of school mathematics with only college-bound students studying rigorous mathematics, in the Agenda for Action more mathematics study was recommended for all students. Key outcomes of the study included: (1) problem solving must be the focus of school mathematics in the 1980s; (2) basic skills in mathematics must encompass more than computational facility; (3) mathematics programs must take advantage of the power of calculators and computers at all grade levels; and (4) more mathematics must be required for all students to accommodate the diverse needs of the student population (National Council of Teachers of Mathematics, 1981).

T. H. Bell, Secretary of Education, commissioned the National Commission on Excellence in Education in 1981 to examine the quality of education in the United States and make a report to America, paying particular attention to teenage youth in their high school years. The commission was created because of the widespread public perception that something was seriously wrong with the educational system of the United States, and 
it commissioned papers from education experts, public hearings, existing analyses of problems in education, letters from concerned citizens, and descriptions of promising practices in education. The final report, A Nation at Risk, stated that "the educational foundations of our society are presently being eroded by a rising tide of mediocrity that threatens our very future as a Nation and a people" (National Commission on Excellence in Education, 1983, para. 3). In mathematics, the report noted that average SAT mathematics scores dropped nearly 40 points from 1963 to 1980, and remedial mathematics courses in public four-year colleges increased by $72 \%$ between 1975 and 1980 , constituting $25 \%$ of all mathematics courses taught in those institutions.

The National Commission on Excellence in Education in A Nation at Risk reaffirmed a national belief expressed by Jones and Coxford (1970) in describing the earliest American schools; an educated citizenry is necessary for the progress of society. During the 19th and 20th centuries, history shows that education was increasingly called on to provide solutions to personal, social, and political problems that other institutions could not resolve. This broad mission for education is restated in A Nation at Risk.

All, regardless of race or class or economic status, are entitled to a fair chance and to the tools for developing their individual powers of mind and spirit to the utmost. This promise means that all children by virtue of their own efforts, competently guided, can hope to attain the mature and informed judgment needed to secure gainful employment, and to manage their own lives, thereby serving not only their own interests but also the progress of society itself (1983, para. 2).

Recommendations for strengthening student knowledge of mathematics included requiring four years of mathematics in high school. The traditional sequence of mathematics was recommended for college-bound students and a new, equally demanding curriculum was recommended for those not planning on immediately attending a postsecondary institution. Other recommendations included increasing 
teacher preparation standards and giving states the primary responsibility to finance and govern schools in cooperation with the federal government (National Commission on Excellence in Education, 1983).

Reform efforts of professional mathematics organizations. In the mid 1980s the NCTM took another step toward a unified vision for mathematics instruction by writing a set of mathematics curriculum standards for Kindergarten to Grade 12 schools. The writing group addressed the mathematics they believed was important for all students to learn and did not address other issues such as tracking or an integrated versus a subject matter curriculum (Hirsch as cited in McLeod, 2004). The resulting document, Curriculum and Evaluation Standards for School Mathematics, was published in 1989 after two years of writing and extensive review by mathematics educators and instructors at local, state, and national meetings of mathematics educators.

The Curriculum and Evaluation Standards document provided curriculum guidelines for students in Kindergarten through Grade 12 with examples of the types of mathematics problems students should be doing. The emphasis in the Standards for Kindergarten to Grade 12 mathematics was on problem solving along with communication, connections, and reasoning as components of all mathematics learning. The Standards called for a decreased emphasis on traditional computation and memorizing algorithmic processes; computers and calculators were to be used appropriately in all mathematics instruction. Content standards for grades 9 to 12 included algebra, functions, geometry, trigonometry, statistics, probability, discrete topics, an introduction to calculus concepts, and mathematical structure. Most of the content in each category standard was designated as being appropriate for all students; 
however, a few advanced topics were identified as being necessary for college-bound students. Two companion documents, Professional Standards for Teaching Mathematics and Assessment Standards for School Mathematics, addressing teacher preparation and the role of varied assessments in shaping the curriculum were released in 1991 and 1995, respectively (National Council of Teachers of Mathematics, 1989, 1991, 1995).

The de-emphasis on computation and rote algorithmic processes in Curriculum and Evaluation Standards for School Mathematics became an area of concern for many people and was often interpreted as meaning that students should no longer be required to learn basic facts or learn standard computational algorithmic processes (Mathematically Correct, 2005). The NCTM recognized that the 1989 document was only a first step in establishing high standards for Pre-Kindergarten to Grade 12 mathematics and began a revision process in 1997. New curricular developments, technological advances, and the growing awareness of inequities in mathematics instruction for an increasingly diverse population resulted in a revised document designed to better represent the mathematics needed by citizens at the beginning of the 21 st century. As with Curriculum and Evaluation Standards for School Mathematics, an extensive review process was followed to obtain input from Kindergarten to Grade 12 mathematics instructors, university mathematicians, and mathematics educators. Principles and Standards for School Mathematics was released in 2000. The revised document contains six principles to guide school mathematics: equity, curriculum, teaching, learning, assessment, and technology. Five content standards: number and operation, algebra, geometry, measurement, and probability and data analysis, along with five process standards: problem solving, reasoning, communication, multiple representations, and connections, are described by 
grade band with curricular examples. Additionally, in grades 9 to 12 , the curriculum was defined as being appropriate for all students. No distinction was made between content appropriate for college-intending or non-college-intending students.

Several national professional organizations of mathematics and science educators have been organized to address issues in mathematics as well. The National Council of Supervisors of Mathematics was organized at the Annual Meeting of the NCTM in 1969. Originally formed as an organization for supervisors of Kindergarten to Grade 12 mathematics education, the membership soon included university level mathematics educators and classroom teacher leaders. Its purpose is to support mathematics education leadership at the school, district, college and university, state and province, and national levels. Among the goals of the National Council of Supervisors of Mathematics are: (1) to offer up-to-date information about research, issues, practice, programs, and policy in mathematics education; and (2) to collaborate with other stakeholders in the education community and with business and government to strengthen leadership in mathematics education (National Council of Supervisors of Mathematics, 2005).

The Association of Mathematics Teacher Educators was organized in 1993 to promote the improvement of mathematics teacher education in all its aspects. The principal goals of the Association of Mathematics Teacher Educators are: (1) to promote leadership among mathematics teacher educators; (2) to encourage research related to mathematics teacher education; and (3) to encourage and organize programs focusing on issues related to the preparation and professional development of mathematics teachers in Kindergarten to Grade 16 (Association of Mathematics Teacher Educators, 2004). 
Federal and state reform efforts. In response to the publication of A Nation at Risk in 1983, the federal government continued to increase its role in education in the 1990s. In 1989 state governors and President George H. W. Bush reached an agreement on six goals for America's schools to reach by the year 2000. The concept of national goals for education was the first of its kind. President William Clinton expanded the goals and signed the Goals 2000: Education America Act in 1994. One goal was that U.S. students would be first in the world in mathematics and science achievement. A second piece of critical legislation was the passage of Improving America's Schools Act in 1994. This act was different from previous legislation in that it mandated that states create academic standards to be supported by state testing programs, linked to local school curricula, and targeted toward improving teaching and learning for all students rather than selected groups (Lappan \& Wanko, 2003).

States passed new legislation calling for excellence in education by raising teacher standards, revising curriculums, establishing new testing programs, and raising graduation requirements. Testing became commonplace as a way to assess the success or failure of education initiatives, and criterion-referenced tests were developed and used by most states, with California leading this process. For the most part, tests were machine scoreable with a multiple-choice format. Curricula, however, were beginning to emphasize problem solving, which could not easily be assessed in the multiple-choice format (Long, 2003).

State Kindergarten to Grade 12 education boards developed content standards for all students and initiated statewide assessments based on these standards, but differences in content standards and assessments exist between the states. In some states, students are 
held accountable for attaining established goals; there are penalties for students not attaining a specified performance level, including not receiving a high school diploma. In other states, as in Kentucky, accountability lies with schools and their teachers rather than with individual students. A performance goal is established for each school, and schools are expected to make adequate yearly progress toward that goal. Schools not reaching the performance goals receive sanctions that can result in the firing of an entire school faculty for the lowest performing schools (Kentucky Department of Education, 2006).

Each state has followed a slightly different path in developing curriculum standards and accountability testing for Kindergarten to Grade 12 programs. In Kentucky, the Core Content for Assessment Standards in mathematics was written by a committee of classroom teachers and mathematics educators. In mathematics, the committee was heavily influenced by the Curriculum and Evaluation Standards for School Mathematics issued by the NCTM. There was an extensive review process for the content standards by classroom teachers and interested citizen groups before they were adopted by the State Board of Education, and a statewide assessment was developed based on these content standards. The Core Content for Assessment includes questions in number, geometry, statistics and probability, and algebraic thinking. Questions for the state assessment are written by committees of school and university educators and are extensively field tested for validity and reliability. The test includes multiple choice and open response questions that attempt to assess the mastery of problem solving, communication, connections, and representations with open response questions in each of the four mathematics contents (Kentucky Department of Education, 2006). 
States experienced a shortage of qualified mathematics teachers at the middle or junior high and high school level during World War II, with more students remaining in high school for more years. Through the later part of the 20th century, teachers were either certified for Kindergarten to Grade 8 in all contents or were certified in a specialized content for grades 7 to 12 . Many teachers in middle grades mathematics classes had little more mathematics background than high school algebra and geometry. The majority of teachers certified for teaching mathematics in grades 7 to 12 were teaching high school mathematics, and with increasing school enrollments and gradually increasing requirements for students to complete more years of mathematics in order to graduate from high school, there were not enough certified high school mathematics teachers. By 1983, the National Commission on Excellence in Education in A Nation at Risk noted that 45 states reported shortages of mathematics teachers and that half of newly employed mathematics, science, and English teachers were not qualified to teach these subjects.

State reform movements in the 1990s included raising teacher standards. The range of grade levels for which a teacher could be certified was narrowed, and content specific requirements were increased, especially for middle grades mathematics certification. High school mathematics teachers are still required to have a college major in mathematics. New programs to address the shortage of qualified middle and high school teachers include university certification programs designed to prepare career changers and non-teaching mathematics majors and minors for middle and high school mathematics classrooms (Kentucky Education Professional Standards Board, 2007). Despite these initiatives, there are teachers in middle grades mathematics classes with 
only minimal mathematics backgrounds and high school teachers who are not mathematics majors. In 1999-2000, only $31.5 \%$ of middle grades mathematics teachers were certified with majors in mathematics. Of the remaining teachers, $43.2 \%$ of the teachers were certified to teach but did not have a major in mathematics. Among high school mathematics teachers, $68.6 \%$ were both certified to teach mathematics and had a major in mathematics. The remaining teachers had a mathematics major but were not certified, were certified without a mathematics major, or were neither certified nor had a mathematics major (National Center for Education Statistics, 2003).

States have also strengthened mathematics requirements for high school graduation. In most states, including Kentucky, three years of mathematics are required for all students. At least two years must be algebra and geometry, but it is possible for a student to take a pre-algebra type course to meet one of the requirement years. Students preparing to enter college must also complete another year of algebra (Kentucky Department of Education, 2006; Achieve, Inc., 2004). A downside to all students completing algebra is that in an effort to ensure that as many students as possible complete their mathematics requirements successfully, teachers may weaken the curriculum (Kirst \& Bracco, 2004; Usiskin, 2001).

Local school boards, following the criteria and mandates established by state Boards of Education, have generally aligned their curricula with their state's core contents for assessment. Professional development for classroom teachers most often focuses on strategies for teaching the core content successfully. Teachers are pressured by parents to pass students on to the next level, and administrators, who are anxious for their schools to show improvement on state assessments, pressure teachers to emphasize 
content that will be assessed. Teachers' priorities become preparing students for state assessments and not addressing the preparation of students for college mathematics (Kirst \& Bracco, 2004).

Despite pressures to prepare for state assessments, local school boards often are taking actions that encourage capable students to prepare themselves more successfully for postsecondary education. Students are encouraged to take four years of mathematics in high school and, at the very least, to take mathematics in their senior year of high school.

Tests are being developed that give high school students an opportunity to check their preparedness for college level mathematics. In Kentucky, the Kentucky Early Mathematics Placement Test is a no risk, online test for high school students. Content assessed on the Kentucky Early Mathematics Placement Test reflects traditional symbolic manipulative algebra skills rather than topics such as probability, matrices, and data analysis that are included in the currently adopted state core content mathematics curriculum. Students can complete the test in less than an hour and immediately get a report indicating their weaknesses and readiness for college level mathematics. Teachers are encouraged to have their students take this test prior to senior year scheduling so that students with weaknesses can schedule an appropriate mathematics course for their senior year. Some schools and districts have created a senior year mathematics class for students whose skills are too weak for precalculus. Such classes review previously taught algebra content and stress some of the algebraic manipulation skills that may have been covered quickly or not at all in an earlier course (Kentucky Early Mathematics Placement Test, 2004). 
Textbook reform. The role of the NSF in supporting and funding curriculum projects in science and mathematics continued to increase in the 1990s. In an attempt to address the growing need for mathematics knowledge among Kindergarten to Grade 12 students in the United States, the NSF funded several curriculum projects, the intent of which was to ensure high quality mathematics instruction for all students, based on the vision described in Curriculum and Evaluation Standards for School Mathematics (NCTM, 1989). Descriptions of five curriculum projects for high school mathematics instruction follow.

The Core-Plus Mathematics Project, which eventually was published as Contemporary Mathematics in Context, is a complete high school mathematics program developed by researchers at Western Michigan University under the direction of Christian Hirsch. Each of the four courses was developed using a four-year research, development, and evaluation process. After a year of initial development, a pilot version was tested during the second year in 19 Michigan high schools. Changes were incorporated into a third year field test version that was conducted in 36 high schools in eleven states. The schools involved in the field tests represented a broad cross section of students from urban, suburban, and rural areas with varied ethnic and cultural diversities.

The curriculum features interwoven strands of algebra and functions, geometry and trigonometry, statistics and probability, and discrete mathematics topics in each of the four years of high school. The content is developed within focused units that require students to search for patterns, make and check conjectures, reason with multiple representations, and make convincing arguments and proofs. Based on evidence from nationally standardized tests such as the SAT, ACT, and NAEP, in addition to teacher 
and researcher designed tests, the Core-Plus Mathematics Project curriculum enhances students' mathematical achievement and attitudes toward mathematics. Students perform as well or better than students completing a traditional curricula on the SAT and ACT college entrance exams (Core-Plus Mathematics Project, 2005).

Development of the Interactive Mathematics Program was begun in 1989 by a group of researchers from the California Postsecondary Education Commission and the California State Department of Education. Lynne Alper and Sherry Fraser, mathematics educators, and Dan Fendel and Diane Resek, from San Francisco State University, codirected the project. The initial purpose of the Interactive Mathematics Program was to revamp the traditional three-year Algebra I-Geometry-Algebra II sequence in high school mathematics. A fourth year course was added in 1992 when the NSF began funding the program development. The first three years of the curriculum were field tested in three California high schools between 1989 and 1992. The fourth year of the curriculum was tested in four California high schools during 1993-94. The field test schools represented diverse student ethnicity and cultures. Additional schools began using the materials each year until by 1996, when the curriculum was finally published, approximately 150 schools in 12 states were using Interactive Mathematics Project materials.

The Interactive Mathematics Project curriculum integrates traditional material with additional topics recommended by the NCTM such as statistics, probability, curve fitting, and matrix algebra. The units are structured around a central problem, and bring in multiple mathematics topics as needed to solve the problem. The units require students to experiment with examples, look for patterns, and make, test, and prove conjectures. Research has shown that students in the Interactive Mathematics Project program do as 
well as students in traditional mathematics programs on standardized tests such as the SAT (Key Curriculum Press, 2002).

Mathematics: Modeling Our World, originally known as Applications/Reform in Secondary Education, was developed by the Consortium for Mathematics and Its Applications (COMAP) under the leadership of Solomon Garfunkel, Landy Godbold, and Henry Pollack. The curriculum was written over a four year period by a team of practicing teachers. The materials were field tested with over 5,000 students from a diverse collection of high schools across the United States.

Each unit in the curriculum is based on engaging, real-life situations and the problems and conditions associated with them. The solution to each problem presented in the curriculum is based on the process of mathematical modeling. In order to implement the modeling process, students find a mathematical core to explore and use to find a solution to a problem. The mathematics used may integrate algebra, geometry, trigonometry, data analysis and probability using appropriate technology (COMAP, 2005).

SIMMS Integrated Mathematics is a four year high school mathematics curriculum with six levels. The curriculum was developed by The Montana Council of Teachers of Mathematics under the direction of Johnny Lott at the University of Montana. Levels 1 and 2 provide core mathematics for all students. Two additional levels are intended for students planning mathematics intensive college majors, and the remaining two levels are for students who are not planning on careers in which mathematics plays a central role. Topics in algebra, geometry, trigonometry, data analysis, probability, and discrete topics are integrated throughout each level. The focus 
in each unit is on problem solving, understanding how topics are connected within mathematics and to the real world, communicating and reasoning mathematically, and using multiple representations of mathematics. Students using this curriculum scored at least as well on examinations of traditional mathematics skills as those taking a traditional mathematics course sequence (SIMMS Integrated Mathematics, 2003).

Math Connections is a secondary mathematics core curriculum that was developed in 1992 by the Connecticut Business and Industry Association Education Foundation. June Ellis and Robert Decker, from the University of Hartford, and Robert Rosenbaum, from Wesleyan University, were project leaders. The curriculum blends algebra, geometry, probability, statistics, trigonometry and discrete mathematics with an emphasis on the unity of and interconnection among the mathematical ideas. The materials were field tested for five years before full implementation. Students using the Math Connections curriculum score well on traditional assessments such as the SAT and develop positive attitudes toward mathematics (It's About Time, 2005).

The NSF curriculum materials, which were well researched during their development process, have not brought a great deal of change in mathematics textbooks. Seeley (2003) states that "textbooks in the United States are a reflection of the nation's beliefs about education, and the process of adopting textbooks is a political mechanism for implementing those beliefs" (p. 957). Textbooks have been the primary instructional resource for students since colonial days. Early secondary mathematics textbooks usually included procedures and exercises for algebra or trigonometry because a portion of the population needed to be proficient in those procedures. The textbook was also the basis for the curriculum, particularly for inexperienced and untrained teachers who relied on 
the textbook for guidance in deciding what to teach. Free textbooks for students were not common until the late 1800 s. As free textbooks became more widespread, states began adopting uniform purchase policies that precisely determined which textbooks potentially could be selected by a local school district.

By the 1990s, state legislatures began requiring textbooks to be aligned with the state's curriculum. Since there is variation in the mathematics curriculum between each state, textbooks are written to accommodate a number of state curriculums, and consequently, the end product does not cover any state's curriculum well. Other forces at work in the textbook adoption process include policymakers wanting guaranteed test score increases at the lowest possible cost, special interest groups wanting materials reflecting their particular ideologies, parents wanting materials that look familiar, and teachers wanting materials that will help them teach what they are supposed to teach. By the time a textbook goes through the adoption process, the resulting textbooks from different publishers tend to be similar in content and appearance for that grade level and few, if any topics, are covered in depth (Seely, 2003).

Small publishers offering innovative textbooks usually cannot afford to compete with the major publishers in the state adoption process. Mergers of smaller publishing companies with larger ones often mean that less profitable innovative materials will no longer be available. The few NSF curriculum projects that were marketed by major publishers did not necessarily enjoy widespread adoption. Even when innovative materials appeared on adoption lists, they were less likely to be adopted because of the extensive professional development needed by teachers in order to effectively implement such materials (Seeley, 2003). 
Opposition to the reform efforts. In a manner not unlike Colburn's experience in the 1800 s, reform efforts by the NCTM, the reform curriculums funded by the NSF, and local and state content standards development have not been well received by everyone in the mathematics community or by parents. One of the most outspoken groups opposing new mathematics curriculum standards and reform curriculum materials is a group known as the Mathematically Correct. According to their web site, the Mathematically Correct are an informal group of university mathematicians, parents, and other interested citizens who believe the reform efforts of the 1990s have only aggravated the problems of poor student mathematics achievement. The Mathematically Correct (2005) state that the reform focus

is on things like calculators, blocks, guesswork, and group activities and they shun things like algorithms and repeated practice. The new programs are shy on fundamentals and they also lack the mathematical depth and rigor that promotes greater achievement. As a result, our children have less and less exposure to rigorous, content-rich mathematics.

When the NSF made positive recommendations for several of the reform curriculums based on the NCTM standards, the Mathematically Correct took out full page advertisements in major newspapers denouncing the action.

A perception by some citizens that mathematics reform efforts are missing the mark continues today as Seeley (2003) notes in her discussion of the impact of textbooks on curriculum.

In many states across the nation including Texas but particularly in California, strong conservative factions and pockets of academic activism at the college and university level became engaged in energetic state-level debate over recommendations [on textbooks] of any review committee. Ever since the days of 'new math' in the 1960s, there had been calls to go 'back to the basics,' generally pushing for more drill and practice on isolated computational facts and procedures. Such opposition to mathematics reform was based partly on a lack of clarity regarding what was called for in reform and partly on the quite accurate 
observation that some students were leaving school ill-equipped to function well in the world outside. The late 1990s found these conservative groups, especially religious conservative groups in some states, well organized to oppose any perceived new reform that might divert instruction away from the mastery of computational skills (p. 985).

\section{Current Status of Mathematics Education}

More students than ever before are college-bound, and it appears that that trend will continue into the next decade. The total number of undergraduate students enrolling in degree-granting two-year and four-year institutions nearly doubled from 7,376 million students in 1970 to 14,257 million students in 2002 . This growth trend is expected to continue with an expected total enrollment of approximately 16,500 million students in 2014 (National Center for Education Statistics, 2005). Furthermore, the proportion of total students from minority populations is increasing. Minority students represented nearly a third of all undergraduates in 1999 to 2000, up from about a quarter in 1989 to 1990 (National Center for Education Statistics, 2002).

Student preparedness in the 21st century

Well prepared students. Some students have always demonstrated preparedness for college level mathematics and have made smooth transitions from secondary to postsecondary level study. Many students continue to make good transitions today. Student performance on major mathematics assessments remains mixed but is generally stable or improving. On the NAEP mathematics assessment, students in grades 4 and 8 have shown steady gains in mathematics knowledge, but the Grade 12 results are mixed over the 1990s. Overall, the percentage of 12th graders at or above both Basic and Proficient in mathematics was higher in 2000 than in 1990, but there was a decline in mathematics scores in 1996 (National Center for Education Statistics, 2003). On the 
SAT, taken by approximately $48 \%$ of high school seniors in 2004 , mathematics scores show an improving trend since 1994; 2004 scores were 14 points higher than 1994 scores (College Entrance Examination Board, 2003). On the ACT, taken by about $40 \%$ of high school seniors, mathematics scores in 2003 were 0.6 point higher than in 1992 (ACT, Inc., 2004). On the TIMSS assessment, in 1995, the last year for which secondary school scores are available, United States' students scored below the international average score in advanced mathematics (TIMSS International Study Center, 1998). Scores on these tests, taken broadly by high school seniors across the United States, suggest that students know more mathematics now than they did in the early to mid-1990s, and that the number of students taking mathematics courses beyond Algebra 2 is increasing. The percentage of students taking at least one mathematics course beyond Algebra 2 increased from 26\% in 1982 to $45 \%$ in 2000 (National Center for Education Statistics, 2004).

The Advanced Placement program of the College Board is designed to enable high school students to obtain college credit for their high school course work. In selected academic courses, high school students take an end-of-year examination that contains both multiple choice and open-response questions, and tests are scored on a 1 to 5 scale. The number of credit hours a college will give a student completing an Advanced Placement test varies from school to school, but in general, a score of 3 to 5 means a student will get some college level course credit. More high schools are offering Advanced Placement classes because of their rigorous content and are encouraging students to take the Advanced Placement tests administered by the College Board. In Advanced Placement Calculus, 126,588 tests were administered in 1996 and 212,754 
tests were administered in 2003, a 68\% increase (College Entrance Examination Board, 1997, 2003).

Under-prepared students. Within this college-bound population, however, is a group of students who are under-prepared for college level mathematics; this group is the focus of this study. Nearly every postsecondary program of study, including two-year technical and associate degree programs, requires that students successfully complete a credit-bearing college level mathematics course. Steen (2004) states that a common general education requirement in college mathematics is a course titled college algebra with content similar to that defined by Charles Eliot and the Committee of Ten in 1890 . In fall 2000, combined credit-bearing college algebra enrollment in two- and four-year colleges was approximately 400,000, with another 100,000 enrolled in a combined college algebra and trigonometry course. This number has increased about $73 \%$ since 1980, while enrollment in mainstream calculus has remained approximately stable (Small, 2006; Lutzer, Maxwell, \& Rodi, 2002).

Successful achievement in mathematics eludes many students who are enrolled in college algebra. College algebra has a reputation nationally for failing an unusually high percentage of students. The number of students who receive a D, F, or withdraw may be as high as $40 \%$ to $50 \%$ (Herriott, 2006). Even when an applied or survey mathematics course can be substituted for college algebra to meet the general education requirement, success in the course requires some knowledge of algebra.

Another large group of students enroll in college only to discover they are not even well-enough prepared for college algebra or another general education mathematics course. Twenty-two percent of entering freshmen enrolled in remedial mathematics in all 
post-secondary institutions combined in 2000. In public two-year colleges, $35 \%$ of entering freshmen enrolled in remedial mathematics and in public four-year institutions $16 \%$ of entering freshmen enrolled in remedial mathematics (National Center for Education Statistics, 2004, p. 169). The length of time a student spends taking remedial courses increased between 1995 and 2000 from 33\% spending one year or more in remedial coursework in 1995 to 40\% in 2000 (National Center for Education Statistics, 2004, p. 170).

The percentages of students needing remedial mathematics in postsecondary institutions in Kentucky are greater than the national averages. In fall 2004, 44.1\% of entering students were under-prepared for mathematics in four-year colleges and universities, and $74.9 \%$ of entering students were under-prepared for mathematics in the two-year community and technical college system. (Kentucky Council on Postsecondary Education, 2006).

Student placement in college mathematics varies considerably between institutions. Today most colleges and universities expect students to have completed at least two years of algebra and a year of geometry in high school before being admitted to college, but there is no national standard for admission. Each college and university sets its own requirements, basing entry on a number of factors including pre-admissions test scores and high school academic programs. "There has never been a standard of admission to all colleges in the United States. The Educational Testing Service and the ACT program offer uniform examinations across the country, but each college is free to admit students regards of where they place on those examinations" (Cohen \& Brawer, 2003, p. 260). 
Once admitted to a college or university, criteria for placement in college mathematics classes vary between institutions. Data on remedial course taking might suggest that there is a set of standards defining what is meant by college level work, but that is not the case. Phipps (1998), a Senior Research Associate at the Institute for Higher Education Policy, reviewed the literature and concluded that remedial needs are often determined by the needs of a particular institution. Remedial students often are those who had the lowest scores on some type of normative measurement, but where the cutoff line is drawn is arbitrary. Kirst, Venezia, and Antonio (2004) in summarizing the findings of The Bridge Project at Stanford University concluded there is little uniformity among placement tests. They cite a study by the Southern Regional Education Board in 1998 that found postsecondary institutions in the southeastern United States administered nearly 125 combinations of 75 difference placement tests. Institutions differ in the way in which they assign students to remedial coursework. Sixty-one percent of all institutions require all entering students to take a placement test to determine their need for remediation in mathematics. Another $25 \%$ require students who meet various criteria such as a score below a specified cutoff level on the SAT or ACT to take a mathematics placement test (Greene, Parsad, \& Lewis, 2003).

On each of these tests, students are tested on different content with a range of standards. "Differences in the content and format between assessments used at the Kindergarten to Grade 12 exit and college entrance levels point to great variance in expectations regarding what students need to know and be able to do to graduate from high school and enter college" (Kirst, Venezia, \& Antonio, 2004, p. 288). As an example, "approximately $33 \%$ of the items on any state high school-level assessment were framed 
within realistic situations, and as many as $92 \%$ of the items were contextualized. In contrast, the placement tests and college entrance exams assessed examinees primarily with abstract questions" (p. 288). Even students who attend a community college with open-admissions policies learn that the college has a set of placement standards that are higher than the standards needed for high school graduation. Students who are determined to need remediation in mathematics based on institutional criteria are required to enroll in remedial mathematics courses that usually cover beginning and intermediate algebra content for which students may receive institutional credit but not receive college credit (National Center for Education Statistics, 2003; Merisotis \& Phipps, 2000;Phipps, 1998; Southern Regional Education Board, 2000; Jenkins \& Boswell, 2002).

No single measure describes the students who may need remediation in mathematics when entering postsecondary education institutions. It might be expected that a student who completes a college preparatory mathematics curriculum in high school -- Algebra 1, Geometry, and Algebra 2 -- would not need to take remedial mathematics. Adelman (1999) used data from the National Educational Longitudinal Study -1988 to determine which factors contribute the most to students attaining a bachelor's degree and found that of all the pre-college curricula, the highest mathematics course studied in high school has the strongest influence in Bachelor's degree completion. Adelman found that finishing one course beyond Algebra 2 more than doubles the odds that a student will obtain a Bachelor's degree after entering a postsecondary institution. Students who dislike or find it difficult to learn mathematics may choose not to take rigorous mathematics courses in high school if it is not required. To address this issue, the number of years of mathematics required for high school 
graduation is being increased in many states, but having completed a college preparatory curriculum is not necessarily a guarantee of readiness for college level mathematics.

The Maryland Higher Education Commission (1998) conducted a study to measure the college success of high school graduates in public institutions in Maryland from 1996 to 1997. While they found that students who had completed a college preparatory curriculum in high school earned higher grades in their initial mathematics and English courses than students who had not completed a college preparatory curriculum, the commission also found that $40 \%$ of students who completed collegepreparatory courses in high school needed mathematics remediation at community colleges. At public four-year institutions, $14 \%$ of college-preparatory students needed mathematics remediation. For reasons unknown, these students had failed to retain the mathematics they had been taught in high school (Nunley, 1998).

Greene, Parsad, and Lewis (2003) used data from the National Center for Education Statistics to research remedial course offerings at degree-granting postsecondary institutions in fall 2000 . They found that $71 \%$ of degree granting institutions enrolling freshmen offered remedial courses in mathematics in fall 2000. Ninety-seven percent of public two-year and $78 \%$ of public four-year colleges offered remediation in mathematics. Additionally, the number of remedial courses offered in mathematics was greater than the number of remedial courses offered in reading or writing. In 2000, all institutions combined offered an average of 2.5 different remedial mathematics courses compared to 2.0 such courses in reading and writing. Public twoyear institutions offered an average of 3.4 different remedial mathematics courses, and 
public four-year institutions offered an average of 2.0 different remedial mathematics courses.

Transition issues for college-bound students. A group of researchers led by Kirst and Venezia (2004) at Stanford University explored the transition issues for students moving from secondary to postsecondary study. The Bridge Project was a six year study begun in 1996 and supported by the Pew Charitable Trust and the U.S. Department of Education through its National Center for Postsecondary Improvement. The project was designed to study the gaps and transition issues between high school and college curricula transitions for students. The purpose of the study was to examine: 1) the relationships between Kindergarten to Grade 12 and postsecondary education as they relate to student transitions from secondary to postsecondary education, and 2) high school student, parent, and educator understandings of policies at the high school graduation and college entrance levels. These issues were studied in California, Illinois, Georgia, Maryland, Oregon, and Texas. In the first phase of the study, researchers interviewed approximately 165 persons in state education agencies, state-level Kindergarten to Grade 16 committees or councils, twelve universities and six community colleges. One region per state with one more-selective and one less-selective institution were included per region. Six community colleges, one in each of three states, were included. Approximately 15 administrators and faculty were interviewed at each institution, and two student focus group interviews were conducted on each of the community college campuses. The main research questions were to determine: 1) What are the postsecondary education admission and placement policies within the six states? and 2) To what extent are policies, procedures, practices, and expectations compatible; 
i.e., is there alignment between high school assessments and postsecondary admissions criteria across state education institutions?

In the second phase of the study, field research was conducted in 24 high schools that were feeder schools for the postsecondary institutions across the six states. The principal, a vice principal, a senior year counselor, and four teachers typically were interviewed in each school. Two 9th grade and two 11th grade classes were surveyed along with their parents, and 11th grade focus group interviews were conducted. There were some socio-economic differences between the school samples because of logistical issues. The racial makeup of the samples differed and in some states was quite diverse, while in others one racial group was predominant. The main research questions were: 1) How are postsecondary education admissions standards and placement policies, and relevant state-level reforms, communicated to, and interpreted by, Kindergarten to Grade 12 stakeholders? 2) Are there differences in how student groups receive and interpret those policies?

The Bridge Project researchers found several commonalities across the six states affecting the transition of students from high school to college. Their first conclusion was that there are multiple and confusing assessments. Postsecondary institutions are generally unaware of Kindergarten to Grade 12 standards and assessments, and Kindergarten to Grade 12 educators are usually unaware of specific postsecondary admission and placement policies. Also, postsecondary officials are wary of Kindergarten to Grade 12 assessments because they are politically volatile.

Kindergarten to Grade 12 instructors noted that new testing burdens do not allow sufficient time for them to focus on other needs such as helping students prepare for 
college. Students themselves have a confusing array of exams to prepare for. They have to take state mandated assessments and exams in individual courses. If they are collegebound they take the SAT and/or the ACT, and many take Advanced Placement exams in specific content areas and multiple SAT II subject tests. Once admitted to a college or university, students may take an additional placement exam that determines their readiness for college level work. Placement exams vary from an online test such as COMPASS to exams written by department faculty. On each of these tests, students are tested on different content with a range of standards.

Differences in the content and format between assessments used at the Kindergarten to Grade 12 exit and college entrance levels point to great variance in expectations regarding what students need to know and be able to do to graduate from high school and enter college. Many of those differences evolved in an era when only a small fraction of the student-age population attended college. But the differences in expectations are outdated, and the current situation can damage student preparation for a large number of students (Kirst, Venezia, \& Antonio, 2004, p. 288).

The study found several misalignments between secondary and postsecondary assessments. As an example, "approximately $33 \%$ of the items on any state high schoollevel assessment were framed within realistic situations, and as many as $92 \%$ of the items were contextualized. In contrast, the placement tests and college entrance exams assessed examinees primarily with abstract questions" (p. 288). The researchers recommended examining the relationship between postsecondary education placement exams and Kindergarten to Grade 12 exit standards and assessments, and if necessary, establishing alignment between the two sets of standards.

Another conclusion of the Bridge Project researchers was that there is a disconnected curriculum. They noted that teachers teach a set of standards and skills specified by state and district criteria; these standards and skills may not meet the 
demands required by college entrance requirements. Even students who attend a community college with open-admissions policies learn that the college has a set of placement standards that are higher than the standards they met for high school graduation (Kirst, Venezia, \& Antonio, 2004).

Initiatives to improve student success in mathematics. At the beginning of the $21 \mathrm{st}$ century, there was increasing pressure for changes in America's Kindergarten to Grade 12 schools. On the federal level, the No Child Left Behind (NCLB) act was enacted by the United States Congress in 2002. This legislation mandated that every child in every state attain specified performance levels for grades 3 to 8 in reading and mathematics by 2014. Composite school scores are calculated, and every school and school district is expected to have all students, including those from minority populations, special needs categories, and non-native English speaking groups, score well. Schools that do not meet the student performance standards are declared to be deficient, and various penalties can be assessed to deficient schools. Under NCLB, each state uses its current curriculum standards and adapts testing programs already in place to fit the federal guidelines (US Department of Education, 2005).

Other initiatives have been underwritten by national education trust groups and business organizations in an attempt to determine what content should be taught in Kindergarten to Grade 12 schools, with an emphasis on the knowledge students should have mastered as they leave high school for post-secondary education or the work force.

The American Diploma Project (ADP) is sponsored by Achieve, Inc., a bipartisan, non-profit organization of business leaders, The Education Trust, a national organization working toward high academic achievement for all students in grades Kindergarten to 
Grade 16 with an emphasis on providing for the needs of underserved populations, and The Thomas B. Fordham Foundation, an organization that supports research, publications and action projects of national significance in elementary and secondary education reform. ADP and their partner organizations spent two years collecting empirical evidence to codify the knowledge and skills that high school students need in English and mathematics to take credit-bearing courses in colleges and universities or to obtain good career-track jobs in the workplace. Five partner states (Indiana, Kentucky, Massachusetts, Nevada, and Texas) committed teams of state leaders, including the governor, the head education officer, heads of the state higher education system, a business leader, and other citizens, to develop the project.

The ADP gathered data from the Bureau of Labor Statistics and the United States Department of Education's National Educational Longitudinal Survey to define the relationship between education, employment, and earnings. Three levels of employment in 2004 were defined: low- skilled jobs paying less than $\$ 25,000$ per year; well-paid, skilled jobs with earnings of $\$ 25,000-\$ 40,000$ per year; and high paid, professional jobs with earnings over $\$ 40,000$ per year. The top two categories, representing $62 \%$ of all jobs over the next ten years, were the focus of the ADP effort (Achieve, Inc, 2004). The researchers were able to determine the average grades earned and typical courses taken for the top two tiers of earnings categories. For example, $84 \%$ of those persons holding highly paid professional jobs had taken Algebra 2 or higher as their last high school mathematics course; $61 \%$ of the persons in well-paid jobs had taken Algebra 2 or higher, and $78 \%$ had taken geometry or higher as their last high school mathematics course. 
Two panels of curricular experts determined the content of Algebra 1, Geometry, and Algebra 2. ADP used this content to develop preliminary workplace expectations for a first round of employers. Twenty-nine representatives from industries such as health care, gaming, high-tech manufacturing, information technology, law, telecommunications, energy, television media, shipping and transportation, retail services, and financial services were asked to confirm the importance of the content in the preliminary benchmarks. Based on responses from the workplace experts, the workplace benchmarks were refined by the ADP, and post-secondary preliminary benchmarks were developed.

The Education Trust led the effort to define the postsecondary expectations for credit-bearing course work. Faculty representatives from Kindergarten to Grade 12 systems and two- and four-year colleges and universities were assembled in each of the ADP partner states. The faculty representatives examined the content of the state high school graduation tests, national college admissions and placement tests (SAT, ACT, COMPASS, Accuplacer), a sampling of postsecondary placements tests, and the General Education Diploma. Using a protocol developed by the Education Trust, the committees codified the de facto standards for students by evaluating the content of the various assessments.

Achieve and ADP staff examined the alignment between partner state high-school standards and their high school assessments. Using data from all of the analyses, ADP and Achieve staff met with faculty members from two- and four-year colleges in a broad range of content areas and asked them to define the mathematics content and skills necessary for success in freshman credit-bearing courses, locate these must-have 
competencies in state content standards, determine the degree to which current state standards and assessments reflect expectations, and identify missing prioritized content in state standards and assessments.

The workplace and postsecondary expectations were combined into a set of ADP college and workplace readiness benchmarks. Panels of business representatives and content area experts were convened to consider the benchmarks from the partner states as well as throughout the country. Part of their task was to identify which benchmarks were necessary for success in both the workplace and postsecondary education and which were necessary for only one area. During the entire review process, sample workplace tasks and postsecondary assignments were collected to illustrate the benchmarks.

The ADP organized the mathematics benchmarks into four content strands: number sense and numerical operations, algebra, geometry, and data interpretation, statistics, and probability. A separate paragraph was written to cover the relationship of mathematical reasoning across all the content strands with its connections to the workplace. Broad algebra content benchmarks included:

1. Performing basic operations on algebraic expressions fluently and accurately;

2. Understanding functions, their representations and their properties;

3. Applying basic algebraic operations to solve equations and inequalities;

4. Graphing a variety of equations and inequalities in two variables, demonstrating understanding of the relationships between the algebraic properties of an equation and the geometric properties of its graph, and interpreting a graph; 
5. Solving problems by converting the verbal information given into an appropriate mathematical model involving equations or systems of equations; apply appropriate mathematical techniques to analyze these mathematical models and interpret the solution obtained in written form using appropriate units of measurement.

The ADP promotes a number of other recommendations for secondary institutions in its member states, including aligning secondary academic standards with the knowledge and skills required for college and workplace success, specifying core content in English and mathematics for high school graduation, requiring high school exit examinations, validating high school assessments as predictors of postsecondary performance, and establishing high standards for all students. The ADP recommends that postsecondary institutions use high school assessments for college admissions and placement, provide information to high schools on the academic performance of their graduates in college, and hold postsecondary institutions accountable for the academic success of the students they admit, including student learning, persistence, and degree completion (Achieve, Inc., 2004). In the 2006 revision of the Kentucky Core Content for Mathematics Assessment, Version 4.1, mathematics standards were aligned with ADP mathematics benchmarks (Kentucky Department of Education, 2006).

The Standards for Success project was established through a partnership of the Association of American Universities and the Pew Charitable Trusts. Seventeen sponsoring research universities, including Harvard, Massachusetts Institute of Technology, Pennsylvania State University, Indiana University, the University of Michigan, and the University of California, Berkley, were the principal developers of 
content standards in mathematics and five other content areas. All of the participating universities are members of the Association of American Universities. The goal of the project was to answer one question: "What must students know and be able to do in order to succeed in entry-level university courses?" (Conley, 2003, p. 8). Participants were interviewed over two days in group settings. Discussions at five university sites were used to develop preliminary findings. At each meeting, the modus operandi included audio tapes of each discipline-based discussion, flip chart notes recorded by facilitators, student work sample reviews, and ratings of and comments on state academic content standards. Panel participants were either selected by the offices of the university president or provost, and the participants either taught or worked administratively with freshmen. Ph.D. level Standards for Success researchers prepared the data for analysis. Each discussion was transcribed verbatim and analyzed for recurrent themes and keywords. A preliminary draft of the findings was developed; a modified Delphi method was used to obtain feedback and make revisions from academic faculty in their respective fields of expertise. After several iterations of this process, no new standards were emerging; participants were merely restating existing standards. Four additional campus meetings revealed no significant changes in the draft document. In addition to the review process, course syllabi from entry-level university courses were analyzed and comparisons with standards from national content standards were made to uncover any discrepancies.

Five content strands were identified as being essential in mathematics: computation, algebra, trigonometry and geometry, mathematical reasoning, and statistics. Within algebra the participants concluded that successful students: 
1. Know and apply basic algebraic concepts;

2. Use various appropriate techniques to solve basic equations and inequalities;

3. Distinguish between and among expressions, formulas, equations and functions;

4. Understand the relationship between equations and graphs;

5. Understand algebra well enough to apply it procedurally and conceptually to a range of common problems;

6. Demonstrate the ability to work with formulas and symbols algebraically.

(Conley, 2003)

Since its inception, the ACT organization has evolved to take on new roles that include helping middle and secondary students plan for and assess their readiness for postsecondary training in addition to the administration of their pre-college admissions test. One of these initiatives is the Standards for Transition project. The project identifies content in language arts, science, and mathematics that students should know in order to score at specified levels of the ACT test. Students can begin planning for college by taking EXPLORE ${ }^{\circledR}$ in the 8 th grade and $\mathrm{PLAN}^{\circledR}$ in the 10 th grade. The tests are administered through schools and provide information to students regarding their readiness for college level work through interest inventories, completed coursework and grades, and curriculum-based tests in the ACT focus content areas (ACT, Inc., 2006).

The National Assessment of Educational Progress (NAEP) continues to review and modify its assessments to reflect changes in student diversity and in secondary curricular trends. For the 2005 assessment, representatives from national policy organizations, mathematics associations, research mathematicians, business and industry, and educators were included on the steering committee to review the framework for the 
2005 NAEP mathematics assessment. The committee considered reports from state mathematics content standards, NCTM, TIMSS, ADP, and the National Research Council of the National Academy of Sciences, along with incorporating input from mathematics teachers and supervisors (National Assessment Governing Board, 2004). The NAEP mathematics framework influences the work of state content standards committees. The recent Kentucky Core Content for Mathematics Assessment, Version 4.1, is organized using NAEP's 2005 Mathematics Framework (Kentucky Department of Education, 2006).

Professional organizations representing postsecondary mathematics instructors also have proposed changes in two- and four-year college mathematics curricula in order to provide smoother transitions in mathematics for under-prepared high school graduates. The American Mathematical Association of Two-Year Colleges (AMATYC) was organized in 1974. The goals of the AMATYC include spearheading the development and implementation of curricular, pedagogical, and assessment standards for two-year college mathematics education and communicating two-year college mathematics expectations in public, business, and professional sectors (American Mathematical Association of Two-Year Colleges, 2005).

The AMATYC has established standards for mathematics programs that specifically address the needs of college students who plan to pursue careers that do not depend on knowledge of calculus or upper-division mathematics and those students who need calculus but enter college unprepared for mathematics at that level. These types of courses constitute $80 \%$ of the mathematics offerings in two-year colleges. Mathematics standards adopted by the AMATYC are described in Crossroads in Mathematics: 
Standards for Introductory College Mathematics Before Calculus (1995). The purpose of the Crossroads project is to establish standards and make recommendations for two-year college and lower-division mathematics programs below the level of calculus. The AMATYC was motivated to initiate this document because of reform efforts by the NCTM which addressed Kindergarten to Grade 12 education and the calculus reform movement which addressed college level mathematics. The AMATYC believed neither of these reform efforts bridged the gap between high school mathematics and college calculus.

The Crossroads project was funded by the NSF, the Exxon Education Foundation, and the AMATYC. A steering committee consisted of representatives from the AMATYC, the American Mathematical Society, the MAA, the Mathematical Science and Education Board, the National Association for Developmental Education, and the NCTM. The steering committee appointed the Writing Task Force Team that actually prepared the document beginning in 1993. The Task Force reviewed documents and writings on mathematics education reform and developed their own vision statements for needed reforms before meeting to form a common vision. After initial editing, a draft document was reviewed by the entire Task Force, the Steering Committee, and other leaders in mathematics education. After additional editing, the document was widely circulated to the AMATYC members and other interested citizens. Hearings were held at several state and national mathematics conferences. The original draft document was revised in 1994 and re-circulated for comment by the Task Force and other reviewers. The final document was officially released in 1995 (American Mathematical Association of Two-Year Colleges, 1995). 
Three sets of standards for introductory college mathematics are defined in this document: Standards for Intellectual Development, Standards for Content, and Standards for Pedagogy. Guidelines for seven content standards: number sense, discrete mathematics, symbolism and algebra, probability and statistics, geometry, deductive proof, and function are listed. In algebra "students will translate problem situations into their symbolic representations and use those representations to solve problems" (American Mathematical Association of Two-Year Colleges, 1995, Standard C-2). Students will use a combination of algebraic, graphical, and numerical methods to form conjectures about and solve problems. Suggested topics include derivation of formulas, translation of realistic problems into mathematical statements, and solving equations by appropriate graphical, numerical, and algebraic methods.

In 2000, the AMATYC revisited the Crossroads project and began preparation of an additional document currently entitled Beyond Crossroads: Implementing Mathematics Standards in the First Two Years of College. The new document, released in 2006, extends the 1995 Crossroads in Mathematics document to include five implementation standards dealing with the learning environment, instructional strategies, curriculum development, assessment, and instructor professionalism (American Mathematical Association of Two-Year Colleges, 2006). In order to make their vision a reality, the Beyond Crossroads document calls for dialogue and collaboration between two-year colleges and Kindergarten to Grade 12 school districts and between two-year and four-year colleges and universities to align curriculum and assessments so that students make a smooth transition from high school to college mathematics. This call for 
multiple dialogues between the stakeholders who are seeking solutions to facilitating transitions for students in mathematics is unique among the reform efforts.

The MAA continues to make recommendations for changes in undergraduate college mathematics through its Committee on the Undergraduate Program in Mathematics (CUPM). In 2004, the MAA published a curriculum guide addressing the entire college-level mathematics curriculum for all students that was approved by the Board of Governors of the MAA in 2003 after four years of development. The Committee's work was supported by the NSF and the Calculus Consortium for Higher Education. The curriculum initiative focused on what students should know and experience as they complete their coursework in mathematics. Working assumptions of the committee were: (1) one curriculum is not appropriate for all majors; (2) the mathematics program must serve a wide variety of mathematics-intensive majors; and (3) the curriculum must serve the quantitative literacy needs of students enrolled in college algebra courses.

Information for the CUPM Curriculum Guide 2004 was collected directly from the college mathematics profession through a series of sessions at MAA meetings and focus group meetings between 1999 and 2003. In the spring of 2001, a stratified random sample of 300 mathematics departments offering a Bachelor's degree were surveyed with a return rate of $30 \%$. The survey was designed to collect data on student goals, department practices, and advanced courses. Representatives of partner disciplines and other professional associations were invited to review drafts of the Curriculum Guide.

The report of the Committee on the Undergraduate Program in Mathematics made recommendations regarding issues affecting all students taking college mathematics. The 
six recommendations include: (1) understanding the student population and evaluating courses and programs that align with student needs; (2) helping students develop mathematical thinking and communication skills; (3) communicating the breadth and interconnections of the mathematical sciences; (4) promoting interdisciplinary cooperation; (5) using computer technology to support problem solving and to promote understanding; and (6) providing faculty support for curricular and instructional improvement (Mathematical Association of America, 2004).

\section{Algebra is the Gatekeeper}

The RAND Mathematics Study Panel, chaired by Ball from the University of Michigan, was charged with defining a core problem of mathematics teaching and learning and mapping out a long range program of research and development to assist in dealing with the problem. The Study Panel was composed of eighteen mathematics education researchers, mathematicians, mathematics teachers, and policy makers including Bass and Silver from the University of Michigan, Carpenter from the University of Wisconsin-Madison, Ferrini-Mundy from Michigan State University, and Kilpatrick from the University of Georgia. Preliminary recommendations of the panel were posted on the Internet in 2002. Readers were given an opportunity to comment on the document, and eleven mathematics research experts reviewed the document. After review and revision, the final report, Mathematical Proficiency for All Students: Toward a Strategic Research and Development Program in Mathematics Education, was released in 2003 .

A major premise of the RAND report is that algebra is the gatekeeper course for learning mathematics beyond basic computation. All students in all states are required to 
pass a course in algebra in order to graduate from high school, and algebra and geometry are the minimal requirements for entry into a four-year college program. However, the RAND Panel found that there is a general lack of understanding by all mathematics stakeholders about what is happening in algebra classrooms. The report stated that the curriculum, instruction, and various assessments being used need to be analyzed and compared, given the debate and disagreement over what topics, concepts, skills, and procedures should be included in high school algebra. Therefore, the RAND group recommended that research on algebra as it is being taught in high school classrooms should be the priority focus of mathematics education research (RAND Mathematics Study Panel, 2003).

Usiskin (2005) discussed the importance of algebra in life and in the workplace in a paper written for the monograph, Developing Students' Algebraic Reasoning Abilities, published by the National Council of Supervisors of Mathematics. "Most people know they need to know some arithmetic" (p. 4). However, knowledge of algebra is the gatekeeper for skilled workplace jobs and for postsecondary education. Algebra is the gatekeeper requirement for nearly every college in the United States or Canada and for many jobs and job-training programs, even when a four-year college degree is not required. Even in technical schools or community colleges with open door admissions policies, students must acquire algebra skills before admission to associate degree or certificate programs.

Usiskin describes algebra in several ways. (1) Algebra is the language of generalization. It allows us to express rules for computation using generalized symbols. While persons may get along without the formulas, they are less likely to be fooled by 
others if they can work the problem themselves. (2) Algebra allows us to answer all the questions of a particular type at one time. (3) Algebra is the language of relationships among quantities. Expressions such as growing exponentially, varying directly, or the rate at which a rate is changing are often used in everyday language. (4) Algebra is the language for solving problems such as the amount of food you can eat and stay within your diet or what will be the population of a region five years from now? (5) Algebra is the study of structures with specified properties. If we know one relationship between several quantities, we can easily rewrite an expression for the other quantities in the relationship. For example, if we can express the area of a rectangle with the formula $\mathrm{A}=$ $\mathrm{LW}$, then we can also express the length of the rectangle as $\mathrm{L}=\mathrm{A} / \mathrm{W}$. (6) Algebra shows that our universe possesses order. Algebra helps to explain what to expect when flipping coins, the odds of winning the lottery, or whether a building will withstand the many forces acting on it. (7) Algebra is common to all other mathematics.

Historically, algebra has had a place of importance in the postsecondary mathematics curriculum since Harvard University required it for admission in 1820. Algebra in the 1800s was important for its application in the sciences, and on its own, algebra was thought to develop mental discipline and logic skills. Colleges organized in the westward expansion of the country often had to take any student who applied for admission regardless of background but still included algebra in their preparatory curriculum. As research universities developed in the late 1800s, algebra became the gatekeeper to calculus and research mathematics. Steen notes that mathematics courses have traditionally been designed as preparation for future courses rather than for their 
immediate use. The content is usually designed as the beginning preparation for college calculus and higher levels of research mathematics.

So as mathematics joined other subjects in developing a major - clearly evident in changes in college curricula between 1900 and 1925-it did not need to, nor did it, rethink in any significant way the courses offered to students who did not major in mathematics. These courses, titled variously higher algebra, conic sections, trigonometry, solid and analytic geometry survived Eliot's curricular revolution little changed, gradually morphing into what is now generally termed college algebra or precalculus. Unlike professors in other subjects, a college professor from 1850 would not find today's college algebra course at all unfamiliar (Steen, 2004, p. 6).

In 1895 the Committee of Ten put strong emphasis on the importance of algebra in the high school curriculum and recommended that every student complete two years of algebra in high school. Every committee making recommendations for high school mathematics since that time has included one or more courses in high school algebra for all college intending students. The NCTM, the ACT, the College Board, the American Diploma Project, Standards for Success, the AMATYC, and the MAA all recommend that all students have skills and knowledge of algebra.

\section{Teachers' beliefs}

Several researchers have documented that teachers' beliefs and practices determine what students learn in mathematics classrooms (Richardson, 1996; Thompson, 1984, 1992). Borko and Shavelson (1990) found that teachers consider students' ability to have the greatest influence on classroom planning decisions (as cited in Nathan \& Koedinger, 2000). Some secondary teachers may not believe that all students can be successful learning higher level mathematics. As a result, the curriculum that is taught may not be as rigorous and demanding as that taught to students deemed to be more capable. Another factor affecting teacher delivery of content is the preparedness of their 
students. If students are under-prepared for high school mathematics, the teacher, taking the students from where they are, will not be able to cover the curriculum or may cover some topics very sparsely (Usiskin, 2001).

Thompson (1984) found that "differences in teachers' prevailing views of mathematics were related both to differences in their views about the appropriate locus of control in teaching and of what constituted evidence of mathematical understanding in their students, and to differences in their perceptions of the purpose of planning lessons" (as cited in Thompson, 1992, p. 135). Teachers' conceptions of mathematics teaching are also likely to reflect their views, though tacit, of students' mathematical knowledge, and of how they learn mathematics (Carpenter, Fennema, Peterson, \& Carey, 1988 as cited in Thompson, 1992).

Rachlin (1989 as cited in Kieran, 1992) states that "regardless of what content society ascribes to algebra, there is a need for research on the learning and teaching of the curriculum at two levels - that of the students and that of the teachers" (p. 394). Rachlin goes on to suggest that "we must understand the nature of teachers' beliefs and cognitions and the roles these beliefs and cognitions play in the decisions teachers make as they present the new curriculum to their students" (p. 395). Kiernan notes that very little literature exists on algebra teachers' beliefs and cognitions. Most of the studies that do exist are focused on teaching a specific algebraic content.

Additionally, even less is known about postsecondary instructor beliefs. "Noticeably absent is work on the beliefs of mathematics faculty, how those beliefs impact instruction, how mathematics faculty changes their teaching in response to 
reforms, or how the culture of the mathematics department impacts teaching" (Hart, 1999, p. 4).

Hart (1999) from Georgia State University reviewed the literature on research in postsecondary mathematics instruction and found that practically no work exists that closely studies collegiate mathematics teachers. Hart's search for research studies examining postsecondary mathematics instruction revealed 205 studies which had appeared since 1987. Of these, the majority were focused on the student. Hart found only two dissertations, seven published pieces, and one sponsored project dealing with postsecondary mathematics teaching and teacher change, and none of these dealt with teacher perceptions of the content being taught.

A study that suggests there are differences in secondary and postsecondary beliefs about the mathematics that students should learn in order to make smooth transitions from high school to college mathematics was conducted by Herman, Webb, and Zungia (2003), from the University of California, Los Angeles. These researchers investigated differences in secondary and postsecondary instructor beliefs about mathematics at secondary and postsecondary levels. They received funding for a seminar in which twenty high school and college mathematics instructors compared the Golden State Exam in High School Mathematics, based on Kindergarten to Grade 12 Mathematics Standards for California Public Schools, to the Statement of Competencies in Mathematics Expected of Entering College Students, developed by representatives from the University of California, Calilfornia State University, and the California Community Colleges. An early task for the instructors was to determine the topic an item measured. The majority, ( $50 \%$ or more) of the combined group of high school and university mathematics 
instructors, agreed on the topic classification of 35 out of 42 items. Raters were also asked to indicate the depth of knowledge required for each item using a three level scale: Level 1 required a recall of fact or simple procedure; Level 2 required some mental processing beyond simple recall; and Level 3 required reasoning, planning, and a higher level of original thinking. "On the average, across the 42 items, high school educators assigned significantly higher depth-of-knowledge ratings than did the University of California faculty ( $M=1.7$ vs. $M=1.5$ on a scale of 1 to $3 ; t(18)=2.21, p=.05)$ )" (p. 25). Herman et al. observed that college instructors appeared to favor greater depth of content on the state examination, but high school instructors expressed concerns about all their students being able to function at that high a level. The authors also noted that the challenge of reaching agreement on item classification may well extend to the problem of communicating and enabling teachers and students to understand what is expected of them. "That is, it may be difficult for teachers who do not agree or think that a given standard translates into the kind of performance represented by specific items on the test to teach the standard in a way that is reflected in test performance" (p. 36).

\section{Summary}

Several major teacher professional organizations, representing all levels of mathematics instructors, are aware of problems with student preparedness and are supporting efforts to find solutions to the transition problems of students in mathematics. State boards of education have developed state standards for mathematics and are administering state-wide accountability tests to students at multiple grade levels to measure how well students are mastering state-defined content material. The federal government is promoting improved Kindergarten to Grade 12 teacher preparation and 
school accountability nationwide as mandated by No Child Left Behind. The federal initiatives in turn are impacting planning by state boards of education and local school districts. The NSF continues to fund projects designed to improve mathematics and science teaching and learning through research, teacher professional development, and curriculum development projects. State post-secondary departments of education are also developing curriculum standards for mathematics, including adult education programs. Political trusts and private foundations are providing financial support for various projects that are developing and promoting secondary curriculum standards.

Algebra is the gatekeeper course in mathematics for high school graduation, entrance into college, and entrance into nearly every postsecondary program of study. Several initiatives have defined a set of algebra skills that high school students need to have for achieving success in postsecondary study. However, as the RAND Mathematics Study Panel noted, an understanding of exactly what is happening in secondary algebra classrooms is not clear. Additionally, Hart found that little is known about college instructors' beliefs and practices in their classrooms.

The initiatives designed to improve student transitions in mathematics from secondary to postsecondary study appear to be working in isolation from each other. A major recommendation of the Bridge Project researchers is that college-level stakeholders must be brought to the table when Kindergarten to Grade 12 standards are developed (Kirst, Venezia, \& Antonio, 2004). Several states such as Maryland, Georgia, California, and Kentucky have P-16 councils whose intent is to develop transition standards for students. While their effectiveness in finding solutions to the transition issues in regard to curriculum is limited, there is some evidence that dialog is occurring. In Kentucky a 
recent review of the Kentucky Core Content for mathematics assessment brought together high school and college level personnel to review and make recommendations for changes in the content to be assessed. Likewise, however, Bridge Project researchers recommended that Kindergarten to Grade 12 educators must be engaged as postsecondary education admission and placement policies are reviewed. "Reforms across the two education systems will be difficult if not impossible to implement without meaningful communication and policymaking between the levels" (Venezia, Kirst, \& Antonio, 2003, p. 47).

\section{Purpose of This Study}

The purpose of this study was to explore the differences in perceptions high school, two-year college, and university mathematics instructors have regarding how well students are learning algebra in high school, non-credit-bearing college, and creditbearing college algebra classes. Since Kentucky is a partner state in the development and validation of the ADP benchmarks, and twenty-six states are currently committed to the ADP benchmarks, the algebra content of the ADP benchmarks were used as the algebra content for this research. The research questions are:

4. Do high school, two-year community and technical college, and four-year college and university mathematics instructors differ in their perceptions of how well students typically learn algebra content in secondary classes?

5. Do high school, two-year community and technical college and four-year college and university mathematics instructors differ in their perceptions of how well students typically learn algebra content in non-credit-bearing or remedial college algebra classes? 
6. Do high school, two-year community and technical college, and four-year college and university mathematics instructors differ in their perceptions of how well students typically learn algebra content in credit-bearing college algebra classes?

This study is important because too many students are under-prepared for college mathematics. As a result, these students have difficulty making successful transitions to postsecondary mathematics and may be blocked from obtaining necessary skills for productive work and life satisfaction in our technological society. If there are differences in instructor perceptions of algebra learning at key instructional levels, these differences may be another indicator of the need for dialogue between secondary and postsecondary mathematics instructors and stakeholders in order to ensure smooth transitions from high school to postsecondary mathematics for all students. 


\section{CHAPTER III METHODOLOGY}

The purpose of this study was to investigate an aspect of the secondary-topostsecondary mathematics transition issues for students by determining whether there are differences in instructors' perceptions of how well students are learning algebra content in different institutional settings. A researcher-developed survey was administered to high school, two-year community and technical college, and four-year college and university mathematics instructors to capture their perceptions of how well they believed American Diploma Project (ADP) algebra benchmarks are learned by students in high school mathematics classes, non-credit-bearing or remedial college algebra classes, and credit-bearing college algebra classes.

Topics presented in this chapter include instrument development, participant selection, study design, results of the pilot study, and the statistical analysis used to address the research questions.

\section{Instrumentation}

A researcher-developed survey was used to capture secondary, two-year community and technical college, and four-year college and university instructors' perceptions of how well they believe students in high school, non-credit-bearing or 
remedial college and credit-bearing college classes are learning the ADP algebra benchmarks.

The ADP algebra benchmarks were chosen for the survey because they were developed with input from a variety of stakeholders and were subjected to a rigorous content validity process. Kentucky was one of five partner states that supported the development of the ADP benchmarks in mathematics, which were written and validated over a two year time period. Faculty representatives from Kindergarten to Grade 12 systems and two- and four-year colleges and universities were assembled in each of the ADP partner states to draft mathematics benchmarks. The content of state high school graduation tests, national college admissions and placement tests such as SAT, ACT, COMPASS, and Accuplacer, a sampling of postsecondary placements tests, and the GED were examined, and de facto standards for students were codified using a protocol developed by the Education Trust. Achieve and ADP staff examined the alignment between partner state high school standards and their high school assessments. Using data from all of the analyses, ADP and Achieve staff met with faculty members from two- and four-year colleges in a broad range of content areas and asked them to: (1) define the mathematics content and skills necessary for success in freshman credit-bearing courses; (2) locate these must-have competencies in state content standards; (3) determine the degree to which current state standards and assessments reflect expectations; and (4) identify missing prioritized content in state standards and assessments. Two additional panels of curricular experts determined the algebra and geometry content needed for workplace readiness. ADP staff used this content to develop preliminary workplace expectations, and 29 representatives from industries such as health care, gaming, high- 
tech manufacturing, information technology, law, telecommunications, energy, television media, shipping and transportation, retail services, and financial services were asked to confirm the importance of the content in the preliminary benchmarks. The workplace and postsecondary expectations were combined into the final set of ADP college and workplace readiness benchmarks (Achieve, Inc, 2004). Currently 26 states, serving more than half of the nation's pre-college students are members of the ADP network (Achieve, Inc., 2006).

The ADP staff grouped the algebra benchmarks into five broad content categories: (1) operations on algebraic expressions; (2) function representations and properties; (3) equations and inequalities; (4) graphs; and (5) problem solving with mathematical models. A sixth category, mathematical reasoning tasks that involve higher levels of thinking, was described separately from the mathematics skill benchmarks. Some of these tasks were included in the survey. Each category contains four to ten benchmark skills; algebra benchmarks are listed in Appendix H.

Many of the ADP benchmarks describe more than one learning task. For example, Benchmark J4.1 states "Graph a linear equation and demonstrate that it has a constant rate of change" (Achieve, Inc., 2004, p. 61). Graphing a linear equation requires a different solution strategy than demonstrating that a linear equation has a constant rate of change. When a benchmark included more than one learning task, the benchmark was split into two or more parts. The benchmarks as they appeared on the survey are listed by algebra category in Appendix I.

Instructors rated how well they believed students learn each algebra benchmark in high school using a Likert-type scale $(1=$ Not at All; 2 = Very Little; $3=$ Some; $4=$ 
Well; $5=$ Very Well). Likewise, instructors rated how well they believed students learn each algebra benchmark in non-credit-bearing or remedial college classes and creditbearing college classes using the same Likert-type scale. The Likert-type scale was based on a survey of student perceptions of how well they were learning selected technology topics for use in K - 12 classrooms (McCutcheon \& Franklin, 1997).

In order to compare demographics of survey participants to those of the teaching population, data regarding level of student taught, primary appointment, employment status, gender, highest academic degree held, major field of study for the Bachelor's degree, major field of study for the highest degree held beyond the Bachelor's degree, a list of classes taught in the last five years, total number of years teaching, and number of years teaching at specified grade levels were also collected.

The format of the survey followed recommendations suggested by Dillman (2000).

\section{Participants}

Mathematics instructors in high schools, two-year community and technical colleges, and four-year colleges and universities in Kentucky were the target population for the study. The sample size was determined a priori by performing a power analysis according to procedures recommended by Stevens (2002, p. 245-247) for a k-group MANOVA. The parameters set for the power analysis included the following (a) a planned alpha level $(\alpha=.05)$; (b) a minimum power level $(1-\quad)=.80$; and (c) an estimated large effect size. Using tables in Stevens (2002, p. 628), a three-group MANOVA with eighteen dependent variables yielded a required cell size $(n=59)$ and 
required sample size $(N=177)$. In order to obtain a hoped-for response rate of $60 \%$, a random sample of 300 participants was selected.

A medium-to-large effect size was expected because of the differences between traditionalists and reformers in mathematics education with regard to the algebra content that should be taught and the intensity of those discussions. Lundin, Oursland, Lundren \& Reilly (2004) noted that "Math Wars between traditionalists and reformers continue to emphasize conflicting belief/value systems with respect to content, pedagogy, and assessments. Both sides have valid points, but a lack of coherence has led to confusion about what is important at many levels" (p. 18).

Lists of names and school mailing addresses of mathematics instructors in high schools, two-year community and technical colleges, and four-year colleges and universities in Kentucky were compiled using information that individual schools provide on the Internet. As determined by the power analysis, 60 participants were needed from each sub-group. Anticipating a $60 \%$ return rate from a mailed survey, 100 participants were randomly selected from each sub-group from pools of high school $(n=547)$, twoyear community and technical college $(n=135)$, and four-year college and university mathematics instructors $(n=332)$ using the last three digits of telephone numbers on a randomly selected page from a city telephone directory.

\section{Study Design}

The study employed a non-experimental design in which the data were collected with a researcher-developed instrument using mail survey procedures recommended by Dillman (2000). Participants received a pre-notice letter indicating that in a few days they would receive a request to assist in the study. The survey was mailed approximately one 
week later with a cover letter explaining the purpose of the survey, a consent form and a pre-addressed postage-paid envelope in which to return the instrument. Each survey was coded with a number that was used only for the purpose of identifying who returned the survey. Lists of participants were stored separately from survey data. Participants who returned blank surveys were removed from the participant list.

A follow-up thank you and reminder postcard was sent to all participants approximately one week after the survey, except those who indicated by returning a blank survey they did not wish to participate. Participants who did not respond were sent a replacement survey with a new cover letter restating the importance of the survey and a pre-addressed stamped envelope. A reminder postcard was sent to participants who did not respond within two to three weeks of the second survey mailing. Copies of correspondence are shown in Appendices A through E, the informed letter of consent in Appendix F, and the survey in Appendix G. The procedures and the instruments for this study received University of Louisville Institutional Review Board (IRB) approval through $11 / 29 / 2006$, as evidenced by the assigned study number 643.05 dated November 30, 2005, and a letter of consent insuring participants were apprised of their rights and confidentiality as human subjects. Continued IRB approval has been granted through November 29, 2007.

\section{Variables}

Independent variable. The independent variable in the study was instructor institutional level in one of three settings: (1) high school; (2) two-year community or technical college; and (3) four-year college or university. 
High school mathematics instructors were selected as one level of the independent variable because they bear the responsibility for students successfully completing algebra in high school.

Mathematics instructors in two-year community and technical colleges were chosen as the second instructor level. Most students enrolling in two-year community colleges are planning to either complete a two-year degree program for a skilled job in the workplace or they are planning to complete core academic courses and transfer to a four-year college or university to complete a Bachelor's degree program. Regardless of the program, students must complete a general education mathematics course that requires knowledge of algebra. Students who are considered under-prepared for college level mathematics are required to enroll in some type of non-credit-bearing or remedial mathematics class which repeats much of the algebra content taught in high school classes. Community colleges have born the "brunt of the poor preparation of students in the 20th century" (Cohen \& Brawer, 2003, p. 260). Demographically, community college instructors differ from instructors in other types of postsecondary schools. Most of these instructors hold a Master's degree and their primary responsibility is teaching. Over half are part-time employees because they are paid an hourly rate with few fringe benefits and therefore cost less to employ than full-time instructors (Cohen \& Brawer, 2003).

Four-year college and university mathematics instructors were chosen as a third instructor level. As in the community college, students in nearly every program in a fouryear college and university are expected to complete a general education mathematics requirement that requires knowledge of algebra. Algebra content knowledge is the foundation content for all mathematics classes beyond college algebra. As in two-year 
community and technical colleges, students who are considered under-prepared for college level mathematics may be required to complete a non-credit-bearing course in algebra before enrolling in a general education mathematics course.

Faculty in four-year colleges and universities are more likely to hold a Doctorate in mathematics, and faculty responsibilities may include research. Even if graduate teaching assistants or adjunct faculty are hired to teach remedial and general education mathematics classes, the teaching environment is different from the community college (Cohen \& Brawer, 2003; National Research Council, 1991).

Dependent variables. The three main dependent variables were instructor perceptions of student learning across all algebra content in each of three classroom settings -- high school, non-credit-bearing or remedial college, and credit-bearing college algebra classes. High school classrooms were selected as one setting because many of the mathematics initiatives recommend a rigorous high school mathematics curriculum. Noncredit-bearing college classes were selected as a second classroom setting because a large number of college students find themselves placed in this setting in both two- and fouryear colleges. Credit-bearing college algebra classes were chosen as the third classroom setting because nearly every two-and four-year college offers college algebra as a general education mathematics requirement and because this is the gateway course to higher level mathematics. Algebra content was selected as the mathematics focus for the survey because it is considered the gatekeeper course for high school graduation, college preparedness, and entrance into college majors and careers requiring calculus and/or higher level mathematics. 
Since it was also of interest to examine instructor perceptions of student learning in each of the six algebra content categories, instructor perceptions of student learning were averaged by category to obtain composite mean learning scores in each of the three classroom settings. A list of the sub-dependent variables follows in Table 1. 
Table 1

Sub-Dependent Variables

Var. Mean learning score for

Class level

1. algebraic expressions

in high school classes.

2. function representations and properties

3. solving equations and inequalities

4. graphing equations and inequalities

5. problem solving with mathematical models

6. mathematical reasoning

7. algebraic expressions

in non-credit-bearing college classes.

8. function representations and properties

9. solving equations and inequalities

10. graphing equations and inequalities

11. problem solving with mathematical models

12. mathematical reasoning

13. algebraic expressions

in credit-bearing college algebra classes.

14. function representations and properties

15. solving equations and inequalities

16. graphing equations and inequalities

17. problem solving with mathematical models

18. mathematical reasoning 


\section{Pilot Study}

Pre-study. A draft instrument was written and several expert mathematics educators were contacted and asked to review the draft to determine readability, validity of content items, and ease of use. The experts included a developer of a major secondary curriculum project and a developer of mathematics assessments used in teacher preparation programs. The experts completed two tasks: (a) completion of the draft instrument; and (b) completion of a questionnaire with regard to readability, understandability, and ease of use. Based on their feedback, major revisions in the instrument were made and a pilot study was conducted.

Procedures. The pilot study was conducted with two objectives: (a) to decide whether the Likert scale should include a Don't Know option because its inclusion was a concern of the expert reviewers; and (b) to assess the reliability of the dependent variable measures using a test and retest design. Two versions of the survey were written, one with the Likert scale including a Don't Know option for rating student learning of algebra topics, and one with the Don't Know option omitted from the Likert scale. Pilot study survey instruments are shown in Appendices J and K. Demographic information and algebra topics were identical on the two versions of the survey. Students $(n=20)$ in a college mathematics education class and classroom teachers $(n=22)$ attending a local professional development meeting were invited to participate in the pilot study with permission of the instructor and meeting leaders respectively. Participants were given a brief explanation of the purpose of the survey and told they would be asked to retake the survey in a few weeks. The participants were randomly given one of the two versions of the survey which contained an informed consent letter according to the human subjects' 
guidelines of the University of Louisville. Participants were assured that any information they provided would be considered confidential and anonymous, but they were asked to provide some identifying information on the survey such as their initials or the last four digits of their social security number solely for purposes of pairing their responses with those they would give on the second administration of the survey.

Participant demographics. Table 2 contains descriptive statistics for the pilot study participants. 
Table 2

Number of Participants in Key Variable Categories - Pilot

Variable Group $\mathrm{A}^{\mathrm{a}} \quad$ Group $^{\mathrm{b}}$

1. Instructional level

High school

17

17

Four-year college

1

1

Community college

0

0

Missing

4

4

2. Primary appointment

Mathematics Department

15

21

Education

3

0

Other discipline/office

3

1

3. Employment Status

Full time

20

Part time

2

1

4. Gender

Male

9

5

Female

13

17

5. Mean total years of teaching

$8.67(9.91)$

$9.74(10.91)$

${ }^{a}$ Group receiving Don't Know as a Likert-scale option. ${ }^{b}$ Group not receiving Don't Know as a Likert-Scale option.

$N=44$ 
Test and retest results. Nineteen students from the mathematics education class and two classroom teachers from the professional development organization retook the survey about three weeks after the initial administration. Composite algebra learning scores by topic and an overall algebra learning score were calculated for each participant for each of the three classroom settings, and a Pearson product moment correlation was calculated for each pair of variables. Results of the test and retest correlation analysis are given in Tables 3 to 5 . 
Table 3

High School Mean Algebra Learning Scores and Std. Deviations - Pilot Test and Retest

\begin{tabular}{|c|c|c|c|c|c|c|}
\hline \multirow[b]{2}{*}{ Variable } & \multicolumn{3}{|c|}{$\begin{array}{c}\text { Don't Know } \\
\text { is a Likert-Scale Option } \\
n=10\end{array}$} & \multicolumn{3}{|c|}{$\begin{array}{l}\text { Don't Know is not a Likert- } \\
\qquad \begin{array}{l}\text { Scale Option } \\
n=11\end{array}\end{array}$} \\
\hline & Test & Retest & Correlation & Test & Retest & Correlation \\
\hline \multirow[t]{2}{*}{ 1. Algebraic expressions } & 3.38 & 3.39 & -.274 & 3.01 & 3.15 & $.754^{*}$ \\
\hline & $(0.39)$ & $(0.34)$ & & $(0.89)$ & $(0.74)$ & \\
\hline \multirow[t]{2}{*}{ 2. Functions } & 3.23 & 3.29 & -.051 & 2.77 & 2.87 & $.810^{*}$ \\
\hline & $(0.40)$ & $(0.29)$ & & $(0.88)$ & $(0.83)$ & \\
\hline \multirow[t]{2}{*}{ 3. Solving equations } & 3.39 & 3.42 & -.578 & 3.13 & 3.31 & $.845^{*}$ \\
\hline & $(0.50)$ & $(0.37)$ & & $(0.87)$ & $(0.76)$ & \\
\hline \multirow[t]{2}{*}{ 4. Graphing } & 3.37 & 3.39 & -.325 & 2.98 & 3.18 & $.783 *$ \\
\hline & $(0.57)$ & $(0.36)$ & & $(0.84)$ & $(0.74)$ & \\
\hline \multirow[t]{2}{*}{ 5. Problem Solving } & 2.98 & 3.27 & -.095 & 2.74 & 2.76 & $.872 *$ \\
\hline & $(0.26)$ & $(0.18)$ & & $(0.97)$ & $(0.84)$ & \\
\hline \multirow[t]{2}{*}{ 6. Reasoning } & 3.13 & 3.17 & -.365 & 2.77 & 2.89 & $.893 *$ \\
\hline & $(0.54)$ & $(0.31)$ & & $(0.92)$ & $(0.68)$ & \\
\hline \multirow[t]{2}{*}{ 7. All algebra content } & 3.27 & 3.34 & -.481 & 2.91 & 3.05 & $.842 *$ \\
\hline & $(0.41)$ & $(0.24)$ & & $(0.84)$ & $(0.71)$ & \\
\hline
\end{tabular}

$* p<.05$ 
Table 4

Non-Credit-bearing College Mean Algebra Learning Scores and Std. Deviations

Pilot Test - Retest

Don't Know is a Likert-Scale Don't Know is not a Likert-

Option

$n=4-6$

Test Retest Correlation Test Retest Correlation

\begin{tabular}{|c|c|c|c|c|c|c|}
\hline \multirow[t]{2}{*}{ 1. Algebraic expressions } & 3.60 & 3.84 & .975 & 3.21 & 3.94 & .320 \\
\hline & $(0.55)$ & $(0.17)$ & & $(0.64)$ & $(1.16)$ & \\
\hline \multirow[t]{2}{*}{ 2. Functions } & 3.32 & 3.90 & $.998 *$ & 2.97 & 3.46 & .204 \\
\hline & $(0.50)$ & $(0.10)$ & & $(0.81)$ & $(0.62)$ & \\
\hline \multirow[t]{2}{*}{ 3. Solving equations } & 3.50 & 3.86 & .965 & 3.41 & 3.76 & .417 \\
\hline & $(0.66)$ & $(0.13)$ & & $(0.56)$ & $(0.44)$ & \\
\hline \multirow[t]{2}{*}{ 4. Graphing } & 3.56 & 3.82 & .989 & 3.06 & 3.63 & .331 \\
\hline & $(0.66)$ & $(0.30)$ & & $(0.68)$ & $(0.46)$ & \\
\hline \multirow[t]{2}{*}{ 5. Problem Solving } & 3.46 & 3.72 & -.866 & 3.04 & 3.29 & .027 \\
\hline & $(0.42)$ & $(0.23)$ & & $(0.59)$ & $(0.51)$ & \\
\hline \multirow[t]{2}{*}{ 6. Reasoning } & 3.50 & 3.61 & .866 & 2.87 & 3.30 & .439 \\
\hline & $(0.27)$ & $(0.23)$ & & $(0.93)$ & $(0.62)$ & \\
\hline \multirow[t]{2}{*}{ 7. All algebra content } & 3.49 & 3.82 & .978 & 3.09 & 3.62 & .291 \\
\hline & $(0.53)$ & $(0.09)$ & & $(0.62)$ & $(0.56)$ & \\
\hline
\end{tabular}

Note. Some participants did not answer all of the content questions.

$p<.05$ 
Table 5

Credit-bearing College Mean Algebra Learning Scores and Std. Deviations - Pilot TestRetest

Don't Know is a Likert-Scale Don't Know is not a Likert-

\section{Option}

$n=6-7$
Scale Option

$n=10$

Variable

Test Retest Correlation Test Retest Correlation

1. Algebraic expressions

$4.04 \quad 4.35$

.456

4.20

4.37

$.951 *$

$(0.47) \quad(0.48)$

$(0.50) \quad(0.46)$

2. Functions

3.87

4.19

.534

4.10

4.27

$.903 *$

(0.40) (0.65)

$(0.48)$

$(0.61)$

3. Solving equations

$4.12 \quad 4.33$

.343

4.30

4.43

$.754 *$

(0.50) (0.48)

$(0.46) \quad(0.50)$

4. Graphing

$3.95 \quad 4.18$

.470

4.15

4.31

.626

(0.50) (.045)

$(0.44) \quad(0.43)$

5. Problem Solving

$3.71 \quad 4.00$

.311

4.02

4.14

$.720 *$

(0.53) (0.83)

$(0.48) \quad(0.65)$

6. Reasoning

$3.90 \quad 3.94$

.499

$4.00 \quad 4.25$

$.873 *$

(0.38) (0.76)

$(0.52) \quad(0.42)$

7. All algebra content

$\begin{array}{ll}3.94 & 4.20 \\ (0.44) & (0.56)\end{array}$

.444

4.14

4.31

$.960 *$

(0.44) (0.56)

$(0.45)$

$(0.43)$

Note. Some participants did not answer all the content questions.

$* p<.05$ 
When respondents answered a question using the Don't Know option, the response was treated as missing data for the analysis. Based on mean instructor learning scores in high school classes, negative correlations when Don't Know was a Likert-scale option were not significant at $p<.05$ and were not explainable other than that the sample size was small. Test and retest correlations when Don't Know was not a Likert scale option, despite the small sample size, were all significant for $p<.05$.

Only one of the correlations on the test and retest for non-credit-bearing college classes was significant at $p<.05$ when Don't Know was a Likert-scale option. Four to six pilot study participants (sample size depended on the number of content questions answered) chose the Don't Know option, substantially reducing the amount of useable data. Any significance needs to be considered with caution because of the small sample size. When Don't Know was not a Likert-scale option, at least nine participants responded to all the questions for non-credit-bearing college classes. Based on questions asked while pilot study participants completed the survey, there was confusion about the meaning of non-credit-bearing college classes, which may explain some of the inconsistencies in these correlations.

None of the correlations from the test and retest were significant when Don't Know was a Likert scale option. Three to four participants chose this option for some of their responses. All of the correlations except for graphing were significant when Don't Know was not a Likert scale option. As in the other classroom settings, the correlations need to be interpreted with caution because of the small sample size.

Across the three test and retest analyses, 13 participants (59\% of the sample) completing the pilot survey with Don't Know included in the Likert scale used Don't 
Know for at least one of the three institutional classroom settings questions. Four participants (18\% of the sample) completing the pilot survey with Don't Know not included in the Likert scale left at least one set of institutional classroom settings questions blank. Based on the pilot study, including Don't Know as a Likert scale option reduced useable data.

Other analysis options were considered (such as comparing graphs of the data), but the sample size was considered too small for meaningful comparisons. The small sample size may have been a factor in the relative inconsistency of correlations when Don't Know was an option on the Likert scale versus the correlations when Don't Know was not an option. Since including Don't Know also reduced the useable data available for analysis, the Don't Know option in the Likert scale was removed from further consideration.

Although correlations for responses regarding non-credit-bearing college algebra classes were inconsistent and not significant, this classroom setting category was left in the survey. Changes in wording were made to clarify the meaning of non-credit bearing college classes on the final survey and in the cover letter that went to participants with the survey.

Internal consistency results. To estimate the internal consistency of the ratings, the coefficient of internal consistency (coefficient alpha) served to assess reliability for all composite scores in order to confirm the reliability of the instrument scales. Coefficient alpha scores for the survey version that did not have a Don't Know option on the Likert scale were used for the reliability analysis. The results are given in Table 6. 
Table 6

Cronbach Alphas for Algebra Content in Each Classroom Setting - Pilot Test

\begin{tabular}{lccc}
\hline Variable & $\begin{array}{c}\text { High School } \\
\text { Classes } \\
n=17-21\end{array}$ & $\begin{array}{c}\text { Non-credit-bearing } \\
\text { College Classes } \\
n=13-18\end{array}$ & $\begin{array}{c}\text { Credit-bearing } \\
\text { College Classes } \\
n=13-19\end{array}$ \\
\hline Algebraic manipulation skills & .948 & .949 & .909 \\
Functions & .930 & .953 & .900 \\
Solving equations/inequalities & .905 & .883 & .861 \\
Graphing & .925 & .940 & .939 \\
Problem Solving and modeling & .891 & .870 & .859 \\
Reasoning & .910 & .924 & .986 \\
All algebra content & .987 & .986 & \\
\hline
\end{tabular}

Note. Cronbach alphas were calculated for the pilot survey that did not have a Don't Know option. The number of responses used to calculate each coefficient alpha varied because some participants did not answer a survey item.

All the magnitudes of coefficient alpha exceeded the minimum value of 0.7 suggested by Nunnally (1978) for composite scores in statistical analysis. Fifteen of the 21 composite algebra learning scores had alphas that exceeded 0.9 , confirming one aspect of the quality of the instrument. The alpha-if-item-deleted analysis showed the magnitudes of alpha would be improved slightly for a few composite scores if a topic was removed. Since the sample size for this analysis was small and extensive content reliability analysis by ADP indicated the item was important, no algebra topics were removed from the survey. 


\section{Statistical Analysis}

Descriptive statistics and the internal consistency of each content scale were obtained using SPSS 14.0, and the statistical analysis of the research questions was conducted using SPSS 14.0.

Instructor perceptions of student learning were averaged across all algebra topics to obtain composite mean algebra learning scores in high school classes, non-creditbearing or remedial college algebra classes, and credit-bearing college algebra classes for each participant. Mean algebra learning scores also were calculated for each of the content categories -- algebraic expressions, functions, solving equations, graphing, problem solving, and reasoning -- in each of the three classroom settings. The following describes the statistical technique used to analyze each of the three research questions below.

1. Do high school, two-year community and technical college, and four-year college and university mathematics instructors differ in their perceptions of how well students typically learn algebra content in high school classes?

2. Do high school, two-year community and technical college, and four-year college and university mathematics instructors differ in their perceptions of how well students typically learn algebra content in non-credit-bearing or remedial college algebra classes?

3. Do high school, two-year community and technical college, and four-year college and university mathematics instructors differ in their perceptions of how well students typically learn algebra content in credit-bearing college algebra classes? 
A three-group multivariate analysis of variance (MANOVA) was used to determine differences in high school, two-year community and technical college, and four-year college and university mathematics instructor's mean algebra learning scores in each classroom setting for each algebra content category and the mean overall algebra content learning score. One assumption of MANOVA, independence of observations, was addressed by the design of the study. The other two assumptions, normal distribution of data within groups and equal variances and covariances among data from different groups in the study, were addressed using the Shapiro-Wilk statistic and Box's test, respectively. The Wilks' lambda statistic was used to determine whether there were significant differences in instructor perceptions of algebra learning. Whenever Wilks' lambda was significant, multivariate pairwise group comparisons were examined to determine which instructor groups had significant differences in mean algebra learning scores. A Tukey post hoc test was used to identify the classroom settings and algebra content areas in which instructors' perceived learning scores were significantly different. 


\section{CHAPTER IV}

\section{RESULTS}

The purpose of this study was to investigate one aspect of the secondary to postsecondary mathematics transition issues for students by determining whether there are differences in instructors' perceptions of how well students are learning algebra content in different institutional settings. The study used a researcher-developed survey to capture instructors' beliefs of how well they perceived students were learning algebra as defined by the American Diploma Project (ADP) benchmarks in high school classes, non-credit-bearing or remedial college algebra classes, and credit-bearing college algebra classes. The participants in this study were high school, two-year community and technical college, and four-year college and university mathematics instructors in Kentucky.

The independent variable was mathematics instructor teaching position with three levels -- high school, two-year community and technical college, and four-year college and university. The dependent variables in the study were composite mean algebra perceived learning scores calculated by finding the means of instructor perceptions of how well they perceived students are learning algebra in high school, non-credit-bearing college algebra, and credit-bearing college algebra classes using Likert-type belief scales. The research design used a three-group multivariate analysis of variance (MANOVA) as described by Stevens (2002) to determine whether there were significant differences in 
mean algebra perceived learning scores between the instructor groups in each of the three classroom settings.

\section{Study Participants}

Following the protocol explained in Chapter III, each instructor received a mailed survey and was invited to participate in the study by completing the survey and returning it using an enclosed, stamped, self-addressed envelope. A total of 114 surveys (38\% of the sample) were returned with 92 surveys ( $31 \%$ of the sample) containing useable information. The number of returned surveys was smaller than anticipated, and some of the returned surveys were not fully completed. Only six out of 29 high school instructors (21\%) answered all survey questions on student learning at all three institutional levels.

Eighteen out of 31 four-year college and university instructors (58\%) and 27 out of 32 community and technical college instructors (84\%) answered all the questions about algebra learning in all of the classroom settings.

\section{Descriptive Statistics}

Descriptive statistics for the study participants appear in Table 7. Using all of the surveys containing some useable data, group sizes for the independent variable, instructor teaching level, were approximately equal. Thirty-one percent of the participants were high school mathematics instructors, 35\% were two-year community and technical college instructors, and 34\% were four-year college and university instructors.

An overwhelming majority of participants were full-time mathematics instructors in their respective institutions. Ninety-eight percent of the participants were employed full-time and $2 \%$ were employed part-time. Compared to the general population of mathematics teachers in the United States, full-time mathematics instructors were over- 
represented in the study sample. In $2000,45 \%$ of the mathematics faculty in two- and four-year colleges and universities combined were part-time employees (Lutzer, Maxwell, \& Rodi, 2002), and in 1999-2000, 90\% of elementary and secondary school teachers were full-time employees (National Center for Education Statistics, 2004). Ninety-five percent of participants were assigned to mathematics departments and 5\% were in education departments or other disciplines

Thirty-eight percent of participants in the study were male and $62 \%$ were female, which means that males were slightly underrepresented in this sample compared to the general population of mathematics instructors in the United States. In 2000, $79 \%$ of fulltime mathematics faculty in two- and four-year colleges and universities were male (Lutzer, Maxwell, \& Rodi, 2002), and 45\% of high school teachers were male (National Center for Education Statistics, 2004). Participant teaching experience was evenly distributed over the range of years of experience (1-40), and mean number of years teaching was 19.3 . 
Table 7

Descriptive Statistics for Study Participants

\begin{tabular}{|c|c|c|c|c|c|}
\hline Variable & $n$ & $\%$ & $M$ & $S D$ & Range \\
\hline \multicolumn{6}{|l|}{ Instructional Level } \\
\hline High School & 29 & 31.5 & & & \\
\hline Four-year College and University & 31 & 33.7 & & & \\
\hline Two- year Community and Technical College & 32 & 34.8 & & & \\
\hline \multicolumn{6}{|l|}{ Primary Appointment } \\
\hline Mathematics Department & 87 & 94.6 & & & \\
\hline Education & 3 & 3.3 & & & \\
\hline Other Disciplines or Offices & 2 & 2.2 & & & \\
\hline \multicolumn{6}{|l|}{ Employment Status } \\
\hline Full Time & 90 & 97.8 & & & \\
\hline Part Time & 2 & 2.2 & & & \\
\hline \multicolumn{6}{|l|}{ Gender } \\
\hline Male & 35 & 38.0 & & & \\
\hline Female & 57 & 62.0 & & & \\
\hline Total Years of Teaching & & & 19.27 & 10.08 & $1-40$ \\
\hline
\end{tabular}

$$
N=92
$$


The educational background of participants is shown in Table 8. Sixty-five percent of the participants had at least one Masters' degree and 25\% had a Doctorate in mathematics or mathematics education. Within the population of mathematics instructors in the United States in 2000, 59\% of full-time two- and four-year college and university mathematics faculty had Doctorates (Lutzer, Maxwell, \& Rodi, 2002); in 2000, 46\% of all secondary teachers had a Master's degree and 6\% had a Doctorate (National Center for Education Statistics, 2002). In the study sample, $81 \%$ of the participants majored in mathematics and/or mathematics education for their highest degree held. In the population, $85 \%$ of public school secondary students have mathematics instructors who majored in mathematics (National Center for Education Statistics, 2004). 
Table 8

Educational Background of Study Participants

\begin{tabular}{lll}
\hline Variable & $n \quad \%$ \\
\hline
\end{tabular}

Highest degree held

$\begin{array}{lll}\text { Bachelor of Arts or Bachelor of Science } & 2 & 2.2\end{array}$

$\begin{array}{lrl}\text { Master of Arts or Master of Science } & 50 \quad 54.3\end{array}$

$\begin{array}{llr}\text { Multiple Master of Arts or Science } & 10 & 10.9\end{array}$

$\begin{array}{lll}\text { Doctorate in Mathematics } & 20 & 21.7\end{array}$

$\begin{array}{lll}\text { Doctorate in Math Education } & 3 & 3.3\end{array}$

$\begin{array}{lll}\text { Other Disciplines or Education Fields } & 7 & 7.6\end{array}$

Major field of study for the highest degree held

Middle School Education $\quad 1 \quad 1.1$

$\begin{array}{lll}\text { Mathematics Education } & 13 & 14.1\end{array}$

$\begin{array}{lll}\text { Mathematics } & 41 & 44.6\end{array}$

$\begin{array}{lll}\text { Math Education and Math } & 20 & 21.7\end{array}$

$\begin{array}{lll}\text { Other Disciplines or Education Fields } & 16 & 17.4\end{array}$

$N=92$

Mathematics teaching experience of participants is shown in Table 9. The data indicate strong experience in secondary, two-year community and technical college, and four-year college and university settings. Forty-seven participants (51\%) had taught in more than one of the institutional settings, which is an indicator of instructor familiarity with more than one of the classroom settings in this study. 
Table 9

Number of Years Teaching at Institutional Level

Institutional Level

Years Teaching

$\begin{array}{lllll}< & 1-3 & 4-10 & 11-20 & >20\end{array}$

Elementary School

0

2

Middle School

0

8

2

16

$\begin{array}{ll}0 & 2\end{array}$

2

17

14

6

Four-Year College and University

0

7

15

17

9

$N=92$

Teaching experience by course is shown in Table 10. Algebra I, Algebra II, Geometry, Statistics and Probability, and Calculus were the most frequently taught high school courses. Forty-five percent of participants indicated they had taught developmental or remedial mathematics in the last five years. Thirty-two percent had taught a college general education mathematics class and $57 \%$ had taught College Algebra. 
Table 10

Mathematics Courses Taught by Participants in the Last Five Years

\begin{tabular}{|c|c|c|}
\hline Course & $n$ & $\%$ \\
\hline 7 th or 8 th grade mathematics & 1 & 1.1 \\
\hline Pre-Algebra & 14 & 15.2 \\
\hline Algebra I & 26 & 28.3 \\
\hline Algebra II or Advanced Algebra & 27 & 29.3 \\
\hline Geometry & 22 & 23.9 \\
\hline Precalculus & 15 & 16.3 \\
\hline Statistics and Probability & 23 & 25.0 \\
\hline Calculus or Advanced Mathematics & 26 & 28.3 \\
\hline Integrated Mathematics & 7 & 7.6 \\
\hline Other high school mathematics & 9 & 9.8 \\
\hline College Developmental Mathematics & 41 & 44.6 \\
\hline College General Education Mathematics & 30 & 32.6 \\
\hline College Algebra & 52 & 56.5 \\
\hline College Precalculus & 19 & 20.7 \\
\hline College Calculus & 33 & 35.9 \\
\hline Classes for college mathematics majors & 23 & 25.0 \\
\hline None of these & 2 & 2.2 \\
\hline
\end{tabular}

$N=92$ 
A broad cross-section of teachers from across Kentucky was represented by the participants as evidenced by the number of secondary and post-secondary institutions in which participants were employed. Survey respondents represented 14 four-year colleges and universities, 12 community and technical colleges, and 26 high schools.

Overall, the participants in this study had solid algebra teaching experience in the target classroom courses being investigated. Based on college majors, participant demographics were representative of the population of mathematics instructors in regard to mathematics background, although fewer participants held Doctorates than might be true of the general population. Compared to the population of mathematics instructors, part-time instructors were under-represented in this sample, and males were slightly under-represented.

The response rate to this survey was not unlike that achieved by the National Council of Teachers of Mathematics in the Priorities for Reform in School Mathematics project during the late 1970s. The response rate of the survey in the Priorities for Reform in School Mathematics project was 29\%. The National Council of Teachers of Mathematics (1981) concluded that their response rate represented a solid sample of those who were most concerned with mathematics issues in the late 1970s. While the responses from this survey involved far fewer numbers of teachers than the PRISM project, the depth of education background, teaching experience, and geographic distribution of respondents are indicators that the respondents represent a meaningful sample of instructors who are interested in student learning of mathematics in Kentucky's high schools and colleges. 


\section{Reliability Analysis}

The size of the coefficient alphas is an indicator of the internal reliability of the algebra content and the content within categories as defined by the American Diploma Project (Achieve, Inc., 2004). A reliability analysis was performed using coefficient alpha on each of the composite mean algebra perceived learning scores by content category and overall algebra perceived learning scores in each of the three institutional settings. Coefficient alphas appear in Table 11. The size of coefficient alpha for each mean composite perceived learning score exceeded the minimal acceptable level of 0.7 as recommended by Nunnally (1978), confirming the reliability of the instrument. Ten of the 21 alphas were greater than 0.9. The alpha-if-item deleted analysis indicated deleting any one item from six of the composite scores: high school graphing; high school problem solving; non-credit-bearing college problem solving; credit-bearing college equation solving; credit-bearing college graphing; and credit-bearing problem solving, would have reduced the magnitude of alpha by .001 to .037 . For every composite score, the magnitude of the original alpha would not be substantially lower by deleting one or more items. The number of observations used to compute each alpha varied because some participants did not answer every question. Given the small sample size relative to the number of individual items in the analysis and the strength of the coefficient alpha measures for this analysis, all items were retained. 
Table 11

Reliability Analysis - Cronbach Alpha Values

Institutional Level

Variable

1

2

3

Algebraic manipulation skills - 15 items

$\begin{array}{lll}.953 & .905 \quad .890\end{array}$

Functions - 14 items

$.953 \quad .923$

.893

Solving equations and inequalities -7 items

$.916 \quad .775$

Graphing - 15 items

.951

.916

.822

Problem Solving and modeling - 6 items

.897

.822

.745

Reasoning -6 items

.874

.815

.809

All algebra content - 63 items

.988

.977

.963

Note. The number of cases varied because some participants left survey items blank.

1. High school classes (71-77 cases)

2. Non-credit-bearing or remedial college algebra classes (51-55 cases)

3. Credit-bearing college algebra classes (59-67 cases)

\section{Data Analysis}

\section{Comparison of overall algebra learning}

A three-group multivariate analysis of variance (MANOVA) was performed on the overall composite mean algebra learning scores for the three classroom settings -high school, non-credit-bearing college, and credit-bearing college algebra classes. The 
MANOVA analysis, Wilks' lambda $=.666, F(6,100)=3.755, p=.002$, indicated there was a significant difference between instructor groups regarding their perceptions of student algebra learning. Effect size indicated by partial eta squared was 0.184 which exceeds the effect size of 0.15 that is considered large (Stevens, 2002; Cohen, 1988). This means that institutional level had a large effect on instructors' perceptions of students' learning in mathematics. This result reflected experiences over the last six years in regional conferences co-led by university and high school mathematics educators in Kentucky, where discussion revealed clear differences between secondary and postsecondary instructors' perceptions of mathematics learning in secondary and postsecondary institutions (Ronau, Seif, \& Jones, 2001; Ronau \& Jones, 2003). The observed power, the probability of correctly detecting a false null hypothesis, was 0.953 which exceeds the conventional value of .80 used in social science research (Cohen, 1988).

The multivariate pairwise comparisons (Stevens, 2002) indicated overall significant differences between high school and four-year college instructors' perceptions of algebra learning, $F(3,50)=8.329, p=.000$, and overall high school and two-year college instructors' perceptions of algebra learning, $F(3,50)=5.274, p=.003$. Differences in two- and four-year college instructor perceptions of algebra learning were not significant, $F(3,50)=1.120, p=.350$.

A Tukey post hoc analysis was performed to determine which instructor groups displayed significant differences in perceptions of student algebra learning in each classroom setting. Results of the Tukey post hoc analysis comparing mean instructor perceptions of student learning in each of the institutional settings are shown in Table 12 . 
Table 12

Results of Tukey Post Hoc Analysis of Algebra Learning

Means, Standard Deviations, and Mean Differences

\begin{tabular}{|c|c|c|c|c|c|c|}
\hline \multirow{2}{*}{$\begin{array}{l}\text { Institutional Setting of } \\
\text { Students }\end{array}$} & \multicolumn{3}{|c|}{ Instructor level } & \multicolumn{3}{|c|}{ Mean Differences } \\
\hline & $\begin{array}{l}\text { High } \\
\text { School } \\
(n=6)\end{array}$ & $\begin{array}{l}\text { 2-year } \\
\text { college } \\
(n=21)\end{array}$ & $\begin{array}{l}\text { 4-year } \\
\text { college } \\
(n=28)\end{array}$ & $\begin{array}{c}\text { HS } \\
\text { vs. } \\
2-y r . \\
\text { college }^{a}\end{array}$ & $\begin{array}{c}\text { HS } \\
\text { vS. } \\
\text { 4-yr. } \\
\text { college }^{b}\end{array}$ & $\begin{array}{c}\text { 2-yr. } \\
\text { vs. } \\
4-y r . \\
\text { college }\end{array}$ \\
\hline High school & $\begin{array}{c}3.15 \\
(0.54)\end{array}$ & $\begin{array}{c}2.47 \\
(0.60)\end{array}$ & $\begin{array}{c}2.28 \\
(0.62)\end{array}$ & $0.68 *$ & $0.87 *$ & 0.19 \\
\hline Non-credit college & $\begin{array}{c}2.66 \\
(1.08)\end{array}$ & $\begin{array}{c}2.50 \\
(0.45)\end{array}$ & $\begin{array}{c}2.42 \\
(0.50)\end{array}$ & 0.16 & 0.24 & 0.08 \\
\hline Credit-bearing college & $\begin{array}{c}3.94 \\
(0.50)\end{array}$ & $\begin{array}{c}3.40 \\
(0.38)\end{array}$ & $\begin{array}{c}3.23 \\
(0.44)\end{array}$ & $0.54^{*}$ & $0.71 *$ & 0.17 \\
\hline
\end{tabular}

${ }^{a}$ High school instructors compared to two-year community college instructors

${ }^{b}$ High school instructors compared to four-year college and university instructors

${ }^{\mathrm{c}}$ Two-year community college instructors compared to four-year college and university

instructors

$* p<.05$

The Tukey post hoc analysis indicated significant differences in high school $(M=$ 3.16) and four-year college and university $(M=2.29)$ instructors' perceptions of algebra 
learning in high school classes $(p=.008)$ and significant differences in high school $(M=$ 3.16) and community and technical college $(M=2.47)$ instructors' perceptions' of algebra learning in high school classes $(p=.039)$. No significant differences were found for perceptions of student learning in high school classes between community and technical college and four-year college and university instructors $(p=.542)$.

The analysis also showed significant differences in high school $(M=3.94)$ and four-year college and university $(M=3.23)$ instructors' perceptions of algebra learning in credit-bearing college classes $(p=.002)$ and significant differences in high school $(M=$ 3.94) and two-year community college $(M=3.41)$ instructors' perceptions of algebra learning in credit-bearing college algebra classes $(p=.018)$. No significant differences were found for perceptions of student learning in credit-bearing college algebra classes between community and technical college and four-year college and university instructors $(p=.305)$. Differences in instructor perceptions of algebra learning in noncredit-bearing college algebra classes were not significant for any of the instructor teaching levels.

Mean high school teachers' perceptions of algebra learning were higher than the perceptions of either two- or four-year college instructors in all the institutional settings, and four-year college instructors' perceptions of algebra learning were lower than the perceptions of either high school or two-year college instructors in all the institutional settings. Two-year college instructors' mean perceptions of algebra learning fell between the mean perceptions of algebra learning of the high school teachers and the four-year college instructors in all the institutional settings. 
Comparison of instructor perceptions of learning by algebra category

A MANOVA was also performed on the 18 sub-dependent variables as determined by six algebra category mean perceived learning scores: (1) algebraic expressions; (2) functions; (3) solving equations and inequalities; (4) graphing; (5) problem solving; and (6) reasoning, in each of the three classroom settings. The MANOVA analysis, Wilks' lambda $=0.249, F(36,62)=1.728, p=.029$, indicated there were significant differences between instructor groups regarding their perceptions of student algebra learning. Effect size indicated by partial eta squared was 0.501 which exceeds the effect size of 0.15 that is considered large (Stevens, 2002; Cohen, 1988) and is an indication of large differences in instructor perceptions of student learning across the 18 sub-dependent variables. Observed power was 0.979 which exceeds the accepted value of .80 used in social science research (Cohen, 1988). The multivariate pairwise comparisons (Stevens, 2002) indicated significant differences between high school and four-year college instructors' perceptions, $F(18,31)=2.259, p=.022$, and high school and two-year college instructors' perceptions of algebra learning, $F(18,31)=2.100, p=$ .034. Differences in two- and four-year college instructors' perceptions of algebra learning were not significant, $F(18,31)=1.262, p=.277$.

A Tukey post hoc analysis was performed to determine which instructor groups showed significant differences in perceptions of student algebra learning by algebra content category in each classroom setting. Results of the Tukey post hoc analysis comparing instructors' mean perceptions of student learning in algebraic expressions, function representations, equations and inequalities, graphing, problem solving, and reasoning in the three transitional classroom settings are shown in Tables $13-15$. 
Table 13 shows the results of the Tukey post hoc analysis in high school classes. The analysis indicated significant differences in high school and four-year college and university instructors' perceptions of algebra learning in all algebra content categories ( $p$ $=.015$ to .034 ) in high school classes for $p<.05$. The analysis also showed significant differences in high school and community and technical college instructors' perceptions of algebra learning in all content categories $(p=.030$ to .034$)$ except graphing $(p=.054)$ in high school classes. High school teachers' perceived student learning scores in high school classes were higher in all categories than the other two instructor groups, and fouryear college instructors perceived student learning scores were the lowest in all categories between the instructor groups. Differences between community and technical college and four-year college and university instructors' perceptions of algebra learning in high school classes were not significant. 
Table 13

Results of Tukey Post Hoc Analysis of Algebra Category Means, Standard Deviations, and Mean Differences: High School Classes

Instructor level Mean Difference

Algebra Category

\begin{tabular}{lllll}
\hline HS & 2-yr. & 4-yr. & HS/2-yr. ${ }^{a}$ HS/4-yr. ${ }^{b} \quad$ 2-yr./4-yr. ${ }^{c}$ \\
$(n=6) \quad(n=26) \quad(n=19)$
\end{tabular}

\begin{tabular}{|c|c|c|c|c|c|c|}
\hline Algebraic & 3.17 & 2.48 & 2.39 & $0.69 *$ & $0.78 *$ & 0.09 \\
\hline expressions & $(0.55)$ & $(0.60)$ & $(0.58)$ & & & \\
\hline Function & 3.13 & 2.35 & 2.16 & $0.78 *$ & $0.97 *$ & 0.19 \\
\hline representations & $(0.62)$ & $(0.69)$ & $(0.65)$ & & & \\
\hline Equations and & 3.57 & 2.88 & 2.74 & $0.69 *$ & $0.83 *$ & 0.14 \\
\hline inequalities & $(0.48)$ & $(0.66)$ & $(0.46)$ & & & \\
\hline \multirow[t]{2}{*}{ Graphing } & 3.26 & 2.53 & 2.44 & 0.73 & $0.82 *$ & 0.09 \\
\hline & $(0.60)$ & $(0.71)$ & $(0.64)$ & & & \\
\hline \multirow[t]{2}{*}{ Problem solving } & 2.79 & 2.10 & 2.02 & $0.69 *$ & $0.77 *$ & 0.08 \\
\hline & $(0.56)$ & $(0.63)$ & $(0.54)$ & & & \\
\hline \multirow[t]{2}{*}{ Reasoning } & 2.83 & 2.12 & 2.01 & $0.71 *$ & $0.82 *$ & 0.11 \\
\hline & $(0.59)$ & $(0.63)$ & $(0.58)$ & & & \\
\hline
\end{tabular}

${ }^{a}$ High school instructors compared to two-year community college instructors.

${ }^{\mathrm{b}}$ High school instructors compared to four-year college and university instructors.

${ }^{\mathrm{c}}$ Two-year community college instructors compared to four-year college instructors.

$* p<.05$ 
Table 14 shows the results of the Tukey post hoc analysis for the six algebra content categories in non-credit bearing college classes. Differences in instructor perceptions of learning of algebra content by category in non-credit-bearing college algebra classes were not significant for any of the instructor teaching levels. However, high school teachers rated learning higher in non-credit-bearing algebra classes in all categories except solving equations and inequalities than did the two- and four-year college instructors. Four-year college instructors rated learning in the non-credit-bearing college classes lower than any of the other instructor groups for all the content categories. 
Table 14

Results of Tukey Post Hoc Analysis of Algebra Category Means, Standard Deviations, and Mean Differences: Non-Credit-Bearing College Algebra Classes

Instructor level Mean Difference

\begin{tabular}{|c|c|c|c|c|c|c|}
\hline \multirow{3}{*}{ Algebra Category } & \\
\hline & HS & 2-yr. & 4-yr. & $\mathrm{HS} / 2-\mathrm{yr}^{\mathrm{a}}$ & HS/4-yr. ${ }^{b}$ & 2-yr. $/ 4-y r .^{c}$ \\
\hline & $(n=6)$ & $(n=26)$ & $(n=19)$ & & & \\
\hline Algebraic & 2.69 & 2.68 & 2.59 & 0.01 & 0.10 & 0.09 \\
\hline expressions & $(1.06)$ & $(0.44)$ & $(0.46)$ & & & \\
\hline Function & 2.55 & 2.30 & 2.14 & 0.25 & 0.41 & 0.16 \\
\hline representations & $(1.24)$ & $(0.58)$ & $(0.54)$ & & & \\
\hline Equations and & 2.98 & 3.10 & 2.83 & -0.12 & 0.15 & 0.27 \\
\hline inequalities & $(1.16)$ & $(0.47)$ & $(0.46)$ & & & \\
\hline \multirow[t]{2}{*}{ Graphing } & 2.71 & 2.48 & 2.45 & 0.23 & 0.26 & 0.03 \\
\hline & $(1.09)$ & $(0.63)$ & $(0.52)$ & & & \\
\hline \multirow[t]{2}{*}{ Problem solving } & 2.48 & 2.13 & 2.04 & 0.35 & 0.44 & 0.09 \\
\hline & $(0.99)$ & $(0.58)$ & $(0.51)$ & & & \\
\hline \multirow[t]{2}{*}{ Reasoning } & 2.50 & 2.13 & 2.06 & 0.37 & 0.44 & 0.07 \\
\hline & $(0.80)$ & $(0.58)$ & $(0.53)$ & & & \\
\hline
\end{tabular}

${ }^{a}$ High school instructors compared to two-year college instructors.

${ }^{\mathrm{b}}$ High school instructors compared to four-year college instructors.

${ }^{\mathrm{c}}$ Two-year college instructors compared to four-year college instructors. 
Table 15 shows the results of the Tukey post hoc analysis for the six algebra content categories in credit-bearing college classes. The differences in high school and four-year college and university instructors' perceptions of learning in credit-bearing college classes in all algebra content categories $(p=.010$ to .012$)$ were significant. Differences in high school and community and technical college instructor perceptions of learning in credit-bearing college classes were significant only for algebraic expressions $(p=.019)$ and reasoning $(p=.002)$. Differences between community and technical college and four-year college and university instructors' perceptions of algebra learning in credit-bearing college algebra classes were not significant.

High school teachers' perceived student learning scores in credit-bearing college algebra classes were higher in all categories than the other two instructor groups, and four-year college instructors perceived student learning scores were the lowest in all categories than the other instructor groups. Differences between two-year community and technical college and four-year college and university instructors' perceptions of algebra learning in high school classes were not significant, although the two-year college instructors rated learning slightly higher in all categories than the four-year college instructors. 
Table 15

Results of Tukey Post Hoc Analysis of Algebra Category Means, Standard Deviations, and Mean Differences: Credit-Bearing College Algebra Classes

Instructor level Mean Difference

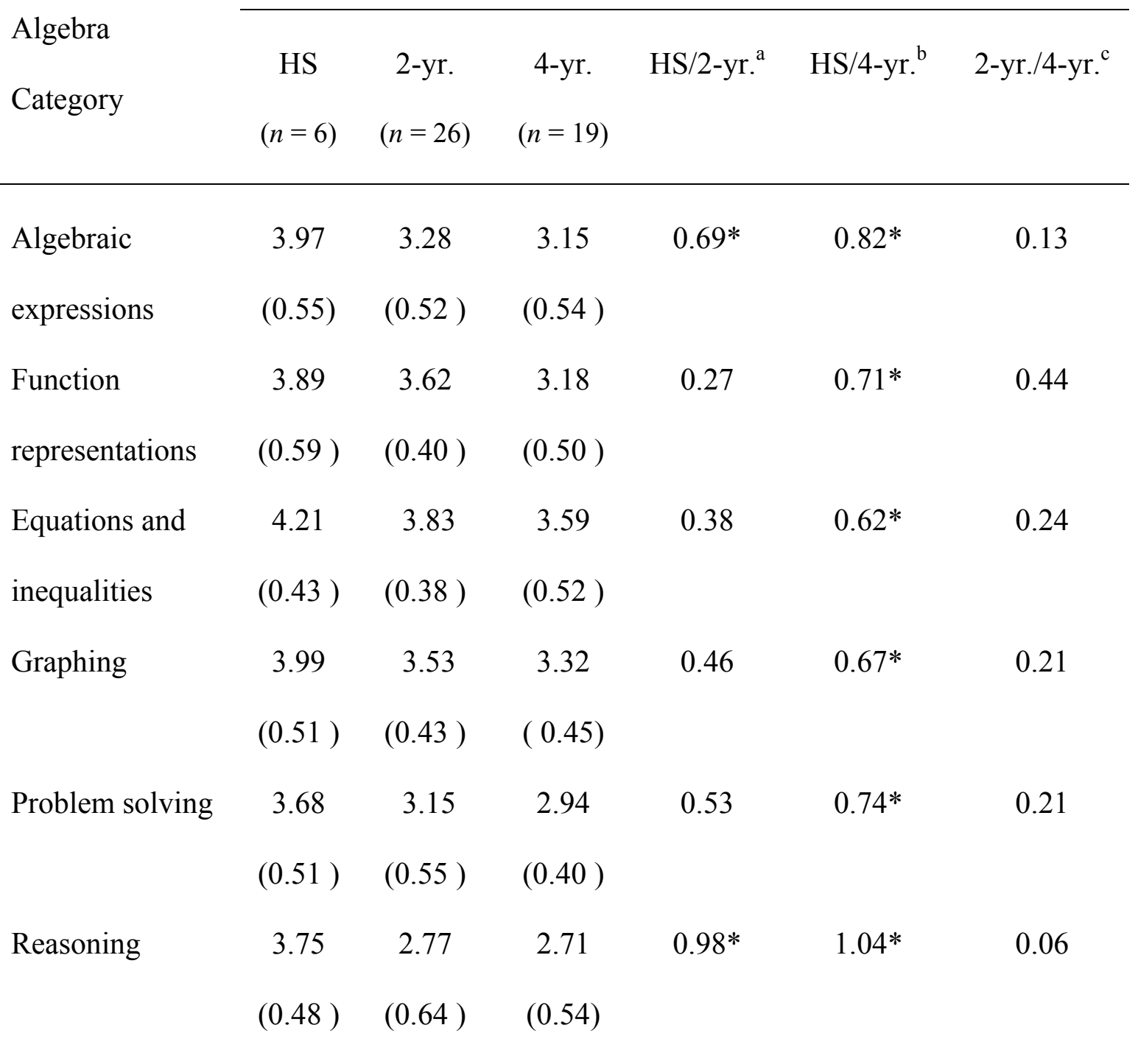

${ }^{a}$ High school instructors compared to two-year college instructors

${ }^{\mathrm{b}}$ High school instructors compared to four-year college instructors

${ }^{\mathrm{c}}$ Two-year community college instructors compared to four-year college instructors

$* p<.05$ 
Some participants at each institutional level opted not to answer questions about student learning at other levels. Twenty-three high school instructors, 13 college and university instructors, and 5 community and technical college instructors did not answer questions about algebra learning at all three levels, which resulted in unequal cell sizes for the MANOVA analysis. Stevens (2002) recommends the ratio of largest to smallest group size not exceed 1.5 which was not achieved. To address this issue, the three assumptions of MANOVA, independence of observations, normal distribution of data within groups, and equal variances and covariances among data were examined. By design, participant observations were independent of each other.

Stevens recommends using the Shapiro-Wilk statistic to test for normality of data. Non-normality would be an indication of bias in the data toward a Type I error. ShapiroWilk was significant for community college instructor perceptions of problem solving in high school classes, Shapiro-Wilk $(27)=.917, p=.033$, of reasoning in non-creditbearing college classes, Shapiro-Wilk $(30)=.922, p=.031$, and of solving equations in credit-bearing college classes, Shapiro-Wilk $(30)=.928, p=.043$. The statistic was also significant for high school instructor perceptions of learning to manipulate algebraic expressions in credit-bearing college classes, Shapiro-Wilk $(7)=.792, p=.034$, and fouryear college instructor perceptions of reasoning in credit-bearing college classes, Shapiro-Wilk $(30)=.925, p=.036$. An examination of histograms of the data from the questionable groups, indicated by the Shapiro-Wilk statistic, did not indicate the presence of outliers or skewness in the data, meaning that the assumption of data normality was not violated. 
Box's test was used to check for equal variances and covariances among the groups. In the analysis of overall algebra content learning scores, Box's test for equality of covariance matrices was not significant, $F(12,920.526)=1.309, p=.207$, meaning that variances and covariances from the three levels of the dependent variable were approximately equal. In the analysis of algebra learning scores by content categories, Box's test for equality of covariance matrices was significant, $F(171,4642.398)=1.227$, $p=.025$, meaning that variances and covariances generated by dependent variables were not the same for the three groups of teachers.

Using Stevens guidelines for checking MANOVA assumptions for data with unequal cell sizes, the data used for the analysis of the overall algebra learning scores may not be seriously biased by any violations of the assumptions. Some of the data used in the analysis of the algebra learning scores by content category appears to exhibit some non-normality and heterogeneity, but the small cell sizes hinder making a definitive judgement. Stevens notes that even with a violation of normality and homogeneity in a kgroup MANOVA, Wilk's lambda is robust and bias toward a Type I or Type II error might not be large. Differences in cell size for this study are a concern. However, the results of tests for normality and homogeneity indicate that, while some bias in the data may exist, using Wilk's lambda to test for multivariate effects may be justified.

\section{Summary}

The instrument used for this study demonstrated internal consistency. ADP algebra benchmarks were carefully selected and validated by mathematics educators over several years of study. Cronbach alpha coefficients in both the pilot and the actual study 
exceeded Nunnally's recommended value of 0.7 for internal reliability, confirming an important quality of the instrument.

While the actual sample size for the study was smaller than expected, the participants indicated strong preparation in mathematics and extensive teaching experience in the focus algebra classes, with nearly half having teaching experience in more than one institutional setting. Part-time instructors were somewhat underrepresented and males may also have been slightly under-represented in the sample, but overall, the sample represented a cross-section of Kentucky mathematics instructors that exhibited characteristics comparable to the population of mathematics instructors in the United States.

Only six of the high school teachers responded to the non-credit-bearing and credit-bearing college questions. High school teachers' willingness to respond to the college level questions was raised early in the instrument development process and seemed to be a problem again during the pilot study. Wording was changed on the survey and on the cover letter accompanying the survey, and a Don't Know option was omitted from the Likert-scale in order to address the issue. Likewise, some college and university instructors did not answer all the questions in classroom settings outside their teaching environment.

Since there were participants in each instructor group who did not answer some of the classroom setting questions, cell sizes were unequal, affecting the reliability of the MANOVA analysis. The independence of observations assumption was met by the study design. An inspection of the data using the Wilk-Shapiro statistic and Box's test indicated some lack of normality and heterogeneity, respectively, which is an indicator that Type I 
or Type II error rates might be greater than if assumptions had been met. Given the small sample size, it was not possible to make any further observations about the quality of the data. Since Wilks' lambda for the k-group MANOVA is robust, data concerns may not seriously affect results.

MANOVA results indicated that there were significant differences among three groups of mathematics instructors' perceptions of algebra learning in three transitional classroom settings -- high school, non-credit-bearing college algebra, and credit-bearing college algebra classes. A summary of the results for each of the research questions follows.

1. Do high school, two-year community and technical college, and four-year college and university mathematics instructors differ in their perceptions of how well students typically learn algebra content in high school classes?

The overall algebra content analysis and the analysis by algebra content category indicated there were differences in high school and two-year community and technical college, and high school and four-year college and university instructors' perceptions of algebra learning in high school classes. High school teachers consistently rated algebra learning higher in high school classes than did two-year community and technical college instructors and four-year college and university instructors. The difference in learning scores related to graphing was not significant between high school and two-year community and technical college instructors. The differences between two-year community and technical college and four-year college and university instructors' perceptions of algebra learning in high school classes were small and not significant. 
2. Do high school, two-year community and technical college, and four-year college and university mathematics instructors differ in their perceptions of how well students typically learn algebra content in non-credit-bearing or remedial college algebra classes?

The analyses did not indicate any significant differences between the perceptions of the instructor groups about algebra learning in non-credit-bearing college algebra classes.

3. Do high school, two-year community and technical college, and four-year college and university mathematics instructors differ in their perceptions of how well students typically learn algebra content in credit-bearing college algebra classes?

The analysis indicated there were differences in high school and four-year college and university instructors' perceptions of algebra learning in credit-bearing college classes, with high school instructors consistently rating learning higher in credit-bearing college classes than the four-year college and university instructors for all algebra content in all the algebra content categories. Differences in high school and two-year community and technical college instructor perceptions of learning in credit-bearing college algebra classes were significant for overall content and for two of the algebra category contents, algebraic expressions and reasoning. There were no significant differences between twoyear community and technical college and four-year college and university instructor perceptions of algebra learning in credit-bearing college algebra classes. 


\section{CHAPTER V \\ DISCUSSION AND IMPLICATIONS}

Many students have difficulty making smooth transitions from high school to postsecondary mathematics. To investigate teacher perceptions of student learning in key transitional algebra classes, a researcher-developed survey based upon the algebra benchmarks found in the American Diploma Project (ADP) posited by Achieve, Inc., (2004) was mailed to high school, two-year community and technical college, and fouryear college and university instructors in Kentucky. Participants were asked to indicate how well they believed students were learning content defined by the ADP algebra benchmarks in three key transitional classroom settings -- high school, non-credit-bearing or remedial college algebra, and credit-bearing college algebra classes. The research questions were:

1. Do high school, two-year community and technical college, and four-year college and university mathematics instructors differ in their perceptions of how well students typically learn algebra content in high school classes?

2. Do high school, two-year community and technical college, and four-year college and university mathematics instructors differ in their perceptions of how well students typically learn algebra content in non-credit-bearing or remedial college algebra classes? 
3. Do high school, two-year community and technical college, and four-year college and university mathematics instructors differ in their perceptions of how well students typically learn algebra content in credit-bearing college algebra classes?

A MANOVA was performed to compare mean algebra learning scores between the three instructor levels in each of the transitional classroom settings. The analysis showed there are differences between high school and two-year college and high school and four-year college instructors' perceptions of algebra learning in high school classes. High school teachers consistently rated algebra learning higher in high school classes than did either two- or four-year college instructors, and the differences were statistically significant $(p<.05)$ with the exception of the perceived learning of graphing between high school and two-year community and technical college instructors.

The analysis also indicated there were statistically significant $(p<.05)$ differences in high school and four-year college and university instructors' perceptions of algebra learning in credit-bearing college classes. High school instructors consistently rated learning higher in credit-bearing college classes than the four-year college and university instructors across all the algebra content categories. Differences in high school and twoyear community and technical college instructor perceptions of learning in credit-bearing college algebra classes were significant for overall content and for two of the algebra category contents, algebraic expressions and reasoning.

\section{Discussion}

Based on discussions between high school and college mathematics instructors in the local community, differences found in this study between high school and college 
instructors' perceptions of student learning of algebra in high school and college classrooms were not unexpected. High school, two-year community college, and fouryear college and university instructors met and discussed transition issues for students in two local conferences at the University of Louisville in 2001 and 2003. Teacher presentations and group discussion revealed that high school teachers in these groups attempted to present material in an engaging manner and make connections to real-world situations whenever possible in order to capture student interest and involvement. Handson activities and the use of technology were incorporated into instruction to develop concepts and engage students more deeply in the learning process. Teachers used informal mathematics vocabulary and terminology during instruction. In the high school environment, student grades were based on multiple aspects of student learning including homework, projects, participation and effort, quizzes, tests, and possibly a final examination. High school teachers noted that state mathematics assessments and emphasis did not match the topics included on the SAT or ACT pre-college assessments.

College instructors in the local groups used more abstract mathematical language than the high school teachers. The pace of instruction was fixed. If a student couldn't keep up with the pace of instruction or had forgotten critical content, the burden was on the student to get additional one-on-one tutoring. Some instructors taught in a large lecture hall; content was presented in a lecture format with minimal opportunity for questions and classroom discussion. Hands-on activities and technology were used minimally, if at all. Course grades were based on major tests and a final examination. Homework, if considered at all, was a small percentage of the final grade (Ronau, Seif, \& Jones, 2001; Ronau \& Jones, 2003). 
High school teachers might perceive student learning to be higher than college instructors because of differences in the classroom environments. High school teachers are working with their students daily and structure their instruction to build on what the student already knows. Assessments such as frequent quizzes and end-of-chapter or unit tests to measure student progress are usually teacher developed and may be preceded with a class review of the material to be tested. Students may do well when tested on discrete amounts of recently covered material. Final examinations, if given, usually have little weight in the student's course grade (South Carolina Commission on Higher Education, 1999). From this perspective, teachers are likely to believe their students are learning the content that is being taught.

Several months, sometimes several years, elapse before college instructors see these students in their classrooms. "Time lapses [that occur] between mathematics courses are extremely detrimental in high school, in college, and in the transition between the two" (South Carolina Commission on Higher Education, 1999). Students who took their last mathematics class in the junior year "are out of practice when they enter college and, not surprisingly, often need refresher courses" (Southern Regional Education Board, 2000, p. 13). Over this period of time, many students forget some of the mathematics concepts they once knew. As one college instructor noted on the survey, "Continued practice with algebraic concepts and skills is essential for mastery." The instructor has a set amount of material that must be covered regardless of student preparation. The student who is under-prepared or has forgotten previously taught material must obtain additional help learning the material on his or her own. Most of the student's grade in the 
course will be based on a few major tests and a comprehensive final examination (South Carolina Commission on Higher Education, 1999).

If students are under-prepared for college mathematics, the instructor may assume that the students were never taught the material. Therefore, a solution to the problem of under-prepared students might be promoting more rigorous mathematics instruction in high school. Surveys of postsecondary faculty indicate that over half believe that having students better prepared to handle course requirements would improve their teaching environment (Cohen \& Brawer, 2003). If college instructors do not perceive students are learning mathematics well, then from their perspective, a solution for improving their work environment would be more rigorous mathematics preparation for students coming into their classrooms.

Differences in high school and college instructor beliefs found in this study about student learning in high school and credit-bearing college algebra classes seem to be another indicator of the isolated and conflicting belief systems that are apparent at each of the institutional levels. These conflicting belief systems are prevalent in the Math Wars discussions that continue among mathematics educators (Mathematically Correct, 2006; Mathematically Sane, 2006; Lundin, Oursland, Lundgren, \& Reilly, 2005) and in the variety of solutions that have been proposed or implemented with the intent of solving the problems associated with difficult transitions for students in mathematics. Four different reform initiatives illustrate different and unconnected solutions to the transition issues.

The National Council of Teachers of Mathematics (NCTM), representing Kindergarten to Grade 12 and college mathematics educators, is focused on teaching and learning in pre-college schools. The curriculum framework promoted by the NCTM, 
along with strategies for implementation in Pre-Kindergarten to Grade 12 classrooms, has influenced state content standards and instructional strategies used by K-12 teachers. While not ignoring the importance of skill development, standards include building conceptual understanding of mathematics content along with developing problem solving, reasoning, and communication skills. Research based teaching strategies are supported to help teachers provide effective instruction for all students $(1989,2000)$.

A second major reform effort that is directly focused on improving transition problems for students in mathematics is the American Diploma Project (ADP). College mathematicians involved in the project, with support from state governments and the business community, have formulated lists of standards or benchmarks for high school students in mathematics and other contents. The developers of these standards promote rigorous mathematics instruction with an emphasis on traditional algebraic manipulation skills (Achieve, Inc., 2004, 2006), with little regard for the high school teaching and learning environment.

A third group of stakeholders, the college mathematics community, is represented by The Mathematical Association of America (MAA). The focus is on the undergraduate curriculum in mathematics with recommendations for mathematics instruction that address the needs of students preparing for non-mathematics intensive careers, students preparing to teach in Kindergarten to Grade 12 schools, and students planning to major in mathematics. The guidelines of the MAA are presented as discussion points for college mathematics departments and do not address specific curricula or instructional methods (2004). 
Two-year community college instructors are represented in the reform movement by the American Mathematical Association of Two-Year Colleges (AMATYC). Content standards and instructional strategies recommendations for two-year community and technical colleges are presented in their documents Crossroads in Mathematics: Standards for Introductory College Mathematics Before Calculus and Beyond Crossroads: Implementing Mathematics Standards in the First Two Years of College. Unique among all the initiatives, the AMATYC recommends a three-way dialogue between representatives from undergraduate mathematics, two-year community and technical colleges, and four-year colleges and universities to develop strategies for improving the transitions for students in mathematics $(1995,2006)$.

Differences in perceptions of student learning in algebra classrooms may also be a reflection of the different goals and environments for student learning that exist between high school, two-year community and technical college, and four-year college and university instructors. High school instructors must deal with a number of conflicting pressures that affect the quality and depth of their classroom instruction. The most immediate pressure comes from daily interactions with students. Students come to any classroom with different knowledge bases, different reasons for being in the class, and different home expectations. Instruction is usually student-centered and starts at the student's knowledge level (Kentucky Education Professional Standards Board, 2006), which may require re-teaching content that might have been covered in earlier grades. As one high school teacher noted in a comment from the survey, "We have too much to teach in a short time in high school. We have to teach things that should have been mastered in middle school and was not. We cannot spend enough time teaching what they 
need to learn in high school." Another high school teacher noted, "The capabilities of students in our classes vary greatly, from students with Individual Education Plans to advanced students. Therefore, mastery of concepts is varied." College instructors also have students coming to class under-prepared, but the burden is on the student to seek outside of class tutoring if needed (South Carolina Commission on Higher Education, 1999).

In the high school environment, the student's life outside the classroom affects classroom behavior and the ability to engage in learning, which the teacher has to resolve. Discipline issues may have to be addressed before any learning can take place. The high school day includes interruptions such as field trips, all-school assemblies, sporting events, and college recruiter visits, which reduce the available teaching and learning time. In the college environment, students still cope with personal issues that may interfere with their ability to learn, but the instructor is no longer obligated to engage the student in learning. Instruction moves forward with the student bearing the burden of learning the material (South Carolina Commission on Higher Education, 1999).

School administrators generally expect high school teachers to manage discipline problems without main office assistance, and teachers are expected to take actions that do not result in parent complaints. Administrators are often anxious about the school showing adequate yearly progress on state assessments. Required yearly student assessments in grades 3 to 8 and one assessment in grades 10 to 12 mandated by No Child Left Behind have put a strong focus on accountability for all students and their teachers (U.S. Department of Education, 2005; Kirst \& Bracco, 2004). Teacher lesson plans may be monitored to insure teachers are covering content that will be on 
accountability assessments. Required scrimmages that reduce time for new instruction may be held throughout the school year to practice for the state assessments. College instructors do not usually have to be concerned with discipline issues, and there is little accountability in terms of ensuring that the majority of students show evidence of learning the material. At research intensive institutions, some instructors may be more focused on research than teaching. Even if the instructor is not engaged in research, the environment and culture is different from liberal arts and teaching colleges (National Research Council, 1991).

Parents add to the pressures on high school teachers in several ways. Some parents are very anxious about their child receiving high grades in order to obtain college scholarships or enroll in prestigious universities. Learning may be secondary to the grade their child receives in the course (Kirst \& Bracco, 2004). Other parents give the appearance of being uninvolved with their children and may expect the school to deal with social growth issues that other parents instill as part of normal home training. Some parents may be coping with serious survival problems such as unemployment, poor health, and drug dependencies and are unable to provide support for their child's learning. Parent pressures on instructors usually do not exist at the college level.

State content standards for accountability assessments determine what topics will receive the most emphasis in high school classrooms. Textbooks are written to address the content needs of many states and contain some material that is not covered on the accountability assessment in the state of teacher instruction (Seeley, 2003). In large school districts, the order in which content should be taught may be determined by central office administrators. The teacher may need to be prepared to teach textbook 
content out of order and may need to find supplementary material for some topics touched on only briefly in the text. In addition to administering their own classroom assessments to determine student grades in the class, the state content standards, which are designed for all students, may not be completely aligned with college mathematics requirements. Secondary teachers, under pressure to prepare students for state assessments, may not be able to include topics not on the state assessment that are necessary for college preparation (Kirst, Venezia, \& Antonio, 2004). SAT and ACT tests that students take as part of their requirements for enrolling in college may assess content that is not completely aligned with classroom instruction, state assessments, or college entrance requirements. College instructors are rarely concerned with assessment accountability. If students perform poorly on an examination, blame may be placed on the student's lack of preparation.

Even more pressures on secondary classroom teachers are imposed by their professional affiliations. In large schools several teachers teaching the same course must work together to cover the content in the same order and at the same pace. Teachers involved in the professional community outside their school such as the NCTM may want to emphasize content or use materials that differ from what other teachers in their school are using. Teachers with differing beliefs about ways to present content may find it difficult to locate and agree on instructional materials that achieve a balance between their varied approaches to teaching mathematics.

The differences between two-year community and technical college and four-year college and university instructors' perceptions of algebra learning in high school classes and in credit-bearing college algebra classes were small and not significant. This result 
was unexpected since there are clear differences in the teaching and learning

environments between two-year community colleges and four-year colleges and universities. Cohen and Brawer (2003) describe the community college as a transitional educational institution for students with an emphasis on preparing students for college level work or direct entry into the workplace. AMAYTC $(1995,2006)$ envisions the community college as a bridge institution between high school and four-year colleges. In the document, Crossroads in Mathematics: Standards for Introductory College Mathematics Before Calculus, one of the basic principles underlying the recommendations for mathematics instruction in two-years colleges states,

Students will acquire mathematics through a carefully balanced educational program that emphasizes the content and instructional strategies recommended in the standards along with the viable components of traditional instruction. These standards emphasize problem solving, technology, intuitive understanding, and collaborative learning strategies. Skill acquisition, mathematical abstraction and rigor, and who-class instruction, however, are still critical components of mathematics education. (American Mathematical Association of Two-Year Colleges, 1995, p. 3).

From this perspective, two-year colleges support a balance between teaching at the student's level of mathematical understanding using appropriate teaching and learning strategies, a learner-centered environment, and the traditional rigorous whole class instruction, a knowledge-centered environment, that is used in most four-year colleges and universities. A report of the National Research Council (2005), How Students Learn Mathematics in the Classroom, discusses the importance of achieving a balance between learner-centered and knowledge-centered instructional environments in order to enable students to develop mathematics expertise over time.

In contrast, the four-year college or university focuses on preparing students for careers that require Bachelor's degrees or higher. Instruction in nearly every four-year 
college and research focused university is knowledge-centered. Content is often

presented in lecture format with rigorous, abstract mathematical language.

The traditional college algebra course is filled with techniques, leaving little time for contextual problems. Students, many of whom have seem this material in prior algebra courses, struggle to master the techniques; three out of four never use these skills, and many of the rest find that they have forgotten the techniques by the time they are needed in later courses (Madison as cited in Steen, 2004, p. 38).

Little or no opportunity is allowed for questions or class discussion. Undergraduate mathematics classes with many students enrolled may be taught in a large lecture hall. A question might be raised as to whether teaching the content is the same as the student learning the content. Yet in this study, two- and four-year college and university instructors' perceptions of student learning in all three classroom settings were so similar that it appears that the two instructor groups might be representative of the same population in regard to their beliefs and attitudes about student learning in algebra.

The analyses did not indicate any significant differences between the instructor groups in their perceptions of algebra learning in non-credit-bearing college algebra classes. Mean perceived learning scores in algebra in non-credit-bearing college classes fell between Very Little and Some for all three teacher groups, which indicates that they perceive students know minimal mathematics. Some students who are required to enroll in remedial college algebra classes may have barely passed high school mathematics, and others may have taken the fewest possible mathematics classes in high school. Students who struggle to learn mathematics often suffer mathematics anxiety and lack confidence in their ability to learn and do mathematics. They may be missing key conceptual understandings, pursing careers that are not mathematics intensive, or dislike mathematics. 
A few survey participants commented on the weak backgrounds of their students in developmental mathematics. "My responses are influenced by the fact that I primarily teach developmental math classes." Another college instructor noted, "We tend to see the products of the failures of public education as opposed to the successes. Most of our students have a long history of doing poorly in mathematics." A third said, "Most of my students in algebra settings enter as developmental students who are very weak." Others expressed concerns about the effectiveness of remedial mathematics. One participant said, "It has been my experience that remedial courses are completely ineffective at teaching algebra skills to students.” Another noted that developmental students who make it to a credit-bearing class are average college algebra students at best.

Another reason for low perceptions of learning in non-credit bearing or remedial college classes may be a lack of knowledge about development students and the role of developmental classes. Comments from high school instructors during the pilot study indicated confusion about the meaning of non-credit-bearing or remedial mathematics classes. On reflection, this lack of understanding by high school teachers about the nature of remedial college mathematics classes is not surprising. Since high school teachers are required to have a college major in mathematics, the majority liked mathematics and began their study of undergraduate mathematics with credit-bearing courses above the college algebra level. Three out of the 32 four-year college and university instructors who responded to the survey indicated they had no experience with remedial classes.

\section{Limitations}

Study results represent the perceptions of mathematics instructors in the limited geographic area of Kentucky, and the population list from which participants were 
randomly selected was incomplete since it was compiled using information available on the Internet. Most of the colleges did not list part-time instructors on their faculty lists, and as a result, part-time instructors were under-represented in the sample compared to the general population of mathematics instructors. Less than half the high schools in Kentucky provided names of faculty members on their websites.

The number of returned surveys with useable data was smaller than anticipated. The survey required 199 responses to complete, and this length may have been a factor in the $30 \%$ return rate. Participants in the pilot study needed 20 to 25 minutes to complete the survey, and comments from some pilot study participants and a participant in the main study who returned a blank survey indicated that the survey was too time consuming. Only 51 participants (55\%) answered all of the questions for the three institutional settings. The modest return rate along with the number of incomplete surveys among those received affected the power and effect size of the results. Timing of the survey distribution also may have been a factor in the return rate. Surveys were mailed close to the end of the spring 2006 semester. Teachers may have a number of closure activities to complete at the end of a semester, and completing a survey may not have been a priority task. The final survey mailing was delayed until the beginning of the fall 2006 term, but the break in the mailing protocol may have affected the response rate.

\section{Implications}

While this study indicates there are differences in instructor perceptions of the algebra content students are learning in key transitional classes, the study does not provide any insight into the sources of these beliefs. Additional research on the sources 
and nature of instructor beliefs is needed in order to answer questions raised by this study such as: (1) Why do high school teachers perceive student learning of algebra to be higher than college instructors? (2) Why do college instructors perceive algebra learning in credit-bearing college algebra classes to be lower than high school teachers? (3) Why are high school teachers unwilling to posit beliefs about how well students learn in college algebra classes? (4) Why did all of the instructors seem to believe that student learning in developmental or remedial algebra classes was not very high? (5) Although there are differences in teaching, research, and service expectations for faculty in twoyear versus four-year institutions, do they harbor similar attitudes towards students and towards teaching mathematics?

Underlying these questions is the need for more research on how teachers' beliefs about students and mathematics affect the content that is taught and student learning. Thompson (1984) investigated whether teachers' beliefs, views, and preferences about mathematics and mathematics teaching were reflected in their instructional practices and found that "[teachers] do have conceptions about their students and the social and emotional make-up of their class. These conceptions appear to play a significant role in affecting instructional decisions and behavior". Thompson goes on to note that "much more remains to be learned about [teachers] conceptions and how these relate to their instructional practices“ (p. 125). Hart (2003) reviewed the literature on postsecondary mathematics education and found that while there have been a number of studies which have investigated the connections between teacher beliefs and student learning in K- 12 schools,

practically no work exists that closely studies collegiate mathematics teachers. Noticeably absent is work on the beliefs of mathematics faculty, how those beliefs 
impact instruction, how mathematics faculty change their teaching in response to reform, or how the culture of the mathematics department impacts teaching (p. 4).

Researchers have documented disconnects between secondary mathematics preparation and postsecondary expectations that are barriers to students making smooth transitions from high school to postsecondary mathematics. High school curricula may not meet the demands of college entrance requirements, and high school exit exams may test content differently that college entrance placement exams (Kirst, Venezia, \& Antonio, 2004). At this time, there is no clear agreement between high school and college instructors on the content that students must master in order to successfully complete college mathematics courses. Numerous organizations, such as the NCTM, Achieve (ADP), Standards for Success, SAT, and ACT have posited content benchmarks or standards that high school students need to master, but there are differences in the topics each group considers important. Stakeholders who are seeking solutions to the transition problems for students need to reach common understandings about the mathematics topics students need to master (Southern Regional Education Board, 2002; Commission on Higher Education in South Carolina, 1999).

Research is needed on effective strategies for teaching mathematics content at all levels.

Although the typical methods of improving instructional quality have been to develop curriculum, and--especially in the last decade--to articulate standards for what students should learn, little improvement is possible without direct attention to the practice of teaching (Ball, 2003).

Traditionally mathematics in postsecondary institutions has been taught using skills-based instruction followed by drill and practice. "Instructional methods that are widely used in undergraduate programs foster a model of teaching [that uses] blackboard 
lectures, template exercises, isolated study, and narrow tests" (National Research Council, 1991, p. 28). "To believe that one can teach mathematics successfully by lectures, one must believe what most mathematicians know to be untrue- that mathematics can be learned by watching someone else do it correctly.... It is widely recognized that lectures place students in a passive role, failing to engage them in their own learning" (p. 24).

Tied closely to mathematics content and teaching is the need for research into effective ways to assess student learning in both high school and college classes. The mandates established with the passage of No Child Left Behind have forced states to develop high-stakes assessment tests for pre-college institutions, but research is needed to know whether these tests truly measure student knowledge and whether these tests are measuring students' mastery of content at a depth needed for success in postsecondary mathematics. Accountability assessments are not given at the college level; nor are assessments often used to inform and guide instruction.

Several changes for replications of this study to explore instructor perceptions of student learning in key transitional classes should be considered. Content should be limited to high school Algebra I and Algebra II topics. This would narrow the questions and serve to shorten the survey. Discussions with teacher groups at all levels prior to developing the survey might help in focusing the content questions.

Rather than a mail survey, administering the survey personally to representative groups of instructors, whether at conferences, workshops, or department meetings, might yield a higher return rate with useable data. Partnerships between a four-year college, two-year community college, and feeder high schools to the postsecondary institutions 
might generate more interest in the survey and result in a better return from respondents. Interviews with selected instructors or focus groups after the data have been analyzed would provide further triangulation and insight into the implications of study results. Attitudinal surveys about mathematics teaching and learning might yield further insights into instructor perceptions of learning.

Developmental programs, given the mixed student base, should be studied separately. The ultimate goal of the reform efforts in mathematics is to prepare students to make successful transitions to credit-bearing college work in mathematics as opposed to developmental college mathematics. Replications or extensions of this study about teacher perceptions of student learning in algebra should focus on high school preparation and successful learning in credit-bearing college algebra classes.

\section{Conclusion}

Making successful transitions from high school to postsecondary study has become necessary for our nation's citizens if they are to obtain and hold good-paying jobs in the workplace (Achieve, Inc., 2004). In the early years in the United States, minimal knowledge of arithmetic was sufficient for citizens to engage in farming and shop keeping. During the 20th century, a high school education was sufficient for citizens to obtain and hold good paying industrial jobs, but technology and the globalization of our economy now requires that citizens complete some education beyond high school "As economic historians have demonstrated in a variety of research, both technology and trade are making the pie bigger, but they are also shifting the shares of that pie away from low-skilled labor to high-skilled labor" (Friedman, 2006, p. 371). 
Knowledge of algebra is a critical gatekeeper for success in completing high school and nearly every postsecondary technical or academic program (RAND Mathematics Study Panel, 2003; Usiskin, 2005). SAT and ACT scores have improved slightly and, along with increasing numbers of students completing Advanced Placement Calculus, are indicators that many students have acquired the mathematics skills that enable them to make good transitions from high school to postsecondary training and the workplace (College Entrance Examination Board, 2003; ACT, 2004; National Center for Education Statistics, 2003). The number of high school students taking mathematics courses beyond Algebra II is increasing (National Center for Education Statistics, 2004).

All these indicators are promising and would lead one to believe mathematics educators are headed toward the goal of ensuring that all students make a successful transition from secondary to postsecondary mathematics. Just the opposite is true for many students, however. Even though a number of initiatives have been implemented with the intent of improving mathematics teaching and learning in Kindergarten to Grade 12 schools so that students will make smooth transitions to postsecondary education, large numbers of high school graduates struggle in their entry-level postsecondary mathematics classes. In 2004, 35\% of recent Kentucky high school graduates who enrolled in a Kentucky public postsecondary institution were under-prepared in mathematics (Kentucky Council on Postsecondary Education, 2006). Once in postsecondary programs, under-prepared students struggle to be successful in their college mathematics courses for which algebra is the foundational content. All too often these struggling students do not complete their degrees. In Kentucky, nearly $40 \%$ of students who were under-prepared in one or more subjects were not retained for a second 
year of postsecondary training in 2004 (Kentucky Council on Postsecondary Education, 2006).

The cost to society in general is high when students are under-prepared for college level work. Obviously providing faculty and teaching space in postsecondary institutions for students who are repeating high school content in postsecondary classrooms is expensive. Tom Layzell, president of the Kentucky Council on Postsecondary Education, estimates remedial education costs in Kentucky at about \$25 million a year, not including tutorial and other support services (Pitsch, 2006). Some states have reacted to the costs of remedial education by eliminating remedial course offerings at public four-year postsecondary institutions and shifting remedial work to community colleges. Other states have put time limits on the amount of time a student can remain in remedial education classes in order to reduce the total number of students taking remedial classes (Greene, Parsad, \& Lewis, 2003). These types of policies may reduce the monetary costs of remedial education but do so at the expense of equity opportunities for students who may be denied access to postsecondary education opportunities because they are not prepared for college level work.

We must find solutions to the national transition problems for students in mathematics in order to insure that these same students will be able to complete a postsecondary program and obtain skilled jobs. The transition issues faced by many students as they enter post-secondary education exasperate the already daunting achievement gap and subsequently widens the gaps between classes. During the last 20 or 30 years, the income gap between the very poor and the very rich has grown. "With each advance in technology and increase in the complexity of services, you need an even 
higher-level of skills to do the new jobs. ... Everyone should have a chance to be educated beyond high school. Otherwise upper-income kids will get those skills and their slice, and the lower-income kids will never get a chance" (Friedman, 2006, p. 174).

The National Research Council (2001), in its report Adding It Up: Helping Children Learn Mathematics, calls for "coordinated, systematic, and sustained modifications ... in how school mathematics instruction has commonly proceeded" in order ensure that all students will become mathematically proficient (p. 432). AMAYTC $(1995,2006)$, representing two-year college instructors who bear much of the burden for preparing under-prepared high school graduates for college level work (Cohen \& Brawer, 2003), recommends more strongly than any other initiative an on-going three-way dialogue between K- 12 schools, two-year colleges, and four-year colleges and universities. Among the conclusions of the Bridge Project researchers is the need for ongoing dialogue between mathematics instructors at all levels.

College-level stakeholders must be brought to the table when K-12 standards are developed. Also, K-12 educators must be engaged as postsecondary education admission and placement policies are under review. Reforms across the two education systems will be difficult, if not impossible, to implement without meaningful communication and policymaking between the levels (Kirst, Venezia, \& Antonio, 2004, p. 309).

A few states have formed P - 16 councils with the intent of beginning dialogue between K - 12 and postsecondary systems, but currently these councils "often have no legislative authority to develop and implement policies“" Kirst, Venezia, \& Antonio, 2004, p. 292). P - 16 councils, if not granted true legislative powers, do need to exert moral authority with respect to the numerous transitions that students undergo, and often falter at, during their school career. Moral authority in this framework means that a broad-based group is truly representative of their constituencies such as universities, two- 
year community colleges and pre-college institutions and speaks with one voice on the issues facing students. The council has the ear of institutional leaders and legislators, is consulted by regulatory bodies, and works with other P-16 councils across districts and state boundaries to develop a common vision or plan for addressing issues that emerge. To do this, individuals on these councils must set-aside their differences and focus on common goals to help the students in their regions.

Friedman (2006) calls for our government to upgrade the educational level of the entire American workforce and to put in place policies that will ensure every person completes at least a two-year community college program. Current reform initiatives to improve the teaching and learning of mathematics for students are fragmented and disjoint. Dialogue between all stakeholders and major systemic change across all levels of our educational system will be needed to ensure that many more students make smooth transitions in mathematics to postsecondary educational programs and have the knowledge needed to successfully complete those programs. This study has shown how far apart three of the groups are and is just one indicator of the need for such dialogue. 


\section{REFERENCES}

Achieve, Inc. (2004). Ready or not: Creating a high school diploma that counts. Washington, DC: Author.

-----. (2006). The American diploma project. Retrieved October 20, 2006 from http://www.achieve.org

-----. (2004). The expectations gap: A 50-state review of high school graduation requirements. [Electronic Version]. Washington, DC: Author.

ACT, Inc. (n.d.). Retrieved July 13, 2005 from http://www.act.org

-----. (n.d.). 1997 ACT National and State Scores. Retrieved January 5, 2005 from http://www.act.org/news/data/01/tsum.html

-----. (n.d.). 2001 ACT National and State Scores. Retrieved January 5, 2005 from http://www.act.org/news/data/97/tsum.html

-----. (n.d.). 2004 ACT National and State Scores. Retrieved January 4, 2005 from http://www.act.org/news/data/04/states.html

-----. (2004, August 16). National Data Release. Retrieved January 4, 2005 from http://www.act.org/news/release/2004/8-18-04.html

-----. (n.d.). Standards for transition. Retrieved January 18, 2005, from http://www.act.org/standard/index.html

Adelman, C. (1999). Answers in the tool box: academic intensity, attendance patterns, and bachelor's degree attainment. [Electronic Version]. Washington, DC: U.S. Department of Education.

American Mathematical Association of Two-Year Colleges. (2006). Beyond Crossroads: Implementing mathematics standards in the first two years of college. [Electronic Version]. Memphis, TN: Author.

-----. (1995). Crossroads in mathematics: Standards for introductory college mathematics before calculus. [Electronic Version]. Memphis, TN: Author. 
Association of Mathematics Teacher Educators. (n.d.). Retrieved July 20, 2005, from http://amte.sdsu.edu/mission.shtml

Ball, D. L. (2003, February). What mathematical knowledge is needed for teaching mathematics? Paper presented at the Secretary's Summit on Mathematics, U.S. Department of Education, Washington, DC.

Behr, M., Lesh, R., Post, T., \& Silver E. (1983). Rational number concepts. [Electronic version]. In R. Lesh \& M. Landau (Eds.), Acquisition of Mathematics Concepts and Processess, (pp. 91-125). New York: Academic Press.

Carnevale, A. P., \& Desrochers, D. M. (2003). Standards for what? The economic roots of K-16 reform. [Electronic Version]. Princeton, NJ: Educational Testing Service.

Clements, M. A. (2003). An outsider's view of North American school mathematics curriculum trends. In G. M. A. Stanic \& J. Kilpatrick (Eds.), A History of School Mathematics (Vol. 2, pp. 1509-1580). Reston, VA: National Council of Teachers of Mathematics.

Cohen, A. M., \& Brawer, F. B. (2003). The American community college (4th ed.). San Francisco, CA: Jossey-Bass.

Cohen, J. (1988). Statistical power analysis for the behavioral sciences (2nd ed.). Hillsdale, NJ: Lawrence Erlbaum Associates.

Cohen, P. C. (2003). Numeracy in nineteenth-century America. In G. M. A. Stanic, J. Kilpatrick, W. G. Martin \& D. Schifter (Eds.), A History of School Mathematics (Vol. 1, pp. 43-76). Reston, VA: The National Council of Teachers of Mathematics.

College Entrance Examination Board. (1997). National summary report. New York, NY: The College Board. Retrieved July 13, 2005 from http://www.apcentral.collegeboard.com

----. (2003). National summary report. New York, NY: The College Board. Retrieved July 13, 2005 from http://www.apcentral.collegeboard.com

COMAP. (n.d.) Mathematics: Modeling our World. Retrieved April 17, 2005, from http://www.comap.com/highschool/projects/mmow/arisemmowvision.htm

Conley, D. T. (2003). Understanding university success. Eugene, OR: Center for Educational Policy Research.

Core-Plus Mathematics Project. (n.d.). Retrieved April 12, 2005, from http://www.wmich.edu/cpmp/evaluation.html 
Dillman, D. A. (2000). Mail and internet surveys: The tailored design method (2nd ed.). New York, NY: John Wiley \& Sons, Inc.

Donoghue, E. F. (2003). The emergence of a profession: Mathematics education in the United States, 1890-1920. In G. M. A. Stanic \& J. Kilpatrick (Eds.), A History of School Mathematics (Vol. 1, pp. 159-194). Reston, VA: The National Council of Teachers of Mathematics.

Fey, J. T., \& Graeber, A. O. (2003). From the new math to the agenda for action. In n G. M. A. Stanic \& J. Kilpatrick (Eds.), A History of School Mathematics (Vol. 1, pp. 521-558). Reston, VA: The National Council of Teachers of Mathematics.

Friedman, T. L. (2006). The world is flat: A brief history of the twenty-first century. New York: Farrar, Straus and Giroux.

Garrett, A. W., \& Davis., O. L. (2003). A time of uncertainty and change: School mathematics from World War II until the new math. In G. M. A. Stanic \& J. Kilpatrick (Eds.), A History of School Mathematics (Vol. 1, pp. 493-520). Reston, VA: National Council of Teachers of Mathematics.

Gates, J. D. (2003). Perspective on the recent history of the National Council of Teachers of Mathematics. In G. M. A. Stanic \& J. Kilpatrick (Eds.), A History of School Mathematics (Vol. 1, pp. 737-752). Reston, VA: The National Council of Teachers of Mathematics.

Goldin, C. (2002). American leadership in the human capital century: Have the virtues of the past become the vices of the present? Retrieved July 15, 2005, from http://www.educationnext.org/unabridged/20031/goldin.pdf

Greene, B., Parsad, B., \& Lewis, L. (2003). Remedial education at degree-granting postsecondary institutions in fall 2000. [Electronic Version]. Washington, DC: National Center for Education Statistics.

Hart, L. C. (1999). The status of research on postsecondary mathematics education. Journal on Excellence in College Teaching, 10(2), 3-26.

Herman, J. L., Webb, N., \& Zuniga, S. (2003). Alignment and college admissions; The match of expectations, assessments, and educator perspectives. CSE technical report (Report No. CSE-TR-593). Los Angeles, CA: Institute of Education Science.

Herrera, T. A., \& Owens, D. T. (2001). The 'new new math'?: Two reform movements in mathematics education. Theory Into Practice, 40(2), 84-93. 
Herriott, S. R. (2006). Changes in college algebra. In N. B. Hastings (Ed.), A fresh state for collegiate mathematics rethinking the courses below calculus (pp. 90-100). Washington, DC: The Mathematical Association of America.

It's About Time. (n.d.). MATH connections. Retrieved September 7, 2005, from http://www.its-about-time.com $/ \mathrm{htmls} / \mathrm{mc} /$ mcintroduction.html

Jenkins, D., \& Boswell, K. (2002). State policies on community college remedial education: Findings from a national survey. [Electronic Version]. Center for Community College Policy. Washington, DC: Education Commission of the States.

Jones, P. S. (1972). Historical Background and Founding of the Association. In K. O. May (Ed.), The Mathematical Association of America: Its First Fifty Years (pp. 123). Washington, DC: The Mathematical Association of America.

Jones, P. S., \& Coxford, A. F., Jr. (1970). Mathematics in the Evolving Schools. In P. S. Jones \& J. Arthur F. Coxford (Eds.), A History of Mathematics Education in the United States and Canada Thirty-second Yearbook. Washington, DC: National Council of Teachers of Mathematics.

----. (1970). The Goals of History: Issues and Forces. In P. S. Jones \& A. F. Coxford (Eds.), A History of Mathematics Education in the United States and Canada Thirty-second Yearbook. Washngton, DC: National Council of Teachers of Mathematics.

Kentucky Council on Postsecondary Education. (2006). The preparation of students entering Kentucky's public colleges and universities in 2002 and 2004. Retrieved November 2, 2006, from http://cpe.ky.gov/NR/rdonlyres/E51AB99E-0D2A-409694E3-B2CB99134C21/0/DevelopmentalEducationUpdate20061005.pdf

Kentucky Department of Education . (2006). Retrieved October 25, 2006 from http://www.education.ky.gov/KDE

Kentucky Department of Education. (2006). Core content for mathematics version 4.1. Retrieved August 30, 2006 from http://education.ky.gov/KDE/Instructional+Resources/Curriculum+Documents $+\mathrm{a}$ $\mathrm{nd}+$ Resources/Core + Content + for + Assessment/Core + Content + for + Assessment +4 . $1 /$

-----. (2006). Kentucky core content for assessment. Retrieved October 25, 2006, from http://www.education.ky.gov/KDE/Instructional+Resources/Curriculum+Docume nts+and+Resources/Core+Content+for+Assessment/default.htm

Kentucky Early Mathematics Testing Program. (n.d.). Retrieved April 2, 2005, from http://www.mathclass.org/kemtp-info/ 
Kentucky Education Professional Standards Board. (n.d.). New teacher standards for preparation and certification. Retreived March 20, 2007 from http://www.kyepsb.net/teacherprep/newteachstandards.asp

Key Curriculum Press. (n.d.). Introduction and implementation strategies for the interactive mathematics program: A guide for teacher-leaders and administrators. Retrieved April 12, 2005, from http://www.mathimp.org/general_info/iis.section2_4.html

Kieran, C. (1992). The learning and teaching of school algebra. In D. A. Grouws (Ed.), Handbook of Research on Mathematics Teaching and Learning (pp. 390-419). Reston, VA: The National Council of Teachers of Mathematics.

Kirst, M. W., \& Bracco, K. R. (2004). Bridging the great divide: How the K-12 and postsecondary split hurts students, and what can be done about it. In M. W. Kirst \& A. Venezia (Eds.), From High School to College: Improving Opportunities for Success in Postsecondary Education (pp. 1-30). San Francisco, CA: Jossey-Bass.

Kirst, M. W., Venezia, A., \& Antonio, A. L. (2004). What have we learned, and where do we go next? In M. W. Kirst \& A. Venezia (Eds.), From High School to College: Improving Opportunities for Success in Postsecondary Education (pp. 285-319). San Francisco, CA: Jossey-Bass.

Kliebard, H. M., \& Franklin, B. M. (2003). The ascendance of practical and vocational mathematics, 1893-1945: Academic mathematics under siege. In G. M. A. Stanic \& J. Kilpatrick (Eds.), A History of School Mathematics (Vol. 1, pp. 399-440). Reston, VA: The National Council of Teachers of Mathematics.

Lappan, G., \& Wanko, J. J. (2003). The changing roles and priorities of the federal government in mathematics education in the United States. In G. M. A. Stanic \& J. Kilpatrick (Eds.), A History of School Mathematics (Vol. 2, pp. 897-930). Reston, VA: The National Council of Teachers of Mathematics.

Lawrence, I. M., Rigol, G. W., Essen, T. V., \& Jackson, C. A. (2003). A historical perspective on the content of the SAT. [Electronic Version]. New York, New York: College Entrance Examination Board.

Long, V. M. (2003). The role of state government in the custody battle over mathematics education. In G. M. A. Stanic \& J. Kilpatrick (Eds.), A History of School Mathematics (Vol. 2, pp. 931-956). Reston, VA: The National Council of Teachers of Mathematics.

Lundin, M. A., Oursland, M., Lundgren, M., \& Reilly, M. (2005). Mathematics preparation for college: Some things we learned the hard way, and what we do about them. NCSM Journal of Mathematics Education Leadership, 7(2), 18-23. 
Lutzer, D. J., Maxwell, J. W., Rodi, S. B. (Eds.). (2002). Statistical abstract of undergraduate programs in the mathematics sciences in the United States: Fall 2000 CBMS survey. [Electronic version]. Conference Board of the Mathematical Sciences. American Mathematical Society.

Mathematical Association of America. (2004). (2004). Undergraduate programs and courses in the mathematical sciences: CUPM curriculum guide 2004. $\mathrm{H}$. Pollatsek, W. Barker, D. Bressoud, S. Epp, S. Ganter, \& B. Haver (Eds).Washington, DC.

Mathematically Correct. (n.d.). Retrieved July 16, 2005, from http://www.mathematicallycorrect.com/

Mathematically Sane. (n.d.). Retrieved April 12, 2005, from http://mathematicallysane.com

McLeod, D. B. (2003). From consensus to controversy: The story of the NCTM standards. In G. M. A. Stanic \& J. Kilpatrick (Eds.), A History of School Mathematics (Vol. 1, pp. 753-818). Reston, VA: The National Council of Teachers of Mathematics.

McCutcheon, J. W., \& Franklin, T. (1995/1996). Assessing the technology component of teacher education. Retrieved September 8, 2005, from http://www.ohiou.edu/instres/assessments/97_98assess/dept/educstdy.htm

Merisotis, J. P., \& Phipps, R. A. (2000). Remedial education in colleges and universities: What's really going on? The Review of Higher Education, 24(1), 67-85.

Michalowicz, K. D., \& Howard, A. C. (2003). Pedagogy in text: An analysis of mathematics texts from the nineteenth century. In G. M. A. Stanic \& J. Kilpatrick (Eds.), A History of School Mathematics (Vol. 1, pp. 77-112). Reston, VA: The National Council of Teachers of Mathematics.

Montague, H. F. (1972). The Sections. In K. O. May (Ed.), The Mathematical Association of America: Its First Fifty Years (pp. 78-103). Washington, DC: The Mathematical Association of America.

Nathan, M. J., \& Koedinger, K. R. (2000). Teachers' and researchers' beliefs about the development of algebraic reasoning. Journal for Research in Mathematics Education. 31 (2), 168-190.

National Assessment Governing Board. (2004). Mathematics framework for the 2005 national assessment of educational progress. [Electronic Version]. Washington, DC: U. S. Department of Education. 
National Center for Education Statistics. (2002). The condition of education 2002.

Washington, DC: U.S. Department of Education.

-----. (2003). The condition of education 2003. Washington, DC: U.S. Department of Education.

----. (2004). The condition of education 2004. Washington, DC: U.S. Department of Education.

----. (2005). The condition of education 2005. Washington, DC: U.S. Department of Education.

-----. (2001). The nation's report card: Mathematics highlights 2000. [Electronic Version]. Washington, DC: U.S. Department of Education.

National Commission on Excellence in Education. (1983). A nation at risk: The imperative for educational reform. Washington, DC: U.S. Department of Education. Retrieved March 29, 2005, from http://www.goalline.org/Goal\%20Line/NatAtRisk.html

National Council of Supervisors of Mathematics. (2005). Retrieved July 20, 2005, from http://mathforum.org/ncsm/NCSMOperations/mission.html

National Council of Teachers of Mathematics. (1980). An agenda for action:

Recommendations for school mathematics of the 1980s. Reston, VA: Author.

-----. (1995). Assessment Standards for School Mathematics. Reston, VA: Author.

-----. (1989).Curriculum and evaluation standards for school mathematics. Reston, VA: Author.

-----. (2000). Principles and standards for school mathematics. Reston, VA: Author.

-----. (1981). Priorities in school mathematics: Executive summary of the PRISM project. Reston, VA: Author.

-----. (1991). Professional Standards for Teaching Mathematics. Reston, VA: Author.

National Research Council. Adding it up: Helping children learn mathematics. (2001). J. K. Kilpatrick, J. Swafford, \& B. Findell (Eds.). Washington, DC: National Academy Press.

----. (1989). Everybody counts: A report to the nation on the future of mathematics education. Washington, DC: National Academy of Sciences. 
-----. (2000). How People Learn Brain, Mind, Experience, and School. J. D. Bransford, A. L. Brown, \& R. R. Cocking (Eds.). Washington, DC: The National Academy Press.

-----. (2005). How Students Learn Mathematics in the Classroom. M. S. Donovan and J. D. Bransford (Eds.). Washington, DC: The National Academies Press.

-----. (1991). Moving Beyond Myths. Washington, DC: The National Academy Press.

Nunley, C. R. (1998). Report of the remedial education subcommittee, Maryland partnership for teaching and learning K-16 work group. Retrieved August 5, 2005, from http://mdk16.usmd.edu/images/files/Final_Report_of_the_Remedial_Education_S ubcommittee.pdf

Nunnally, J. C. (1978). Psychometric theory Second Edition. New York, NY: McGrawHill.

Osborne, A. R., \& Crosswhite, F. J. (1970). Forces and Issues Related to Curriculum and Instruction, 7-12. In P. S. Jones \& J. A. F. Coxford, Jr. (Eds.), A History of Mathematics Education in the United States and Canada Thirty-second Yearbook. Washington, DC: National Council of Teachers of Mathematics.

Parshall, K. H. (2003). Historical contours of the American mathematical research community. In G. M. A. Stanic \& J. Kilpatrick (Eds.), A History of School Mathematics (Vol. 1, pp. 113-157). Reston, VA: The National Council of Teachers of Mathematics.

Phipps, R. (1998). College remediation: What it is, what is costs, what's at stake. [Electronic Version]. Washington, DC: The Institute for Higher Education Policy.

-----. (2006, October 7). Many still unprepared for college. The Courier-Journal, p. A1.

Post, T. R., Behr, M. J., Lesh, R., \& Wachsmuth, I. (2005). Selected results from the rational number project. Retrieved March 28, 2005, from http://education.umn.edu/rationalnumberproject/86_4.html

RAND Mathematics Study Panel. (2003). Mathematical proficiency for all students: Towards a strategic research and development program in mathematics education. [Electronic Version]. D. L. Ball, (Chair).Washington, DC.

Ronau, R.N., Seif, S., \& Jones, J. H. (2001, September). Building bridges to connect high school and college mathematics: Improving the transitions for students. Paper presented at the meeting of the Kentucky Council of Teachers of Mathematics, Owensboro, KY. 
Ronau, R. N, \& Jones, J. H. (2003). Building bridges from high school to college mathematics. Unpublished manuscript, University of Louisville.

Rudolph, F. (1990). The American college \& university. Athens, GA: The University of Georgia Press.

School Science and Mathematics Association. (n.d.) Retrieved July 20, 2005 from http://www.ssma.org/mission.html

Seeley, C. L. (2003). Mathematics textbook adoption in the United States. In G. M. A. Stanic \& J. Kilpatrick (Eds.), A History of School Mathematics (Vol. 2, pp. 957988). Reston, VA: The National Council of Teachers of Mathematics.

SIMMS integrated mathematics. (n.d.). Retrieved April 12, 2005, from http://www.montana.edu/wwwsimms/descript.html

Small, D. (2006). College algebra: A course in crisis. In N. B. Hastings (Ed.), A fresh state for collegiate mathematics: Rethinking the courses below calculus (pp. 8389). Washington, DC: The Mathematical Association of America.

South Carolina Commission on Higher Education. (1999). Great expectations mathematics report: Recommendations for a successful first year of postsecondary mathematics. [Electronic version]. Rock Hill, SC: Winthrop University, Department of Mathematics.

Southern Regional Education Board. (2000). Reducing remedial education: What progress are states making? [Electronic version] Atlanta, GA: Author.

Steen, L. A. (2004). Achieving quantitative literacy: An urgent challenge for higher education. Washington, DC: The Mathematical Association of America.

Stevens, J. P. (2002). Applied multivariate statistics for the social sciences (4th ed.). Mahwah, NJ: Lawrence Erlbaum Associates.

Thompson, A. G. (1984). The relationship of teachers' conceptions of mathematics and mathematics teaching to instructional practice. Educational Studies in Mathematics, 15, 105-127.

-----. (1992). Teachers' beliefs and conceptions: A synthesis of the research. In D. A. Grouws (Ed.), Handbook of Research on Mathematics Teaching and Learning (pp. 127-146). Reston, VA: The National Council of Teachers of Mathematics.

TIMSS International Study Center. (1998, February). TIMSS highlights. [Electronic Version]. Chestnut Hill, MA: Boston College. 
U.S. Department of Education. (2001). No child left behind: Executive summary. Retrieved April 18, 2005, from http://www.ed.gov/print/nclb/overview/intro/execsumm.html

Usiskin, Z. (2001). High school overview and the transition to college. Retrieved April 10, 2003, from http://www.oswego.edu/nsf-precalc/Zal\%20Usiskin\%20$\% 20$ revised\%2012_21_01.pdf

(2003). A personal history of the UCSMP secondary school curriculum, 1960-1999. In G. M. A. Stanic \& J. Kilpatrick (Eds.), A History of School Mathematics (Vol. 1, pp. 673-736). Reston, VA: The National Council of Teachers.

-----. (2005). Should all students learn a significant amount of algebra? In C. Greenes \& C. Findell (Eds.), Developing Students' Algebraic Reasoning Abilities (pp. 4-16). Lakewood, CO: National Council of Supervisors of Mathematics.

Veterans Administration. (n.d.). GI bill history. Retrieved June 4, 2005, from http://www.gibill.va.gov/education/GI_Bill.htm

Willoughby, S. S. (2000). Perspectives on mathematics education. In M. J. Burke \& F. R. Curcio (Eds.), Learning Mathematics for a New Century, 2000 Yearbook (pp. 115). Reston, VA: The National Council of Teachers of Mathematics. 


\section{APPENDIX A}

\section{PRE-NOTICE LETTER}

March, 2006

Dear Colleague:

A few days from now you will receive in the mail an invitation to complete a survey for my dissertation research in the College of Education and Human Development at the University of Louisville.

The survey is about the perceptions secondary and postsecondary mathematics instructors have regarding student learning in algebra classes using the algebra benchmarks developed by the American Diploma Project (ADP). Kentucky is one of the partner states that worked with ADP to develop these benchmarks.

I am writing in advance so that you will know ahead of time you will be contacted to complete the survey. The study is important because it will inform secondary and postsecondary education planners as they work together to align mathematics content so that all of our students will have the opportunity to be successful in their secondary and postsecondary training.

Thank you for your time. It's only with the help of people like you that our research can be successful.

Sincerely,

Jane H. Jones

Doctoral Candidate

University of Louisville

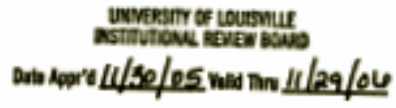




\section{APPENDIX B}

\section{SURVEY COVER LETTER}

March, 2006

We are writing to ask for your help in a study of secondary and postsecondary instructors' perceptions of student learning in algebra classes in secondary and postsecondary classes.

We have randomly selected secondary, two-year college and university mathematics instructors in Kentucky to ask how well they think students are learning algebra benchmarks that were developed by the America Diploma Project.

Results from the survey will be used to inform discussions between secondary and postsecondary education planners as they make mathematics content decisions that will affect instruction and student learning in Kentucky's secondary and postsecondary institutions.

Your answers are completely confidential and will be used only in summaries in which no individual's answers can be identified. When you return your completed survey your name will be deleted from the mailing list and never connected to your answers in any way. This survey is voluntary. However, you can help us very much by taking a few minutes to share your perceptions about student learning in algebra classes even if you have little or no personal knowledge of the student learning taking place in a given environment. If for some reason you prefer not to respond, please let us know by returning the blank survey in the enclosed stamped envelope.

The letter at the beginning of the survey provides more information about your being a participant in this study with contact information if you have additional questions.

Thanks you very much for helping with this important study.

Sincerely,

Robert N. Ronau

Associate Dean of Research

College of Education and Human Development

University of Louisville
Jane H. Jones

Doctoral Candidate

University of Louisville

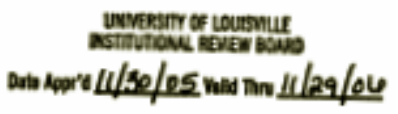




\section{APPENDIX C \\ REMINDER POSTCARD SPRING}

May, 2006

Last week a survey asking for your perceptions of student learning in secondary and postsecondary algebra classes was mailed to you.

If you have already completed and returned the survey to us, thank you very much for your consideration and time. If not, please do so today. We are especially grateful for your help because it is only by asking mathematics instructors like you to share your perceptions that we can understand how well students are learning algebra content in our secondary and postsecondary classes.

Robert N. Ronau

Associate Dean of Research

College of Education and Human Development

University of Louisville
Jane H. Jones

Doctoral Candidate

University of Louisville

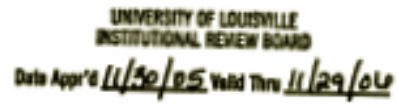




\section{APPENDIX D \\ REPLACEMENT SURVEY COVER LETTER}

June, 2006

Dear Colleague:

In late spring I sent a survey to you that asked for your perceptions of student learning in secondary and postsecondary algebra classes. My records show that your survey has not yet been returned.

We are writing again because of the importance your data has for helping to get accurate results. Although we sent surveys to secondary and postsecondary instructors throughout the region, it's only by hearing from nearly everyone in the sample that we can be sure our results are truly representative of the opinions of mathematics faculty in Kentucky.

If you are returning to school after the summer break, it is not too late for you to complete the survey, or if you are receiving this letter because you are replacing the person to whom it is addressed, we invite you to complete the survey in their stead. We hope that you will fill out and return the enclosed survey soon, but if for any reason you prefer not to answer it, please let us know by returning a note or blank survey in the enclosed stamped envelope.

Sincerely,

Robert N. Ronau

Associate Dean of Research

College of Education and Human Development

University of Louisville
Jane H. Jones

Doctoral Candidate

University of Louisville

\section{UNIVERSITY OF LOUISVILLE \\ INSTITUTIONAL REVIEW BOARD \\ Date Appr'd $6 / 5 / 06$ Valid Thru $11 / 29 / 06$}




\section{APPENDIX E \\ REPLACEMENT POSTCARD FALL}

October, 2006

In late summer a survey asking for your perceptions of student learning in secondary and postsecondary algebra classes was mailed to you.

If you have already completed and returned the survey to us, thank you very much for your consideration and time. If you have been unable to complete the survey, please consider doing so now. We understand you may feel unqualified to answer questions about student learning in institutions outside your experience. However, your perceptions would still be valuable for this study.

We are grateful for your help because it is only by asking mathematics instructors like you to share your perceptions that we can understand how well students are learning algebra content in our secondary and postsecondary classes.

Robert N. Ronau, Associate Dean of Research Jane H. Jones College of Education and $\mathrm{P}$ mand University of Louisville

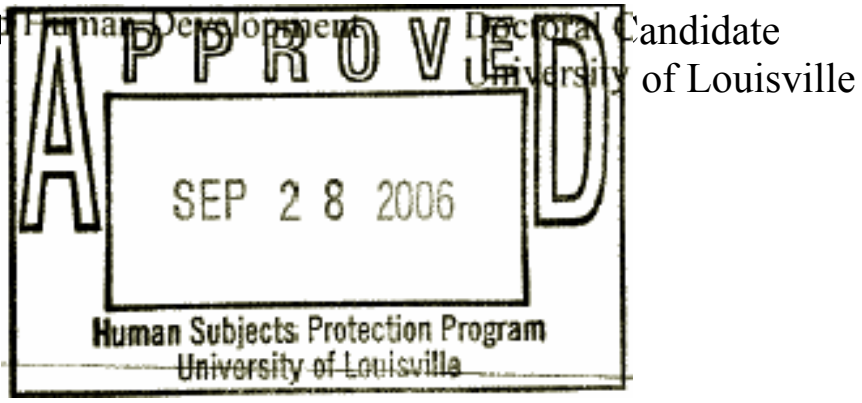




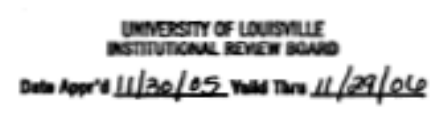

\section{APPENDIX F \\ LETTER OF CONSENT}

March, 2006

Instructor Perceptions of Student Learning in Secondary and Postsecondary Algebra Classes

\section{Dear Colleague:}

You are being invited to participate in a research study by answering the attached survey about algebra content students learn in high school, non-credit bearing college, and credit bearing college classes. There are no known risks for your participation in this research study. The information collected may not benefit you directly. The information learned in this study may be helpful to others. The information you provide will inform discussions regarding algebra content alignment between secondary and postsecondary institutions. Your completed survey will be stored at the College of Education and Human Development at the University of Louisville. The survey will take approximately 20 minutes time to complete.

Individuals from the department of Teaching and Learning in the College of Education and Human Development at the University of Louisville, the Institutional Review Board (IRB), the Human Subjects Protection Program Office (HSPPO), and other regulatory agencies may inspect these records. In all other respects, however, the data will be held in confidence to the extent permitted by law. Should the data be published, your identity will not be disclosed.

Taking part in this study is voluntary. By completing this survey you agree to take part in this research. You do not have to answer any questions that make you uncomfortable. You may choose not to take part at all. If you decide to be in this study you may stop taking part at any time. If you decide not to be in this study or if you stop taking part at any time, you will not lose any benefits for which you may qualify.

If you have any questions, concerns, or complaints about this research study, please contact Bob Ronau at 502-852-0593 or Jane Jones at 502-228-5633.

If you have any questions about your rights as a research subject, you may call the Human Studies Protection Program Office at 502-852-5188. You can discuss any questions about your rights as a research subject, in private, with a member of the Institutional Review Board (IRB). You may also call this number if you have other questions about the research, and you cannot reach the study researchers, or want to talk to someone else. The IRB is an independent committee made up of people from the University community, staff of the institutions, as well as people from the community not connected with these institutions. The IRB has reviewed this study.

If you have concerns or complaints about the research or research staff and you do not wish to give your name, you may call 1-877-852-1167. This is a 24 hour hot line answered by people who do not work at the University of Louisville.

Sincerely,

Robert N. Ronau, PhD

Associate Dean for Research

College of Education and Human Development

University of Louisville
Jane $\mathrm{H}$. Jones

Doctoral Candidate

University of Louisville 


\section{APPENDIX G}

\section{SURVEY INSTRUMENT}

\section{High School and College Algebra Survey}

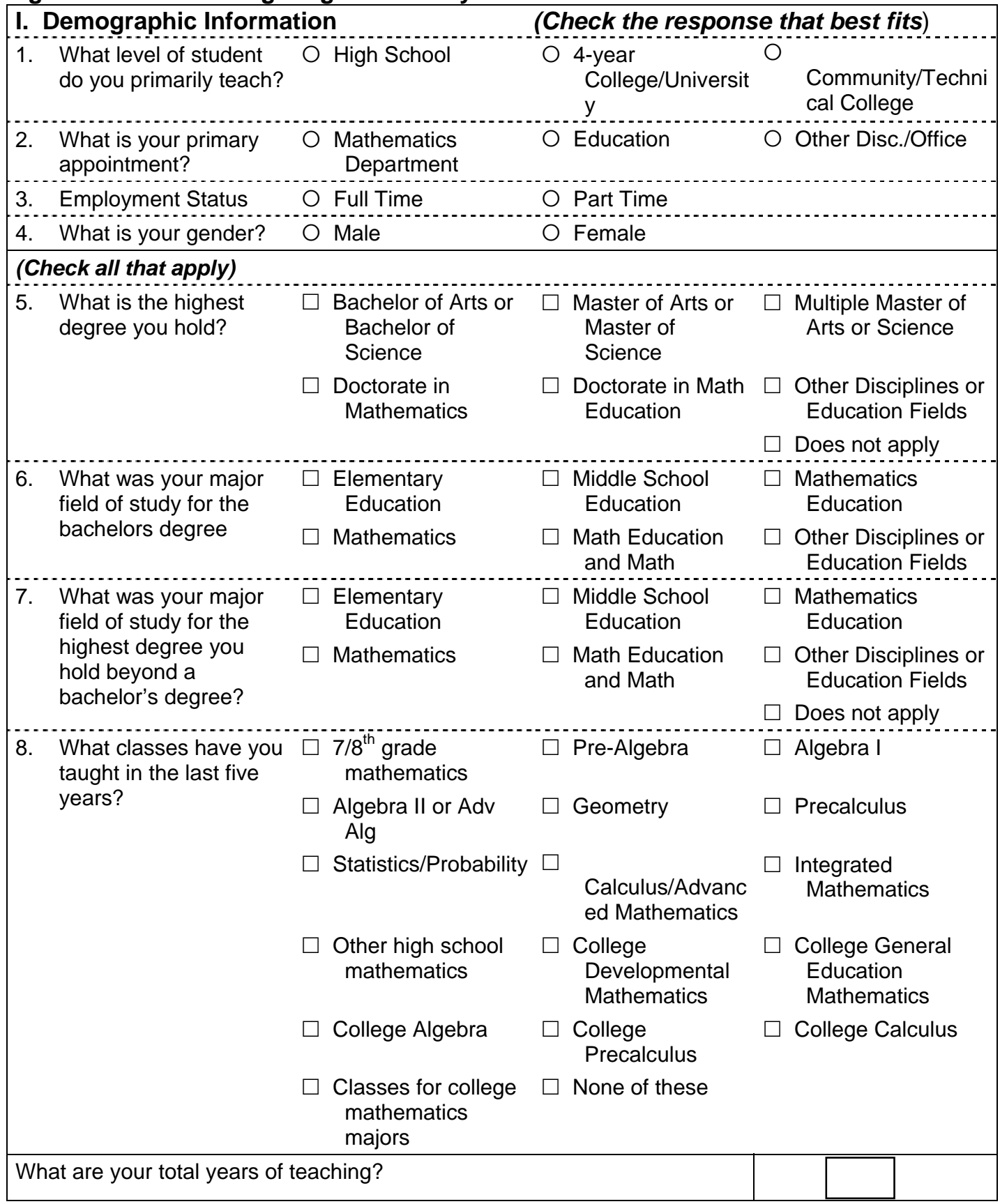


9. Number of years teaching per grade level (check all that best describe your teaching experience)

\begin{tabular}{|l|l|l|l|l|l|}
\hline & $<1$ & $1-3$ & $4-10$ & $11-20$ & $20+$ \\
\hline Early Childhood & & & & & \\
\hline Elementary School & & & & & \\
\hline Middle School & & & & & \\
\hline Secondary School & & & & & \\
\hline Two Year College & & & & & \\
\hline Four Year College/ University & & & & & \\
\hline
\end{tabular}

\section{Perceptions of Levels of Learning Expectations for Students in Algebra}

The term 'remedial' is used in this survey to best assure clarity of the type of classes targeted.

Please indicate your perceptions of the level of learning attained by students for each of the content topics listed below by circling the appropriate response using the specified codes.

\begin{tabular}{|c|c|c|c|c|c|c|c|c|c|c|c|c|c|c|c|c|}
\hline $1=$ Not At All & \multicolumn{3}{|c|}{2 = Very Little } & \multicolumn{4}{|c|}{3 = Some } & \multicolumn{4}{|c|}{$4=$ Well } & \multicolumn{5}{|c|}{$5=$ Very Well } \\
\hline \multicolumn{2}{|c|}{$\begin{array}{l}\text { Circle the number that best } \\
\text { describes your opinion about } \\
\text { student performance on algebra } \\
\text { topics. }\end{array}$} & \multicolumn{5}{|c|}{$\begin{array}{l}\text { How well do } \\
\text { students typically } \\
\text { learn this topic in } \\
\text { high school } \\
\text { classes? }\end{array}$} & \multicolumn{5}{|c|}{$\begin{array}{l}\text { How well do } \\
\text { students typically } \\
\text { learn this topic in } \\
\text { remedial college } \\
\text { classes? }\end{array}$} & \multicolumn{5}{|c|}{$\begin{array}{l}\text { How well do } \\
\text { students typically } \\
\text { learn this topic in } \\
\text { college level algebra } \\
\text { classes? }\end{array}$} \\
\hline \multicolumn{2}{|c|}{$\begin{array}{l}\text { 10. Solve systems of two linear } \\
\text { equations in two variables }\end{array}$} & 1 & & 3 & 4 & 5 & 1 & 2 & 3 & 4 & 5 & 1 & 2 & 3 & 4 & 5 \\
\hline \multicolumn{2}{|c|}{$\begin{array}{l}\text { 11. Solve systems of three linear } \\
\text { equations in three variables }\end{array}$} & 1 & & 3 & 4 & 5 & 1 & 2 & 3 & 4 & 5 & 1 & 2 & 3 & 4 & 5 \\
\hline \multicolumn{2}{|c|}{$\begin{array}{l}\text { 12. Recognize and solve } \\
\text { problems that can be } \\
\text { modeled using a linear } \\
\text { equation in one variable, } \\
\text { such as time/rate/distance } \\
\text { problems, percentage } \\
\text { increase or decrease } \\
\text { problems, and ratio and } \\
\text { proportion problems }\end{array}$} & 1 & & 3 & 4 & 5 & 1 & 2 & 3 & 4 & 5 & 1 & 2 & 3 & 4 & 5 \\
\hline \multicolumn{2}{|c|}{$\begin{array}{l}\text { 13. Graph the solution set of a } \\
\text { system of two or three linear } \\
\text { inequalities }\end{array}$} & 1 & & 3 & 4 & 5 & 1 & 2 & 3 & 4 & 5 & 1 & 2 & 3 & 4 & 5 \\
\hline \multicolumn{2}{|c|}{$\begin{array}{l}\text { 14. Recognize and solve } \\
\text { problems that can be } \\
\text { modeled using a quadratic } \\
\text { equation, such as the motion } \\
\text { of an object under the force } \\
\text { of gravity }\end{array}$} & 1 & & 3 & 4 & 5 & 1 & 2 & 3 & 4 & 5 & 1 & 2 & 3 & 4 & 5 \\
\hline \multicolumn{2}{|c|}{$\begin{array}{l}\text { 15. Divide a polynomial by a low- } \\
\text { degree polynomial }\end{array}$} & 1 & 2 & 3 & 4 & 5 & 1 & 2 & 3 & 4 & 5 & 1 & 2 & 3 & 4 & 5 \\
\hline \multicolumn{2}{|c|}{$\begin{array}{l}\text { 16. Combine functions by } \\
\text { composition }\end{array}$} & 1 & & 3 & 4 & 5 & 1 & 2 & 3 & 4 & 5 & 1 & 2 & 3 & 4 & 5 \\
\hline
\end{tabular}




\begin{tabular}{|c|c|c|c|c|c|c|c|c|c|c|c|c|c|c|c|c|}
\hline $1=$ Not At All & $2=$ Very Lit & & & $3=$ & on & & & & $=\mathrm{W}$ & & & & V & $y \mathrm{~V}$ & & \\
\hline $\begin{array}{l}\text { Circle the numb } \\
\text { describes your } \\
\text { student perform } \\
\text { topics. }\end{array}$ & $\begin{array}{l}\text { at best } \\
\text { on about } \\
\text { on algebra }\end{array}$ & & $\begin{array}{l}\text { Ho } \\
\text { ude } \\
\text { arn } \\
\text { hig }\end{array}$ & $\begin{array}{l}\text { w we } \\
\text { hts t } \\
\text { this } \\
\text { h sc } \\
\text { asse }\end{array}$ & $\begin{array}{l}\text { pice } \\
\text { bpic } \\
\text { ool } \\
\text { s? }\end{array}$ & & & $\begin{array}{l}\text { Hc } \\
\text { tude } \\
\text { earn } \\
\text { eme }\end{array}$ & $\begin{array}{l}\text { his } \\
\text { lial }\end{array}$ & $\begin{array}{l}\text { opic } \\
\text { olle }\end{array}$ & & & & $\begin{array}{l}\text { its } \\
\text { his } \\
\text { lev } \\
\text { ass }\end{array}$ & & \\
\hline 17. Graph a que & tic function & 1 & 2 & 3 & 4 & 5 & 1 & 2 & 3 & 4 & 5 & 1 & 2 & 3 & 4 & 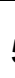 \\
\hline $\begin{array}{l}\text { 18. Identify prop } \\
\text { that provide } \\
\text { information } \\
\text { problem }\end{array}$ & $\begin{array}{l}\text { es of a graph } \\
\text { utul } \\
\text { ut the original }\end{array}$ & 1 & & 3 & 4 & 5 & 1 & 2 & 3 & 4 & 5 & 1 & 2 & 3 & 4 & 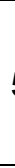 \\
\hline $\begin{array}{l}\text { 19. Identify whe } \\
\text { set of the gr } \\
\text { inequality is } \\
\text { closed half- }\end{array}$ & $\begin{array}{l}\text { the solution } \\
\text { of a linear } \\
\text { open or a } \\
\text { e }\end{array}$ & 1 & & 3 & 4 & 5 & 1 & 2 & 3 & 4 & 5 & 1 & 2 & 3 & 4 & 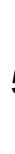 \\
\hline $\begin{array}{l}\text { 20. Graph ellips } \\
\text { hyperbolas } \\
\text { parallel to th }\end{array}$ & $\begin{array}{l}\text { and } \\
\text { se axes are } \\
\text { and y axes }\end{array}$ & 1 & & 3 & 4 & 5 & 1 & 2 & 3 & 4 & 5 & 1 & 2 & 3 & 4 & 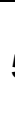 \\
\hline $\begin{array}{l}\text { 21. Understand } \\
\text { integer exp }\end{array}$ & $\begin{array}{l}\text { properties of } \\
\text { ts and roots }\end{array}$ & 1 & & 3 & 4 & 5 & 1 & 2 & 3 & 4 & 5 & 1 & 2 & 3 & 4 & 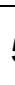 \\
\hline $\begin{array}{l}\text { 22. Recognize } \\
\text { problems th } \\
\text { modeled us } \\
\text { exponential }\end{array}$ & $\begin{array}{l}\text { solve } \\
\text { an be } \\
\text { an } \\
\text { ction }\end{array}$ & 1 & 2 & 3 & 4 & 5 & 1 & 2 & 3 & 4 & 5 & 1 & 2 & 3 & 4 & 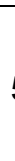 \\
\hline $\begin{array}{l}\text { 23. Recognize } \\
\text { relationship } \\
\text { symbolic for }\end{array}$ & $\begin{array}{l}\text { her a } \\
\text { en in } \\
\text { a function }\end{array}$ & 1 & 2 & 3 & 4 & 5 & 1 & 2 & 3 & 4 & 5 & 1 & 2 & 3 & 4 & 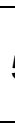 \\
\hline $\begin{array}{l}\text { 24. Identify whe } \\
\text { has an inve }\end{array}$ & a function & 1 & 2 & 3 & 4 & 5 & 1 & 2 & 3 & 4 & 5 & 1 & 2 & 3 & 4 & 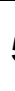 \\
\hline $\begin{array}{l}\text { 25. Evaluate ex } \\
\text { containing } r \\
\text { absolute va } \\
\text { values of th }\end{array}$ & $\begin{array}{l}\text { sions } \\
\text { als and } \\
\text { at specified } \\
\text { ariables }\end{array}$ & 1 & 2 & 3 & 4 & 5 & 1 & 2 & 3 & 4 & 5 & 1 & 2 & 3 & 4 & \\
\hline 26. Factor quad & polynomials & 1 & 2 & 3 & 4 & 5 & 1 & 2 & 3 & 4 & 5 & 1 & 2 & 3 & 4 & 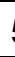 \\
\hline $\begin{array}{l}\text { 27. Recognize } \\
\text { problems th } \\
\text { modeled us } \\
\text { exponential } \\
\text { whose solut } \\
\text { facility with } \\
\text { as exponen } \\
\text { decay probl }\end{array}$ & $\begin{array}{l}\text { solve } \\
\text { an be } \\
\text { an } \\
\text { ction but } \\
\text { requires } \\
\text { rithms, such } \\
\text { growth and }\end{array}$ & 1 & 2 & 3 & 4 & 5 & 1 & 2 & 3 & 4 & 5 & 1 & 2 & 3 & 4 & 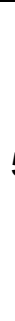 \\
\hline 28. Understand & ction notation & 1 & 2 & 3 & 4 & 5 & 1 & 2 & 3 & 4 & 5 & 1 & 2 & 3 & 4 & \\
\hline $\begin{array}{l}\text { 29. Use multipl } \\
\text { (literal, sym } \\
\text { represent } \\
\text { solutions }\end{array}$ & $\begin{array}{l}\text { oresentations } \\
\text { ems and }\end{array}$ & 1 & 2 & 3 & 4 & 5 & 1 & 2 & 3 & 4 & 5 & 1 & 2 & 3 & 4 & \\
\hline $\begin{array}{l}\text { 30. Determine } t \\
\text { function in } g\end{array}$ & $\begin{array}{l}\text { lomain of a } \\
\text { hical form }\end{array}$ & 1 & 2 & 3 & 4 & 5 & 1 & 2 & 3 & 4 & 5 & 1 & 2 & 3 & 4 & \\
\hline
\end{tabular}




\begin{tabular}{|c|c|c|c|c|c|c|c|c|c|c|c|c|c|c|c|c|}
\hline \multirow{2}{*}{\multicolumn{2}{|c|}{$\begin{array}{l}\mathbf{1}=\text { Not At All } \\
\begin{array}{l}\text { Circle the number that best } \\
\text { describes your opinion about } \\
\text { student performance on algebra } \\
\text { topics. }\end{array}\end{array}$}} & & \multicolumn{5}{|c|}{$3=$ Some } & \multicolumn{4}{|c|}{$4=$ Well } & \multirow{2}{*}{\multicolumn{5}{|c|}{$\begin{array}{c}\mathbf{5}=\text { Very Well } \\
\text { How well do } \\
\text { students typically } \\
\text { learn this topic in } \\
\text { college level algebra } \\
\text { classes? }\end{array}$}} \\
\hline & & \multicolumn{5}{|c|}{$\begin{array}{l}\text { How well do } \\
\text { students typically } \\
\text { learn this topic in } \\
\text { high school } \\
\text { classes? }\end{array}$} & \multicolumn{5}{|c|}{$\begin{array}{l}\text { How well do } \\
\text { students typically } \\
\text { learn this topic in } \\
\text { remedial college } \\
\text { classes? }\end{array}$} & & & & & \\
\hline \multicolumn{2}{|c|}{$\begin{array}{l}\text { 31. Understand the role of } \\
\text { definitions, proofs, and } \\
\text { counterexamples in } \\
\text { mathematical reasoning and } \\
\text { construct simple proofs }\end{array}$} & 1 & 2 & 3 & 4 & 5 & 1 & 2 & 3 & 4 & 5 & 1 & 2 & 3 & 4 & 5 \\
\hline \multicolumn{2}{|c|}{$\begin{array}{l}\text { 32. Explain why the graph of a } \\
\text { function and its inverse are } \\
\text { reflections of one another } \\
\text { over the line } y=x\end{array}$} & 1 & 2 & 3 & 4 & 5 & 1 & 2 & 3 & 4 & 5 & 1 & 2 & 3 & 4 & 5 \\
\hline \multicolumn{2}{|c|}{$\begin{array}{l}\text { 33. Solve an equation involving } \\
\text { several variables for one } \\
\text { variable in terms of the } \\
\text { others }\end{array}$} & 1 & 2 & 3 & 4 & 5 & 1 & 2 & 3 & 4 & 5 & 1 & 2 & 3 & 4 & 5 \\
\hline \multicolumn{2}{|c|}{$\begin{array}{l}\text { 34. Understand the relationship } \\
\text { between the coefficients of a } \\
\text { linear equation and the slope } \\
\text { and } x \text { - and } y \text {-intercepts of its } \\
\text { graph }\end{array}$} & 1 & 2 & 3 & 4 & 5 & 1 & 2 & 3 & 4 & 5 & 1 & 2 & 3 & 4 & 5 \\
\hline \multicolumn{2}{|c|}{$\begin{array}{l}\text { 35. Apply the properties of } \\
\text { integer exponents and roots } \\
\text { to simplify algebraic } \\
\text { expressions }\end{array}$} & 1 & 2 & 3 & 4 & 5 & 1 & 2 & 3 & 4 & 5 & 1 & 2 & 3 & 4 & 5 \\
\hline \multicolumn{2}{|c|}{$\begin{array}{l}\text { 36. Add, subtract, multiply, and } \\
\text { divide rational expressions }\end{array}$} & 1 & 2 & 3 & 4 & 5 & 1 & 2 & 3 & 4 & 5 & 1 & 2 & 3 & 4 & 5 \\
\hline \multicolumn{2}{|c|}{$\begin{array}{l}\text { 37. Add, subtract and multiply } \\
\text { polynomials }\end{array}$} & 1 & 2 & 3 & 4 & 5 & 1 & 2 & 3 & 4 & 5 & 1 & 2 & 3 & 4 & 5 \\
\hline \multicolumn{2}{|c|}{$\begin{array}{l}\text { 38. Recognize and solve } \\
\text { problems that can be } \\
\text { modeled using a finite } \\
\text { geometric series, such as } \\
\text { home mortgage problems } \\
\text { and other compound interest } \\
\text { problems }\end{array}$} & 1 & 2 & 3 & 4 & 5 & 1 & 2 & 3 & 4 & 5 & 1 & 2 & 3 & 4 & 5 \\
\hline \multicolumn{2}{|c|}{$\begin{array}{l}\text { 39. Combine functions by } \\
\text { addition, subtraction, } \\
\text { multiplication and division }\end{array}$} & 1 & 2 & 3 & 4 & 5 & 1 & 2 & 3 & 4 & 5 & 1 & 2 & 3 & 4 & 5 \\
\hline \multicolumn{2}{|c|}{$\begin{array}{l}\text { 40. Evaluate a function at a } \\
\text { specified point in its domain }\end{array}$} & 1 & 2 & 3 & 4 & 5 & 1 & 2 & 3 & 4 & 5 & 1 & 2 & 3 & 4 & 5 \\
\hline \multicolumn{2}{|c|}{$\begin{array}{l}\text { 41. Use the formulas for the } \\
\text { general term and } \\
\text { summation of finite } \\
\text { arithmetic and geometric } \\
\text { series }\end{array}$} & 1 & 2 & 3 & 4 & 5 & 1 & 2 & 3 & 4 & 5 & 1 & 2 & 3 & 4 & 5 \\
\hline \multicolumn{2}{|l|}{$\begin{array}{l}\text { 42. Solve linea } \\
\text { variable }\end{array}$} & 1 & 2 & 3 & 4 & 5 & 1 & 2 & 3 & 4 & 5 & 1 & 2 & 3 & 4 & 5 \\
\hline
\end{tabular}




\begin{tabular}{|c|c|c|c|c|c|c|c|c|c|c|c|c|c|c|c|c|}
\hline \multirow{2}{*}{\multicolumn{2}{|c|}{$\begin{array}{l}\mathbf{1}=\text { Not At All } \quad \mathbf{2}=\text { Very Litt } \\
\begin{array}{l}\text { Circle the number that best } \\
\text { describes your opinion about } \\
\text { student performance on algebra } \\
\text { topics. }\end{array}\end{array}$}} & & & \multicolumn{4}{|c|}{$3=$ Some } & \multicolumn{4}{|c|}{$4=$ Well } & \multirow{2}{*}{\multicolumn{5}{|c|}{$\begin{array}{c}5=\text { Very Well } \\
\text { How well do } \\
\text { students typically } \\
\text { learn this topic in } \\
\text { college level algebra } \\
\text { classes? }\end{array}$}} \\
\hline & & \multicolumn{5}{|c|}{$\begin{array}{l}\text { How well do } \\
\text { students typically } \\
\text { learn this topic in } \\
\text { high school } \\
\text { classes? }\end{array}$} & \multicolumn{5}{|c|}{$\begin{array}{l}\text { How well do } \\
\text { students typically } \\
\text { learn this topic in } \\
\text { remedial college } \\
\text { classes? }\end{array}$} & & & & & \\
\hline 43. Graph a line & quation & 1 & 2 & 3 & 4 & 5 & 1 & 2 & 3 & 4 & 5 & 1 & 2 & 3 & 4 & 5 \\
\hline $\begin{array}{l}\text { 44. Solve linear } \\
\text { one variable }\end{array}$ & qualities in & 1 & & 3 & 4 & 5 & 1 & 2 & 3 & 4 & 5 & 1 & 2 & 3 & 4 & 5 \\
\hline $\begin{array}{l}\text { 45. Distinguish } \\
\text { irrelevant in } \\
\text { identifying } \\
\text { information, } \\
\text { finding what } \\
\text { making app } \\
\text { estimates. }\end{array}$ & $\begin{array}{l}\text { vant from } \\
\text { lation, } \\
\text { ing } \\
\text { either } \\
\text { leeded or } \\
\text { late }\end{array}$ & 1 & & 3 & 4 & 5 & 1 & 2 & 3 & 4 & 5 & 1 & 2 & 3 & 4 & 5 \\
\hline $\begin{array}{l}\text { 46. Recognize } \\
\text { relationship } \\
\text { graphical fo }\end{array}$ & $\begin{array}{l}\text { ther a } \\
\text { en in } \\
\text { s a function }\end{array}$ & 1 & & 3 & 4 & 5 & 1 & 2 & 3 & 4 & 5 & 1 & 2 & 3 & 4 & 5 \\
\hline $\begin{array}{l}\text { 47. Solve linear } \\
\text { inequalities } \\
\text { involving the } \\
\text { of a linear fo }\end{array}$ & $\begin{array}{l}\text { lations and } \\
\text { ne variable } \\
\text { solute value } \\
\text { on }\end{array}$ & 1 & & 3 & 4 & 5 & 1 & 2 & 3 & 4 & 5 & 1 & 2 & 3 & 4 & 5 \\
\hline $\begin{array}{l}\text { 48. Solve quadr } \\
\text { one variable }\end{array}$ & equations in & 1 & 2 & 3 & 4 & 5 & 1 & 2 & 3 & 4 & 5 & 1 & 2 & 3 & 4 & 5 \\
\hline $\begin{array}{l}\text { 49. Derive the } \mathrm{f} \\
\text { general tern } \\
\text { of finite arith } \\
\text { geometric } \mathrm{s}\end{array}$ & $\begin{array}{l}\text { ulas for the } \\
\text { d summation } \\
\text { tic and } \\
\text { s }\end{array}$ & 1 & 2 & 3 & 4 & 5 & 1 & 2 & 3 & 4 & 5 & 1 & 2 & 3 & 4 & 5 \\
\hline $\begin{array}{l}\text { 50. Find the sur } \\
\text { geometric } \mathrm{s} \\
\text { common rat } \\
\text { interval }(-1,1\end{array}$ & $\begin{array}{l}\text { an infinite } \\
\text { s whose } \\
\text {, is in the }\end{array}$ & 1 & & 3 & 4 & 5 & 1 & 2 & 3 & 4 & 5 & 1 & 2 & 3 & 4 & 5 \\
\hline $\begin{array}{l}\text { 51. Use inductiv } \\
\text { reasoning to } \\
\text { conclusions }\end{array}$ & $\begin{array}{l}\text { nd deductive } \\
\text { ive at valid }\end{array}$ & 1 & 2 & 3 & 4 & 5 & 1 & 2 & 3 & 4 & 5 & 1 & 2 & 3 & 4 & 5 \\
\hline $\begin{array}{l}\text { 52. Demonstrat } \\
\text { of the relatio } \\
\text { the standaro } \\
\text { of ellipses a } \\
\text { and their gra } \\
\text { characteristi }\end{array}$ & $\begin{array}{l}\text { derstanding } \\
\text { ip between } \\
\text { yebraic form } \\
\text { nyperbolas } \\
\text { cal }\end{array}$ & 1 & 2 & 3 & 4 & 5 & 1 & 2 & 3 & 4 & 5 & 1 & 2 & 3 & 4 & 5 \\
\hline $\begin{array}{l}\text { 53. Understand } \\
\text { rational exp }\end{array}$ & $\begin{array}{l}\text { properties of } \\
\text { nts }\end{array}$ & 1 & 2 & 3 & 4 & 5 & 1 & 2 & 3 & 4 & 5 & 1 & 2 & 3 & 4 & 5 \\
\hline $\begin{array}{l}\text { 54. Evaluate po } \\
\text { rational expı } \\
\text { specified va } \\
\text { variables }\end{array}$ & $\begin{array}{l}\text { smial and } \\
\text { sions at } \\
\text { s of their }\end{array}$ & & 2 & 3 & 4 & 5 & 1 & 2 & 3 & 4 & 5 & 1 & 2 & 3 & 4 & 5 \\
\hline
\end{tabular}




\begin{tabular}{|c|c|c|c|c|c|c|c|c|c|c|c|c|c|c|c|c|}
\hline \multirow{2}{*}{\multicolumn{2}{|c|}{$\begin{array}{l}\mathbf{1}=\text { Not At All } \\
\begin{array}{l}\text { Circle the number that best } \\
\text { describes your opinion about } \\
\text { student performance on algebra } \\
\text { topics. }\end{array}\end{array}$}} & & \multicolumn{5}{|c|}{$3=$ Some } & \multicolumn{4}{|c|}{$4=$ Well } & \\
\hline & & \multicolumn{5}{|c|}{$\begin{array}{l}\text { How well do } \\
\text { students typically } \\
\text { learn this topic in } \\
\text { high school } \\
\text { classes? }\end{array}$} & \multicolumn{5}{|c|}{$\begin{array}{l}\text { How well do } \\
\text { students typically } \\
\text { learn this topic in } \\
\text { remedial college } \\
\text { classes? }\end{array}$} & \multicolumn{5}{|c|}{$\begin{array}{c}\mathbf{5}=\text { Very Well } \\
\text { How well do } \\
\text { students typically } \\
\text { learn this topic in } \\
\text { college level algebro } \\
\text { classes? }\end{array}$} \\
\hline $\begin{array}{l}\text { 55. Solve proble } \\
\text { modeled us } \\
\text { two equatio } \\
\text { variables, st } \\
\text { problems }\end{array}$ & $\begin{array}{l}\text { that can be } \\
\text { a system of } \\
\text { t two } \\
\text { as mixture }\end{array}$ & 1 & 2 & 3 & 4 & 5 & 1 & 2 & 3 & 4 & 5 & 1 & 2 & 3 & 4 & 5 \\
\hline \multicolumn{2}{|c|}{$\begin{array}{l}\text { 56. Identify key characteristics of } \\
\text { exponential functions }\end{array}$} & 1 & 2 & 3 & 4 & 5 & 1 & 2 & 3 & 4 & 5 & 1 & 2 & 3 & 4 & 5 \\
\hline \multicolumn{2}{|c|}{$\begin{array}{l}\text { 57. Identify when functions are } \\
\text { inverses of each other }\end{array}$} & 1 & 2 & 3 & 4 & 5 & 1 & 2 & 3 & 4 & 5 & 1 & 2 & 3 & 4 & 5 \\
\hline \multicolumn{2}{|c|}{$\begin{array}{l}\text { 58. Graph the solution set of a } \\
\text { linear inequality }\end{array}$} & 1 & 2 & 3 & 4 & 5 & 1 & 2 & 3 & 4 & 5 & 1 & 2 & 3 & 4 & 5 \\
\hline \multicolumn{2}{|c|}{$\begin{array}{l}\text { 59. Understand the relationship } \\
\text { between a solution of a } \\
\text { system of two linear } \\
\text { equations in two variables } \\
\text { and the graphs of the } \\
\text { corresponding lines }\end{array}$} & \multirow[t]{2}{*}{1} & & 3 & \multicolumn{2}{|l|}{4} & 1 & 2 & 3 & \multicolumn{2}{|c|}{45} & 1 & 2 & 3 & 4 & 5 \\
\hline \multicolumn{2}{|c|}{ 60. Graph exponential functions } & & 2 & 3 & 4 & 5 & 1 & 2 & 3 & 4 & 5 & 1 & 2 & 3 & 4 & 5 \\
\hline \multicolumn{2}{|c|}{$\begin{array}{l}\text { 61. Demonstrate that the graph } \\
\text { of a linear equation has a } \\
\text { constant rate of change }\end{array}$} & \multicolumn{2}{|l|}{1} & 3 & 4 & 5 & 1 & 2 & 3 & 4 & 5 & 1 & 2 & 3 & 4 & 5 \\
\hline $\begin{array}{l}\text { 62. Recognize t } \\
\text { use of apprc } \\
\text { the limits of }\end{array}$ & $\begin{array}{l}\text { ppropriate } \\
\text { ations and } \\
\text { ision }\end{array}$ & 1 & 2 & 3 & 4 & 5 & 1 & 2 & 3 & 4 & 5 & 1 & 2 & 3 & 4 & 5 \\
\hline $\begin{array}{l}\text { 63. Understand } \\
\text { between the } \\
\text { quadratic fu } \\
\text { intercepts o }\end{array}$ & $\begin{array}{l}\text { relationship } \\
\text { al zeros of a } \\
\text { on and the x- } \\
\text { graph }\end{array}$ & 1 & 2 & 3 & 4 & 5 & 1 & 2 & 3 & 4 & 5 & 1 & 2 & 3 & 4 & 5 \\
\hline $\begin{array}{l}\text { 64. Know that th } \\
\text { exponential } \\
\text { logarithm }\end{array}$ & $\begin{array}{l}\text { iverse of an } \\
\text { ction is a }\end{array}$ & 1 & 2 & 3 & 4 & 5 & 1 & 2 & 3 & 4 & 5 & 1 & 2 & 3 & 4 & 5 \\
\hline $\begin{array}{l}\text { 65. Factor polyr } \\
\text { removing th } \\
\text { common fac }\end{array}$ & $\begin{array}{l}\text { als by } \\
\text { atest }\end{array}$ & 1 & 2 & 3 & 4 & 5 & 1 & 2 & 3 & 4 & 5 & 1 & 2 & 3 & 4 & 5 \\
\hline 66. Simplify rati & expressions & 1 & 2 & 3 & 4 & 5 & 1 & 2 & 3 & 4 & 5 & 1 & 2 & 3 & 4 & 5 \\
\hline $\begin{array}{l}\text { 67. Read inform } \\
\text { conclusions }\end{array}$ & $\begin{array}{l}\text { and draw } \\
\text { graphs }\end{array}$ & 1 & 2 & 3 & 4 & 5 & 1 & 2 & 3 & 4 & 5 & 1 & 2 & 3 & 4 & 5 \\
\hline $\begin{array}{l}\text { 68. Prove basic } \\
\text { logarithm us } \\
\text { its inverse }\end{array}$ & $\begin{array}{l}\text { perties of a } \\
\text { properties of }\end{array}$ & 1 & 2 & 3 & 4 & 5 & 1 & 2 & 3 & 4 & 5 & 1 & 2 & 3 & 4 & 5 \\
\hline $\begin{array}{l}\text { 69. Determine t } \\
\text { function in } s\end{array}$ & $\begin{array}{l}\text { lomain of a } \\
\text { jolic form }\end{array}$ & & 2 & 3 & 4 & 5 & 1 & 2 & 3 & 4 & 5 & & 2 & 3 & 4 & 5 \\
\hline
\end{tabular}




\begin{tabular}{|c|c|c|c|c|c|c|c|c|c|c|c|c|c|c|c|}
\hline $1=$ Not At All & \multicolumn{2}{|c|}{$2=$ Very Little } & \multicolumn{4}{|c|}{3 = Some } & \multicolumn{4}{|c|}{$4=$ Well } & \multicolumn{5}{|c|}{$5=$ Very Well } \\
\hline \multicolumn{2}{|c|}{$\begin{array}{l}\text { Circle the number that best } \\
\text { describes your opinion about } \\
\text { student performance on algebra } \\
\text { topics. }\end{array}$} & \multicolumn{4}{|c|}{$\begin{array}{l}\text { How well do } \\
\text { students typically } \\
\text { learn this topic in } \\
\text { high school } \\
\text { classes? }\end{array}$} & \multicolumn{5}{|c|}{$\begin{array}{l}\text { How well do } \\
\text { students typically } \\
\text { learn this topic in } \\
\text { remedial college } \\
\text { classes? }\end{array}$} & \multicolumn{5}{|c|}{$\begin{array}{c}\text { How well do } \\
\text { students typically } \\
\text { learn this topic in } \\
\text { college level algebra } \\
\text { classes? }\end{array}$} \\
\hline \multicolumn{2}{|c|}{$\begin{array}{l}\text { 70. Use the special symbols of } \\
\text { mathematics correctly }\end{array}$} & 1 & 3 & 4 & 5 & 1 & 2 & 3 & 4 & 5 & 1 & 2 & 3 & 4 & 5 \\
\hline \multicolumn{2}{|c|}{$\begin{array}{l}\text { 71. Apply properties of a } \\
\text { logarithm and its inverse to } \\
\text { solve problems }\end{array}$} & 1 & 3 & 4 & 5 & 1 & 2 & 3 & 4 & 5 & 1 & 2 & $v$ & 4 & 5 \\
\hline \multicolumn{2}{|c|}{$\begin{array}{l}\text { 72. Apply the properties of } \\
\text { rational exponents to simplify } \\
\text { algebraic expressions. }\end{array}$} & 1 & 3 & 7 & 5 & 1 & 2 & 3 & 4 & 5 & 1 & 2 & 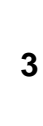 & 4 & 5 \\
\hline
\end{tabular}

73. Additional comments? For example, share details of your experiences that influenced your responses; or share topics you think should have been addressed in the survey; or share your feelings about completing the survey.

\title{
Thank you for participating in this study.
}

\author{
Please return completed surveys to Jane Jones \\ c/o Bob Ronau \\ College of Education \& Human Development \\ University of Louisville \\ Louisville, KY 40292
}




\section{APPENDIX H}

\section{AMERICAN DIPLOMA PROJECT ALGEBRA BENCHMARKS}

The high school graduate can:

J1. Perform basic operations On algebraic expressions fluently and accurately:

J1.1. Understand the properties of integer exponents and roots and apply these properties to simplify algebraic expressions.

J1.2. Understand the properties of rational exponents and apply these properties to simplify algebraic expressions.

J1.3. Add, subtract and multiply polynomials; divide a polynomial by a lowdegree polynomial.

J1.4. Factor polynomials by removing the greatest common factor; factor quadratic polynomials.

J1.5. Add, subtract, multiply, divide and simplify rational expressions.

J1.6. Evaluate polynomial and rational expressions and expressions containing radicals and absolute values at specified values of their variables.

J1.7. Derive and use the formulas for the general term and summation of finite arithmetic and geometric series; find the sum of an infinite geometric series whose common ratio, $r$, is in the interval $(-1,1)$.

J2. Understand functions, their representations and their properties.

J2.1. Recognize whether a relationship given in symbolic or graphical form is a 
function.

J2.2. Determine the domain of a function represented in either symbolic or graphical form.

J2.3. Understand functional notation and evaluate a function at a specified point in its domain.

J2.4. Combine functions by composition, as well as by addition, subtraction, multiplication and division.

J2.5. Identify whether a function has an inverse and when functions are inverses of each other; explain why the graph of a function and its inverse are reflections of one another over the line $y=x$.

J2.6. Know that the inverse of an exponential function is a logarithm, prove basic properties of a logarithm using properties of its inverse and apply those properties to solve problems.

J3. Apply basic algebraic operations to solve equations and inequalities:

J3.1. Solve linear equations and inequalities in one variable including those involving the absolute value of a linear function.

J3.2. Solve an equation involving several variables for one variable in terms of the others.

J3.3. Solve systems of two linear equations in two variables.

J3.4. Solve systems of three linear equations in three variables.

J3.5. Solve quadratic equations in one variable.

J4. Graph a variety of equations and inequalities in two variables, demonstrate understanding of the relationship between the algebraic properties of an equation and the 
geometric properties of its graph, and interpret a graph.

J4.1. Graph a linear equation and demonstrate that it has a constant rate of change. J4.2. Understand the relationship between the coefficients of a linear equation and the slope and $\mathrm{x}$ - and $\mathrm{y}$-intercepts of its graph.

J4.3. Understand the relationship between a solution of a system of two linear equations in two variables and the graphs of the corresponding lines.

J4.4. Graph the solution set of a linear inequality and identify whether the solution set is an open or a closed half-plane; graph the solution set of a system of two or three linear inequalities.

J4.5. Graph a quadratic function and understand the relationship between its real zeros and the $\mathrm{x}$-intercepts of its graph.

J4.6. Graph ellipses and hyperbolas whose axes are parallel to the $\mathrm{x}$ and $\mathrm{y}$ axes and demonstrate understanding of the relationship between their standard algebraic form and their graphical characteristics.

J4.7. Graph exponential functions and identify their key characteristics.

J4.8. Read information and draw conclusions from graphs; identify properties of a graph that provide useful information about the original problem.

J5. Solve problems by converting the verbal information given into an appropriate mathematical model involving equations or systems of equations; apply appropriate mathematical techniques to analyze these mathematical models; and interpret the solution obtained in written form using appropriate units of measurement:

J5.1. Recognize and solve problems that can be modeled using a linear equation in one variable, such as time/rate/distance problems, percentage increase or 
decrease problems, and ratio and proportion problems.

J5.2. Recognize and solve problems that can be modeled using a system of two equation in two variables, such as mixture problems.

J5.3. Recognize and solve problems that can be modeled using a quadratic equation, such as the motion of an object under the force of gravity.

J5.4. Recognize and solve problems that can be modeled using an exponential function, such as compound interest problems.

J5.5. Recognize and solve problems that can be modeled using an exponential function but whose solution requires facility with logarithms, such as exponential growth and decay problems.

J5.6. Recognize and solve problems that can be modeled using a finite geometric series, such a home mortgage problems and other compound interest problems.

Mathematical Reasoning

Woven throughout the four domains of mathematics are the following mathematical reasoning skills:

- Using inductive and deductive reasoning to arrive at valid conclusions

- Using multiple representations (literal, symbolic, graphic) to represent problems and solutions.

- Understanding the role of definitions, proofs and counter-examples in mathematical reasoning: constructing simple proofs.

- Using the special symbols of mathematics correctly and precisely.

- Recognizing when an estimate or approximation is more appropriate than an exact answer and understanding the limits on precision of approximations. 
- Distinguishing relevant from irrelevant information, identifying missing information, and either finding what is needed or making appropriate estimates.

- Recognizing and using the process of mathematical modeling; recognizing and clarifying mathematical structures that are embedded in other contexts, formulating a problem in mathematical terms, using mathematical strategies to reach a solution, and interpreting the solution in the context of the original problem.

- When solving problems, thinking ahead about strategy, testing ideas with special cases, trying different approaches, checking for errors and reasonableness of solutions as a regular part of routine work, and devising independent ways to verify results.

- Shifting regularly between the specific and the general, using examples to understand general ideas, and extending specific results to more general cases to gain insight. 
APPENDIX I

SURVEY ALGEBRA TOPICS BY CATEGORY

$\underline{\text { Symbolic Algebraic Manipulation }}$

Survey No.

Topic

15 Divide a polynomial by a low-degree polynomial

21 Understand the properties of integer exponents and roots

25 Evaluate expressions containing radicals and absolute values at specified values of their variables

$26 \quad$ Factor quadratic polynomials

35 Apply the properties of integer exponents and roots to simplify algebraic expressions

36 Add, subtract, multiply, and divide rational expressions

$37 \quad$ Add, subtract and multiply polynomials

41 Use the formulas for the general term and summation of finite arithmetic and geometric series

49 Derive the formulas for the general term and summation of finite arithmetic and geometric series

50 Find the sum of an infinite geometric series whose common ratio, $r$, is in the interval $(-1,1)$ 
$\underline{\text { Symbolic Algebraic Manipulation }}$

Survey No.

Topic

$53 \quad$ Understand the properties of rational exponents

54 Evaluate polynomial and rational expressions at specified values of their variables

65 Factor polynomials by removing the greatest common factor

66 Simplify rational expressions

72 Apply the properties of rational exponents to simplify algebraic expressions

\section{$\underline{\text { Functions }}$}

Survey No.

Topic

16 Combine functions by composition

23 Recognize whether a relationship given in symbolic form is a function

24 Identify whether a function has an inverse

28 Understand function notation

30 Determine the domain of a function in graphical form

32 Explain why the graph of a function and its inverse are reflections of one another over the line $\mathrm{y}=\mathrm{x}$

39 Combine functions by addition, subtraction, multiplication and division

40 Evaluate a function at a specified point in its domain 
$\underline{\text { Functions }}$

Survey No.

Topic

46 Recognize whether a relationship given in graphical form is a function

57 Identify when functions are inverses of each other

64 Know that the inverse of an exponential function is a logarithm

68 Prove basic properties of a logarithm using properties of its inverse

69 Determine the domain of a function in symbolic form

71 Apply properties of a logarithm and its inverse to solve problems

\section{$\underline{\text { Solving Equations and Inequalities }}$}

Survey No. Topic

10 Solve systems of two linear equations in two variables

11 Solve systems of three linear equations in three variables

33 Solve an equation involving several variables for one variable in terms of the others

42 Solve linear equations in one variable

44 Solve linear inequalities in one variable

47 Solve linear equations and inequalities in one variable involving the absolute value of a linear function

48 Solve quadratic equations in one variable 


\section{Graphing}

Survey No.

Topic

13 Graph the solution set of a system of two or three linear inequalities

17 Graph a quadratic function

18 Identify properties of a graph that provide useful information about the original problem

19 Identify whether the solution set of the graph of a linear inequalities is an open or a closed half-plane

20 Graph ellipses and hyperbolas whose axes are parallel to the $\mathrm{x}$ and $\mathrm{y}$ axes

34 Understand the relationship between the coefficients of a linear equation and the slope and $\mathrm{x}$ - and $\mathrm{y}$-intercepts of its graph

43 Graph a linear equation

52 Demonstrate understanding of the relationship between the standard algebraic form of ellipses and hyperbolas and their graphical characteristics

$56 \quad$ Identify key characteristics of exponential functions

$58 \quad$ Graph the solution set of a linear inequality

59 Understand the relationship between a solution of a system of two linear equations in two variables and the graphs of the corresponding lines

60 Graph exponential functions

61 Demonstrate that the graph of a linear equation has a constant rate of change 
Graphing

Survey No.

Topic

63 Understand the relationship between the real zeros of a quadratic function and the $\mathrm{x}$-intercepts of its graph

67 Read information and draw conclusions from graphs

Mathematical Reasoning

Survey No.

Topic

29 Use multiple representations (literal, symbolic, graphic) to represent problems and solutions

31 Understand the role of definitions, proofs, and counterexamples in mathematical reasoning and construct simple proofs

45 Distinguish relevant from irrelevant information, identifying missing information, and either finding what is needed or making appropriate estimates.

51 Use inductive and deductive reasoning to arrive at valid conclusions

62 Recognize the appropriate use of approximations and the limits of precision

70 Use the special symbols of mathematics correctly 


\section{Problem Solving}

Survey No.

Topic

12 Recognize and solve problems that can be modeled using a linear equation in one variable, such as time/rate/distance problems, percentage increase or decrease problems, and ratio and proportion problems

14 Recognize and solve problems that can be modeled using a quadratic equation, such as the motion of an object under the force of gravity

22 Recognize and solve problems that can be modeled using an exponential function

27 Recognize and solve problems that can be modeled using an exponential function but whose solution requires facility with logarithms, such as exponential growth and decay problems

38 Recognize and solve problems that can be modeled using a finite geometric series, such as home mortgage problems and other compound interest problems

55 Solve problems that can be modeled using a system of two equations in two variables, such as mixture problems 


\section{APPENDIX J}

\section{SURVEY INSTRUMENT - PILOT: DON'T KNOW OMITTED}

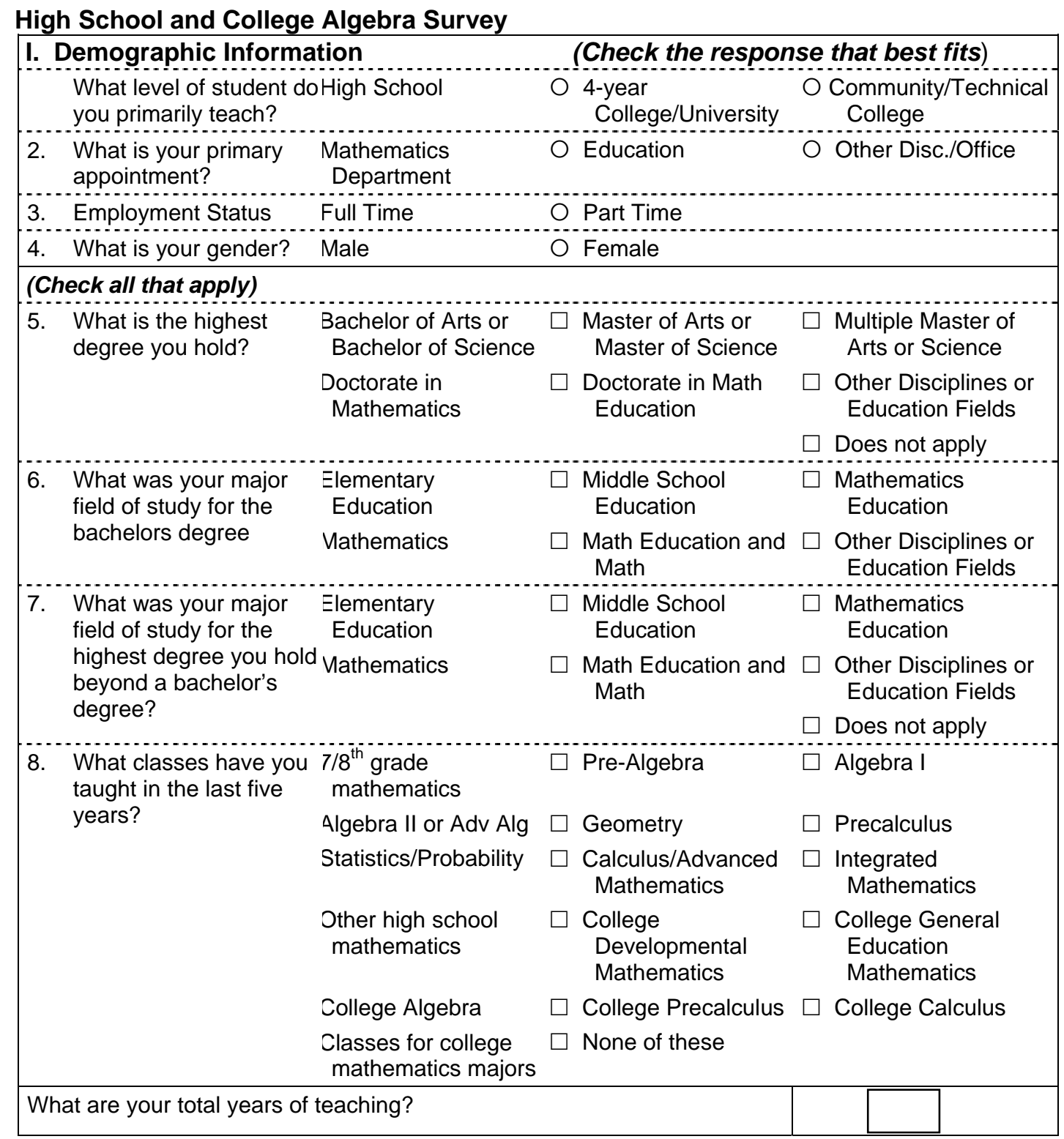


9. Number of years teaching per grade level (check all that best describe your teaching experience)

\begin{tabular}{|l|c|c|c|c|c|}
\hline & $<1$ & $1-3$ & $4-10$ & $10-20$ & $20+$ \\
\hline Early Childhood & & & & & \\
\hline Elementary School & & & & & \\
\hline Middle School & & & & & \\
\hline Secondary School & & & & & \\
\hline Two Year College & & & & & \\
\hline Four Year College/ University & & & & & \\
\hline
\end{tabular}

II. Perceptions of Levels of Learning Expectations for Students in Algebra

Please indicate your perceptions of the level of learning attained by students for each of the content topics listed below by circling the appropriate response using the specified codes.

\begin{tabular}{|c|c|c|c|c|c|c|c|c|c|c|c|c|c|c|c|c|}
\hline $1=$ Not At All & $2=$ Very Little & \multicolumn{5}{|c|}{$3=$ Some } & \multicolumn{4}{|c|}{$4=$ Well } & \multicolumn{6}{|c|}{5 = Very Well } \\
\hline \multicolumn{2}{|c|}{$\begin{array}{l}\text { Circle the number that best describes } \\
\text { your opinion about student } \\
\text { performance in algebra classes. }\end{array}$} & \multicolumn{5}{|c|}{$\begin{array}{l}\text { How well do } \\
\text { students typically } \\
\text { learn this topic in } \\
\text { high school } \\
\text { classes? }\end{array}$} & \multicolumn{5}{|c|}{$\begin{array}{l}\text { How well do } \\
\text { students typically } \\
\text { learn this topic in } \\
\text { non-credit bearing } \\
\text { post-secondary } \\
\text { classes? }\end{array}$} & \multicolumn{5}{|c|}{$\begin{array}{l}\text { How well do } \\
\text { students typically } \\
\text { learn this topic in } \\
\text { credit bearing } \\
\text { post-secondary } \\
\text { classes? }\end{array}$} \\
\hline \multicolumn{2}{|c|}{$\begin{array}{l}\text { 10. Solve systems of two linear } \\
\text { equations in two variables }\end{array}$} & 1 & 2 & 3 & 4 & 5 & 1 & & 3 & 4 & 5 & & 2 & 3 & 4 & 5 \\
\hline \multicolumn{2}{|c|}{$\begin{array}{l}\text { 11. Solve systems of three linear } \\
\text { equations in three variables }\end{array}$} & 1 & 2 & 3 & 4 & 5 & 1 & & 3 & 4 & 5 & 1 & 2 & 3 & 4 & 5 \\
\hline \multicolumn{2}{|c|}{$\begin{array}{l}\text { 12. Recognize and solve problems } \\
\text { that can be modeled using a } \\
\text { linear equation in one variable, } \\
\text { such as time/rate/distance } \\
\text { problems, percentage increase } \\
\text { or decrease problems, and ratio } \\
\text { and proportion problems }\end{array}$} & 1 & 2 & 3 & 4 & 5 & 1 & & 3 & 4 & 5 & 1 & 2 & 3 & 4 & 5 \\
\hline \multicolumn{2}{|c|}{$\begin{array}{l}\text { 13. Graph the solution set of a } \\
\text { system of two or three linear } \\
\text { inequalities }\end{array}$} & 1 & 2 & 3 & 4 & 5 & 1 & 2 & 3 & 4 & 5 & & 2 & 3 & 4 & 5 \\
\hline \multicolumn{2}{|c|}{$\begin{array}{l}\text { 14. Recognize and solve problems } \\
\text { that can be modeled using a } \\
\text { quadratic equation, such as the } \\
\text { motion of an object under the } \\
\text { force of gravity }\end{array}$} & 1 & 2 & 3 & 4 & 5 & 1 & 2 & 3 & 4 & 5 & & 2 & 3 & 4 & 5 \\
\hline \multicolumn{2}{|c|}{$\begin{array}{l}\text { 15. Divide a polynomial by a low- } \\
\text { degree polynomial }\end{array}$} & 1 & 2 & 3 & 4 & 5 & 1 & 2 & 3 & 4 & 5 & 1 & 2 & 3 & 4 & 5 \\
\hline \multicolumn{2}{|c|}{$\begin{array}{l}\text { 16. Combine functions by } \\
\text { composition }\end{array}$} & 1 & 2 & 3 & 4 & 5 & 1 & 2 & 3 & 4 & 5 & 1 & 2 & 3 & 4 & 5 \\
\hline \multicolumn{2}{|c|}{ 17. Graph a quadratic function } & 1 & 2 & 3 & 4 & 5 & 1 & 2 & 3 & 4 & 5 & 1 & 2 & 3 & 4 & 5 \\
\hline
\end{tabular}




\begin{tabular}{|c|c|c|c|c|c|c|c|c|c|c|c|c|c|c|c|}
\hline $1=$ Not At All & 2 = Very Little & \multirow{2}{*}{\multicolumn{5}{|c|}{$\begin{array}{l}\mathbf{3}=\text { Some } \\
\text { How well do } \\
\text { tudents typically } \\
\text { earn this topic in } \\
\text { high school } \\
\text { classes? }\end{array}$}} & \multicolumn{3}{|c|}{4 = Well } & \multicolumn{6}{|c|}{$5=$ Very Well } \\
\hline \multicolumn{2}{|c|}{$\begin{array}{l}\text { Circle the number that best describes } \\
\text { your opinion about student } \\
\text { performance in algebra classes. }\end{array}$} & & & & & & \multicolumn{4}{|c|}{$\begin{array}{l}\text { How well do } \\
\text { students typically } \\
\text { learn this topic in } \\
\text { non-credit bearing } \\
\text { post-secondary } \\
\text { classes? }\end{array}$} & \multicolumn{5}{|c|}{$\begin{array}{l}\text { How well do } \\
\text { students typically } \\
\text { learn this topic in } \\
\text { credit bearing } \\
\text { post-secondary } \\
\text { classes? }\end{array}$} \\
\hline \multicolumn{2}{|c|}{$\begin{array}{l}\text { 18. Identify properties of a graph that } \\
\text { provide useful information about } \\
\text { the original problem }\end{array}$} & 1 & 2 & 3 & 4 & 5 & 12 & 3 & 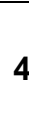 & 5 & 12 & 3 & & & 5 \\
\hline \multicolumn{2}{|c|}{$\begin{array}{l}\text { 19. Identify whether the solution set } \\
\text { of the graph of a linear inequality } \\
\text { is an open or a closed half-plane }\end{array}$} & 1 & 2 & 3 & 4 & 5 & 12 & 3 & 4 & 5 & 12 & 3 & 2 & & 5 \\
\hline \multicolumn{2}{|c|}{$\begin{array}{l}\text { 20. Graph ellipses and hyperbolas } \\
\text { whose axes are parallel to the } x \\
\text { and y axes }\end{array}$} & 1 & 2 & 3 & 4 & 5 & 12 & 3 & 4 & 5 & 12 & 3 & 2 & & 5 \\
\hline \multicolumn{2}{|c|}{$\begin{array}{l}\text { 21. Understand the properties of } \\
\text { integer exponents and roots }\end{array}$} & 1 & 2 & 3 & 4 & 5 & 12 & 3 & 4 & 5 & 12 & 3 & & & 5 \\
\hline \multicolumn{2}{|c|}{$\begin{array}{l}\text { 22. Recognize and solve problems } \\
\text { that can be modeled using an } \\
\text { exponential function }\end{array}$} & 1 & 2 & 3 & 4 & 5 & 12 & 3 & 4 & 5 & 12 & 3 & & & 5 \\
\hline \multicolumn{2}{|c|}{$\begin{array}{l}\text { 23. Recognize whether a relationship } \\
\text { given in symbolic form is a } \\
\text { function }\end{array}$} & 1 & 2 & 3 & 4 & 5 & 12 & 3 & 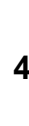 & 5 & 12 & 3 & & & 5 \\
\hline \multicolumn{2}{|c|}{$\begin{array}{l}\text { 24. Identify whether a function has } \\
\text { an inverse }\end{array}$} & 1 & 2 & 3 & 4 & 5 & 12 & 3 & 4 & 5 & 12 & 3 & & & 5 \\
\hline \multicolumn{2}{|c|}{$\begin{array}{l}\text { 25. Evaluate expressions containing } \\
\text { radicals and absolute values at } \\
\text { specified values of their variables }\end{array}$} & & 2 & 3 & 4 & 5 & 12 & 3 & 4 & 5 & 12 & 3 & & & 5 \\
\hline \multicolumn{2}{|c|}{ 26. Factor quadratic polynomials } & 1 & 2 & 3 & 4 & 5 & 12 & 3 & 4 & 5 & 12 & 3 & & & 5 \\
\hline \multicolumn{2}{|c|}{$\begin{array}{l}\text { 27. Recognize and solve problems } \\
\text { that can be modeled using an } \\
\text { exponential function but whose } \\
\text { solution requires facility with } \\
\text { logarithms, such as exponential } \\
\text { growth and decay problems }\end{array}$} & 1 & 2 & 3 & 4 & 5 & 1 & 3 & 4 & 5 & 12 & 3 & & & 5 \\
\hline \multicolumn{2}{|c|}{ 28. Understand function notation } & 1 & 2 & 3 & 4 & 5 & 12 & 3 & 4 & 5 & 12 & 3 & & & 5 \\
\hline \multicolumn{2}{|c|}{$\begin{array}{l}\text { 29. Use multiple representations } \\
\text { (literal, symbolic, graphic) to } \\
\text { represent problems and solutions }\end{array}$} & & 2 & 3 & 4 & 5 & 1 & 3 & 4 & 5 & 12 & 3 & & & 5 \\
\hline \multicolumn{2}{|c|}{$\begin{array}{l}\text { 30. Determine the domain of a } \\
\text { function in graphical form }\end{array}$} & 1 & 2 & 3 & 4 & 5 & 1 & 3 & 4 & 5 & 12 & 3 & & & 5 \\
\hline \multicolumn{2}{|c|}{$\begin{array}{l}\text { 31. Understand the role of } \\
\text { definitions, proofs, and } \\
\text { counterexamples in } \\
\text { mathematical reasoning and } \\
\text { construct simple proofs }\end{array}$} & & 2 & 3 & 4 & 5 & 1 & 3 & 4 & 5 & 12 & 3 & & & 5 \\
\hline \multicolumn{2}{|c|}{$\begin{array}{l}\text { 32. Explain why the graph of a } \\
\text { function and its inverse are } \\
\text { reflections of one another over } \\
\text { the line } y=x\end{array}$} & & 2 & 3 & 4 & 5 & 12 & 3 & & & 12 & 3 & & & 5 \\
\hline
\end{tabular}




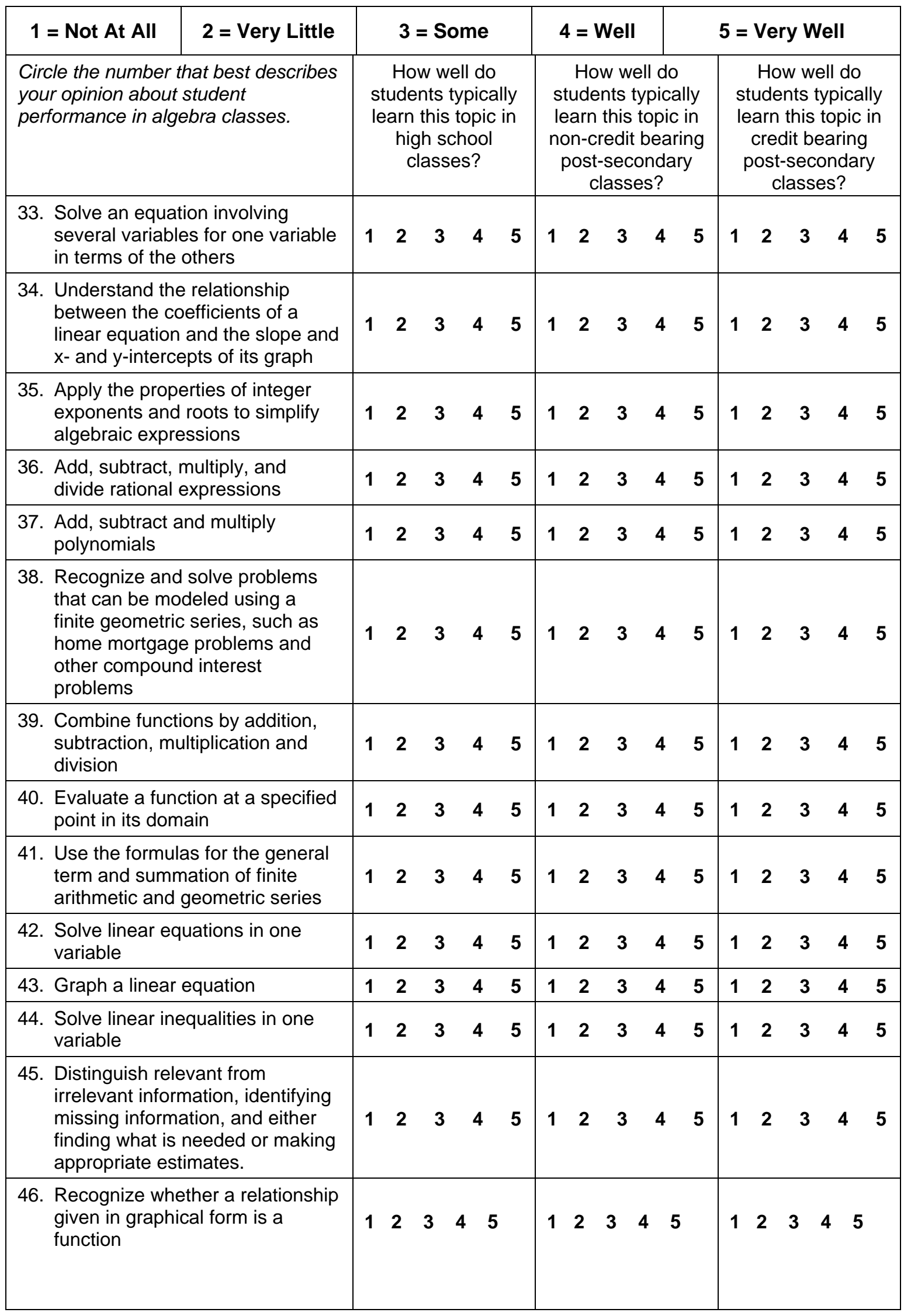




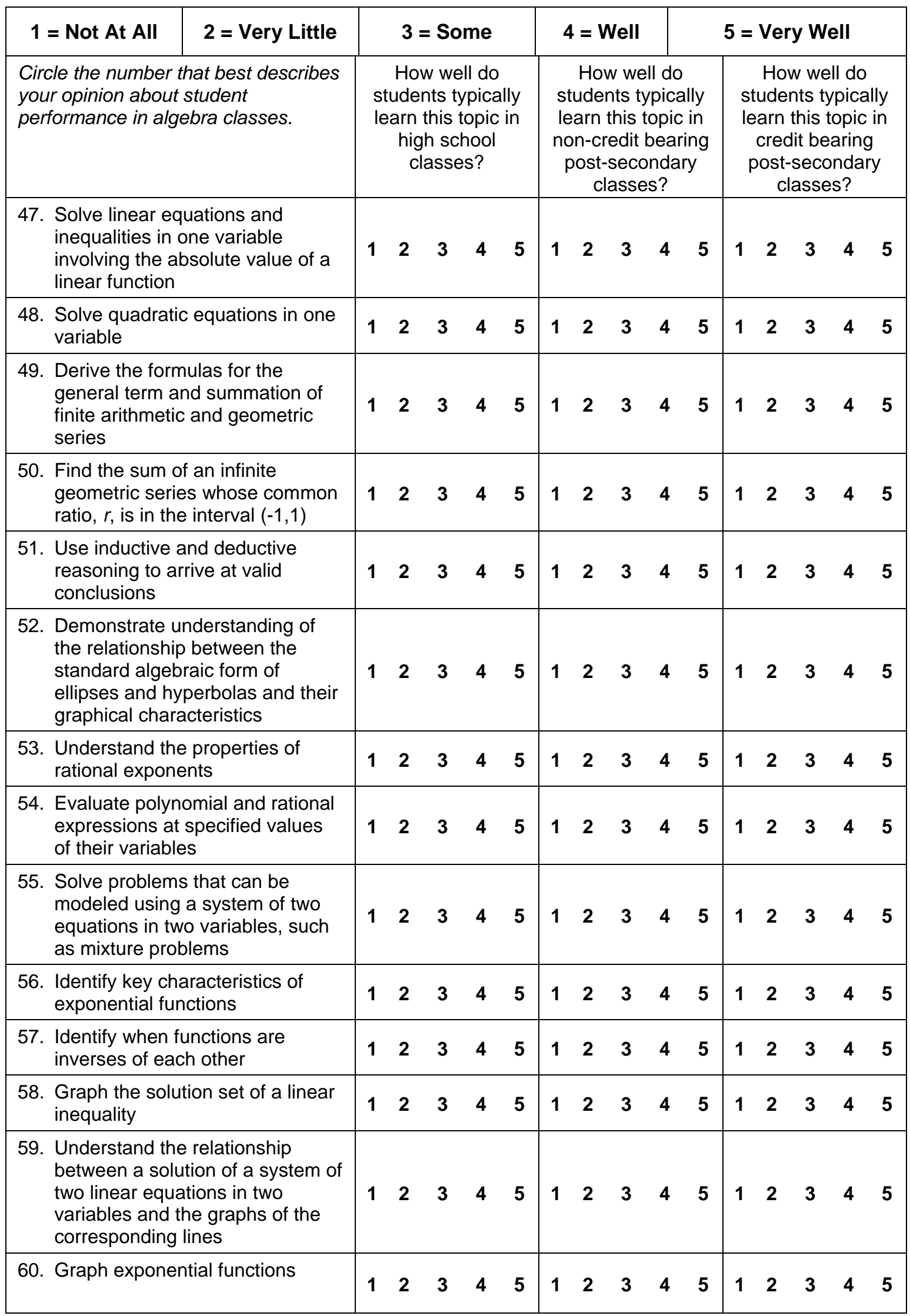




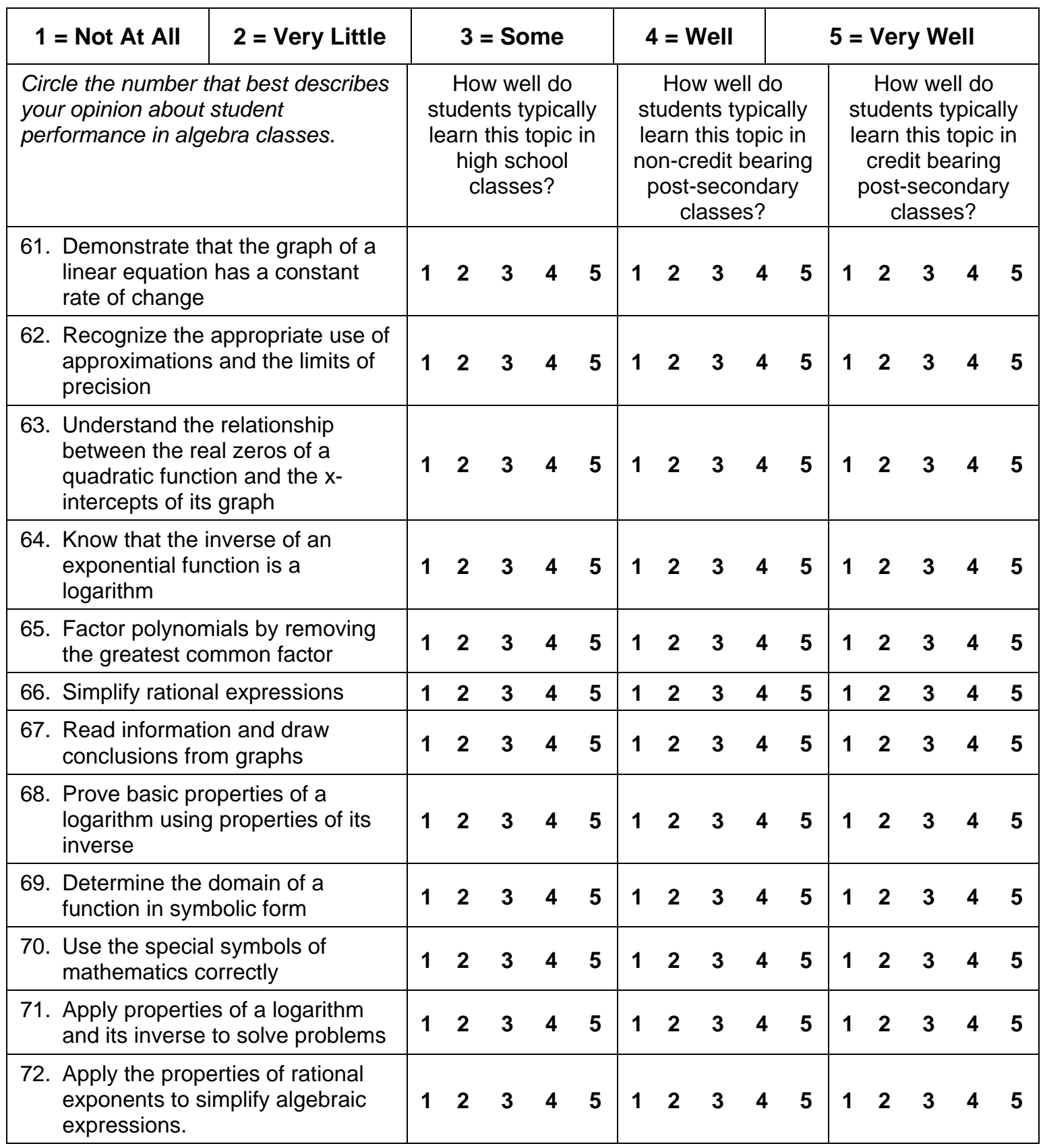


73. Additional comments? For example, share details of your experiences that influenced your responses; or share topics you think should have been addressed in the survey; or share your feelings about completing the survey.

\title{
Thank you for participating in this study.
}

\author{
Please return completed surveys to Jane Jones \\ clo Bob Ronau \\ College of Education \& Human Development \\ University of Louisville \\ Louisville, KY 40292
}




\section{APPENDIX K}

\section{SURVEY INSTRUMENT - PILOT: DON'T KNOW OPTION}

\section{High School and College Algebra Survey}

\begin{tabular}{|c|c|c|c|c|c|}
\hline \multicolumn{3}{|c|}{ I. Demographic Information } & \multicolumn{3}{|c|}{ (Check the response that best fits) } \\
\hline $\begin{array}{l}\text { 1. What level of student } \\
\text { do you primarily teach? }\end{array}$ & & High School & $\begin{array}{l}\text { 4-year } \\
\text { College/University }\end{array}$ & \multicolumn{2}{|c|}{$\begin{array}{l}\text { Community/Technical } \\
\text { College }\end{array}$} \\
\hline $\begin{array}{l}\text { 2. What is your primary } \\
\text { appointment? }\end{array}$ & & $\begin{array}{l}\text { Mathematics } \\
\text { Department }\end{array}$ & Education & \multicolumn{2}{|c|}{ Other Disc./Office } \\
\hline 3. Employment Status & 0 & Full Time & \multicolumn{3}{|l|}{ Part Time } \\
\hline 4. What is your gender? & 0 & Male & \multicolumn{3}{|l|}{ Female } \\
\hline \multicolumn{6}{|l|}{ (Check all that apply) } \\
\hline \multirow[t]{3}{*}{$\begin{array}{l}\text { 5. What is the highest } \\
\text { degree you hold? }\end{array}$} & & $\begin{array}{l}\text { Bachelor of Arts or } \\
\text { Bachelor of } \\
\text { Science }\end{array}$ & $\begin{array}{l}\square \text { Master of Arts or } \\
\text { Master of Science }\end{array}$ & \multicolumn{2}{|c|}{$\begin{array}{l}\square \text { Multiple Master of Arts } \\
\text { or Science }\end{array}$} \\
\hline & $\square$ & $\begin{array}{l}\text { Doctorate in } \\
\text { Mathematics }\end{array}$ & $\begin{array}{l}\square \text { Doctorate in Math } \\
\text { Education }\end{array}$ & \multicolumn{2}{|c|}{$\begin{array}{c}\square \text { Other Disciplines or } \\
\text { Education Fields }\end{array}$} \\
\hline & & & & \multicolumn{2}{|c|}{$\square$ Does not apply } \\
\hline \multirow{2}{*}{$\begin{array}{l}\text { 6. What was your major } \\
\text { field of study for the } \\
\text { bachelors degree }\end{array}$} & & $\begin{array}{l}\text { Elementary } \\
\text { Education }\end{array}$ & $\begin{array}{l}\text { Middle School } \\
\text { Education }\end{array}$ & \multicolumn{2}{|c|}{$\begin{array}{l}\square \text { Mathematics } \\
\text { Education }\end{array}$} \\
\hline & $\square$ & Mathematics & $\begin{array}{l}\square \text { Math Education } \\
\text { and Math }\end{array}$ & \multicolumn{2}{|c|}{$\begin{array}{c}\square \text { Other Disciplines or } \\
\text { Education Fields }\end{array}$} \\
\hline \multirow{3}{*}{$\begin{array}{l}\text { 7. What was your major } \\
\text { field of study for the } \\
\text { highest degree you } \\
\text { hold beyond a } \\
\text { bachelor's degree? }\end{array}$} & & $\begin{array}{l}\text { Elementary } \\
\text { Education }\end{array}$ & $\begin{array}{l}\text { Middle School } \\
\text { Education }\end{array}$ & \multicolumn{2}{|c|}{$\begin{array}{l}\text { Mathematics } \\
\text { Education }\end{array}$} \\
\hline & $\square$ & Mathematics & $\begin{array}{l}\square \text { Math Education } \\
\text { and Math }\end{array}$ & \multicolumn{2}{|c|}{$\begin{array}{c}\square \text { Other Disciplines or } \\
\text { Education Fields }\end{array}$} \\
\hline & & & & \multicolumn{2}{|c|}{$\square$ Does not apply } \\
\hline \multirow{6}{*}{$\begin{array}{l}\text { W. What classes have you } \\
\text { taught in the last five } \\
\text { years? }\end{array}$} & $\square$ & $\begin{array}{l}7 / 8^{\text {th }} \text { grade } \\
\text { mathematics }\end{array}$ & $\square$ Pre-Algebra & \multicolumn{2}{|r|}{ Algebra I } \\
\hline & $\square$ & $\begin{array}{l}\text { Algebra II or Adv } \\
\text { Alg }\end{array}$ & $\square$ Geometry & \multicolumn{2}{|c|}{$\square$ Precalculus } \\
\hline & $\square$ & $\begin{array}{l}\text { Statistics/Probabil } \\
\text { ity }\end{array}$ & $\begin{array}{l}\square \text { Calculus/Advanced } \\
\text { Mathematics }\end{array}$ & \multicolumn{2}{|c|}{$\begin{array}{l}\square \text { Integrated } \\
\text { Mathematics }\end{array}$} \\
\hline & $\square$ & $\begin{array}{l}\text { Other high school } \\
\text { mathematics }\end{array}$ & $\begin{array}{l}\square \text { College } \\
\text { Developmental } \\
\text { Mathematics }\end{array}$ & \multicolumn{2}{|c|}{$\begin{array}{l}\square \text { College General } \\
\text { Education } \\
\text { Mathematics }\end{array}$} \\
\hline & $\square$ & College Algebra & $\begin{array}{l}\square \text { College } \\
\text { Precalculus }\end{array}$ & \multirow{2}{*}{\multicolumn{2}{|c|}{$\square$ College Calculus }} \\
\hline & & $\begin{array}{l}\text { Classes for college } \\
\text { mathematics } \\
\text { majors }\end{array}$ & $\square$ None of these & & \\
\hline \multicolumn{4}{|c|}{ What are your total years of teaching? } & & \\
\hline
\end{tabular}


9. Number of years teaching per grade level (check all that best describe your teaching experience)

\begin{tabular}{|l|c|c|c|c|c|}
\hline & $<1$ & $1-3$ & $4-10$ & $10-20$ & $20+$ \\
\hline Early Childhood & & & & & \\
\hline Elementary School & & & & & \\
\hline Middle School & & & & & \\
\hline Secondary School & & & & & \\
\hline Two Year College & & & & & \\
\hline Four Year College/ University & & & & & \\
\hline
\end{tabular}

\section{Perceptions of Levels of Learning Expectations for Students in Algebra}

Please indicate your perceptions of the level of learning attained by students for each of the content topics listed below by circling the appropriate response using the specified codes.

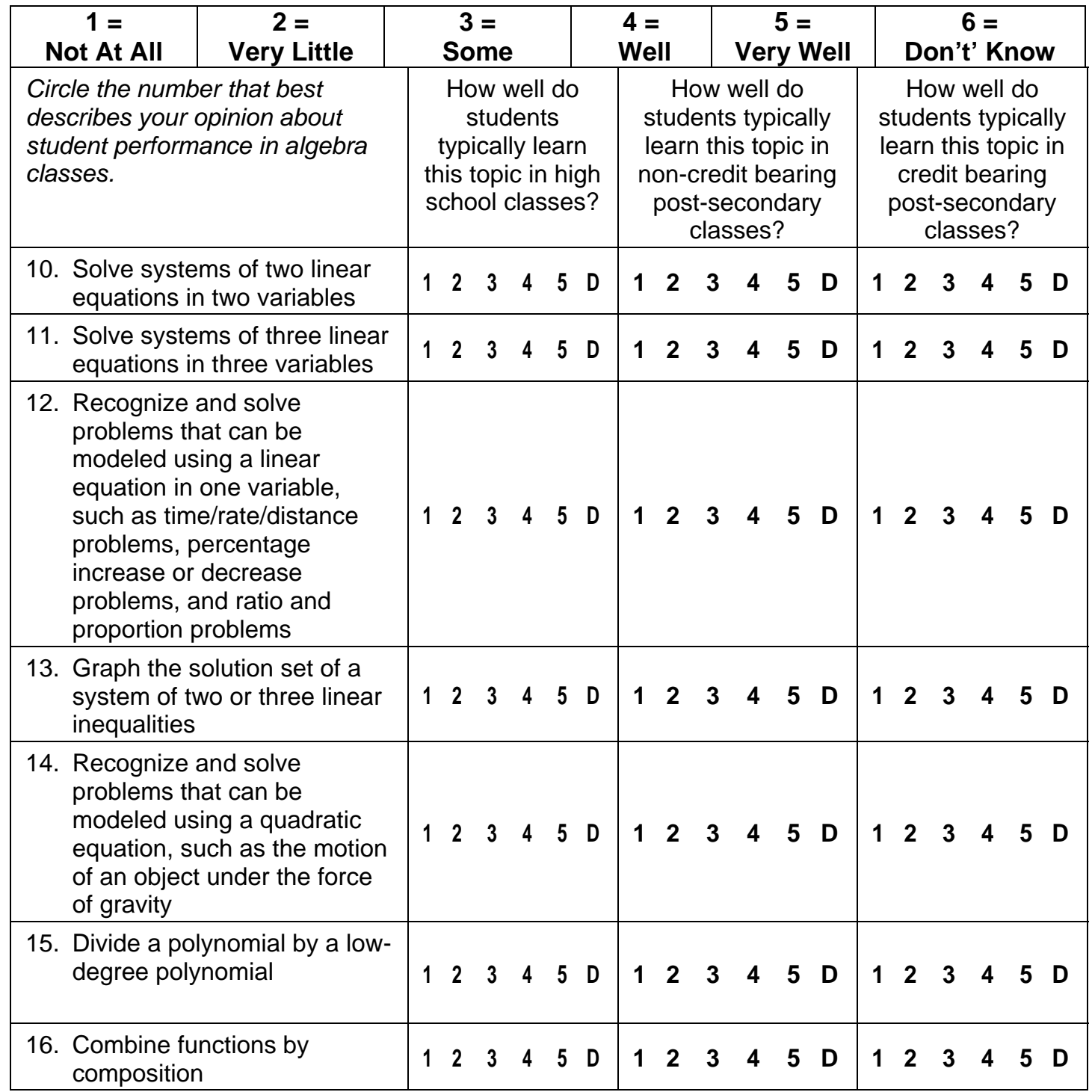




\begin{tabular}{|c|c|c|c|c|c|c|c|c|c|c|c|c|c|c|c|c|}
\hline $\begin{array}{c}1= \\
\text { Not At All }\end{array}$ & $\begin{array}{c}2= \\
\text { Very Little }\end{array}$ & $\begin{array}{r}3 \\
\text { So } \\
\end{array}$ & $\begin{array}{l}= \\
\text { me }\end{array}$ & & & & $\begin{array}{l}4= \\
\text { Well }\end{array}$ & & Ver & $\begin{array}{l}5= \\
y \text { W }\end{array}$ & & & & & & \\
\hline $\begin{array}{l}\text { Circle the nur } \\
\text { describes you } \\
\text { student perfo } \\
\text { classes. }\end{array}$ & $\begin{array}{l}\text { er that best } \\
\text { pinion about } \\
\text { ance in algebra }\end{array}$ & $\begin{array}{r}\text { Ho } \\
\mathrm{s} \\
\text { typi } \\
\text { this t } \\
\text { scho }\end{array}$ & $\begin{array}{l}\text { W w } \\
\text { tude } \\
\text { cally } \\
\text { opic } \\
\text { ol cl }\end{array}$ & $\begin{array}{l}\text { vell } \\
\text { ents } \\
y \text { le } \\
c \text { in } \\
\text { lass }\end{array}$ & $\begin{array}{l}\text { do } \\
\text { s } \\
\text { arn } \\
\text { high } \\
\text { ses? }\end{array}$ & & $\begin{array}{r}\mathrm{Hc} \\
\text { stude } \\
\text { learn } \\
\text { non-c } \\
\text { post }\end{array}$ & $\begin{array}{l}\text { ow } \\
\text { ents } \\
\text { this } \\
\text { red } \\
\text { t-se } \\
\text { class }\end{array}$ & $\begin{array}{l}\text { well } \\
\text { typ } \\
\text { s tor } \\
\text { it be } \\
\text { con } \\
\text { ses? }\end{array}$ & $\begin{array}{l}\text { do } \\
\text { icall } \\
\text { pic i } \\
\text { earin } \\
\text { dary } \\
?\end{array}$ & & $\begin{array}{r}\mathrm{Hc} \\
\text { stude } \\
\text { learn } \\
\text { cre } \\
\text { pos }\end{array}$ & $\begin{array}{l}\text { th } \\
\text { dit } \\
\text { t-se } \\
\text { clas }\end{array}$ & c & & \\
\hline 17. Graph a & dratic function & 12 & 3 & 4 & 5 & & 12 & 3 & 4 & 5 & D & 12 & 3 & 4 & 5 & D \\
\hline $\begin{array}{l}\text { 18. Identify } \mathrm{p} \\
\text { that prov } \\
\text { informati } \\
\text { problem }\end{array}$ & $\begin{array}{l}\text { erties of a graph } \\
\text { useful } \\
\text { about the original }\end{array}$ & 12 & 3 & 4 & 5 & & 12 & 3 & 4 & 5 & D & 12 & 3 & 4 & 5 & D \\
\hline $\begin{array}{l}\text { 19. Identify n } \\
\text { set of the } \\
\text { inequality } \\
\text { closed ha }\end{array}$ & $\begin{array}{l}\text { ther the solution } \\
\text { aph of a linear } \\
\text { an open or a } \\
\text { olane }\end{array}$ & 12 & 3 & 4 & 5 & & 12 & 3 & 4 & 5 & D & 12 & 3 & 4 & 5 & D \\
\hline $\begin{array}{l}\text { 20. Graph ell } \\
\text { hyperbol } \\
\text { parallel tc }\end{array}$ & $\begin{array}{l}\text { es and } \\
\text { whose axes are } \\
\text { le } x \text { and y axes }\end{array}$ & 12 & 3 & 4 & 5 & & 12 & 3 & 4 & 5 & & 12 & 3 & 4 & 5 & D \\
\hline $\begin{array}{l}\text { 21. Understa } \\
\text { integer e }\end{array}$ & $\begin{array}{l}\text { the properties of } \\
\text { nents and roots }\end{array}$ & 12 & 3 & 4 & 5 & & 12 & 3 & 4 & 5 & & 12 & 3 & 4 & 5 & D \\
\hline $\begin{array}{l}\text { 22. Recogniz } \\
\text { problems } \\
\text { modeled } \\
\text { exponent }\end{array}$ & $\begin{array}{l}\text { and solve } \\
\text { at can be } \\
\text { ing an } \\
\text { function }\end{array}$ & 12 & 3 & 4 & 5 & & 12 & 3 & 4 & 5 & D & 12 & 3 & 4 & 5 & D \\
\hline $\begin{array}{l}\text { 23. Recogniz } \\
\text { relationst } \\
\text { symbolic }\end{array}$ & $\begin{array}{l}\text { whether a } \\
\text { given in } \\
\mathrm{m} \text { is a function }\end{array}$ & 12 & 3 & 4 & 5 & & 12 & 3 & 4 & 5 & & 12 & 3 & 4 & 5 & D \\
\hline $\begin{array}{l}\text { 24. Identify n } \\
\text { has an in }\end{array}$ & $\begin{array}{l}\text { ther a function } \\
\text { se }\end{array}$ & 12 & 3 & 4 & 5 & & 12 & 3 & 4 & 5 & & 12 & 3 & 4 & - & D \\
\hline $\begin{array}{l}\text { 25. Evaluate } \\
\text { containin } \\
\text { absolute } \\
\text { values of }\end{array}$ & $\begin{array}{l}\text { pressions } \\
\text { adicals and } \\
\text { ues at specified } \\
\text { eir variables }\end{array}$ & 12 & 3 & 4 & 5 & & 12 & 3 & 4 & 5 & & 12 & 3 & 4 & 5 & D \\
\hline 26. Factor qu & ratic polynomials & 12 & 3 & 4 & 5 & D & 12 & 3 & 4 & 5 & D & 12 & 3 & 4 & 5 & D \\
\hline $\begin{array}{l}\text { 27. Recogniz } \\
\text { problems } \\
\text { modeled } \\
\text { exponent } \\
\text { whose sc } \\
\text { facility wi } \\
\text { as expon } \\
\text { decay pr }\end{array}$ & $\begin{array}{l}\text { and solve } \\
\text { at can be } \\
\text { ing an } \\
\text { function but } \\
\text { ion requires } \\
\text { ogarithms, such } \\
\text { tial growth and } \\
\text { ems }\end{array}$ & 12 & 3 & 4 & 5 & & 12 & 3 & 4 & 5 & & 12 & 3 & 4 & 5 & D \\
\hline 28. Understa & function notation & 12 & 3 & 4 & 5 & D & 12 & 3 & 4 & 5 & D & 12 & 3 & 4 & 5 & D \\
\hline $\begin{array}{l}\text { 29. Use mult } \\
\text { (literal, s) } \\
\text { represen } \\
\text { solutions }\end{array}$ & $\begin{array}{l}\text { representations } \\
\text { polic, graphic) to } \\
\text { oblems and }\end{array}$ & 12 & 3 & 4 & 5 & & 12 & 3 & 4 & 5 & D & 12 & 3 & 4 & 5 & D \\
\hline $\begin{array}{l}\text { 30. Determin } \\
\text { function } i\end{array}$ & $\begin{array}{l}\text { e domain of a } \\
\text { aphical form }\end{array}$ & 12 & 3 & 4 & 5 & & 12 & 3 & 4 & 5 & D & 12 & 3 & 4 & 5 & D \\
\hline
\end{tabular}




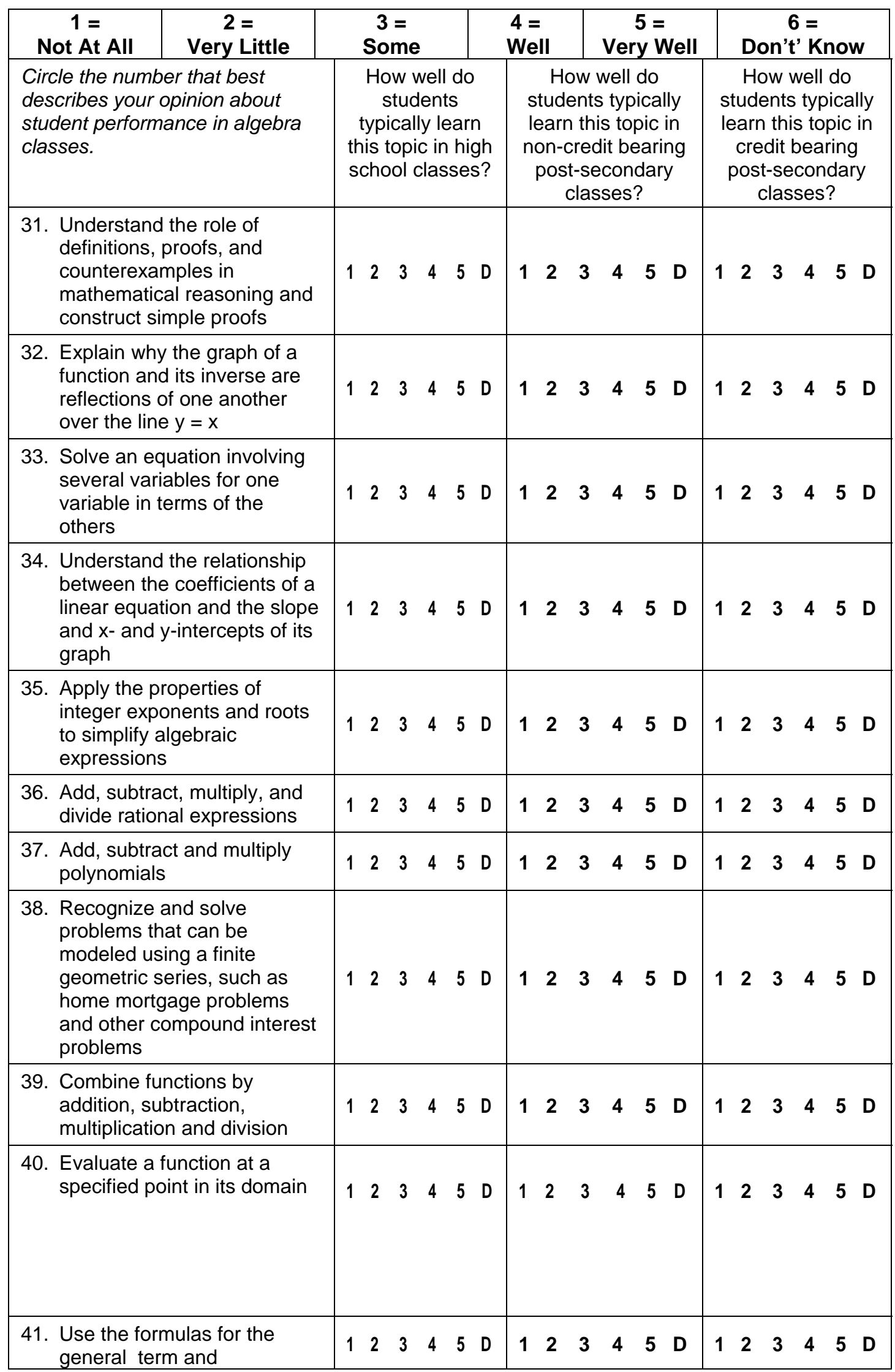




\begin{tabular}{|c|c|c|c|c|c|c|c|c|c|c|c|c|c|c|c|c|}
\hline $\begin{array}{c}1= \\
\text { Not At All }\end{array}$ & $\begin{array}{c}2= \\
\text { Very Little }\end{array}$ & & & & & & $\begin{array}{l}4= \\
\text { Well }\end{array}$ & & $\begin{array}{r}5 \\
\text { Very }\end{array}$ & Well & \multirow{2}{*}{\multicolumn{6}{|c|}{$\begin{array}{c}6= \\
\text { Don't' Know } \\
\text { How well do } \\
\text { students typically } \\
\text { learn this topic in } \\
\text { credit bearing } \\
\text { post-secondary } \\
\text { classes? }\end{array}$}} \\
\hline \multicolumn{2}{|c|}{$\begin{array}{l}\text { Circle the number that best } \\
\text { describes your opinion about } \\
\text { student performance in algebra } \\
\text { classes. }\end{array}$} & \multicolumn{5}{|c|}{$\begin{array}{l}\text { How well do } \\
\text { students } \\
\text { typically learn } \\
\text { this topic in high } \\
\text { school classes? }\end{array}$} & \multicolumn{4}{|c|}{$\begin{array}{l}\text { How well do } \\
\text { students typically } \\
\text { learn this topic in } \\
\text { non-credit bearing } \\
\text { post-secondary } \\
\text { classes? }\end{array}$} & & & & & & \\
\hline \multicolumn{2}{|c|}{$\begin{array}{l}\text { summation of finite } \\
\text { arithmetic and geometric } \\
\text { series }\end{array}$} & & & & & & & & & & & & & & & \\
\hline \multicolumn{2}{|c|}{$\begin{array}{l}\text { 42. Solve linear equations in one } \\
\text { variable }\end{array}$} & 12 & 3 & 4 & 5 & & 12 & 3 & 4 & $5 \mathrm{D}$ & & 2 & 3 & 4 & 5 & D \\
\hline \multicolumn{2}{|c|}{ 43. Graph a linear equation } & 12 & 3 & 4 & 5 & & 12 & 3 & 4 & $5 \mathrm{D}$ & & 2 & 3 & 4 & 5 & D \\
\hline \multicolumn{2}{|c|}{$\begin{array}{l}\text { 44. Solve linear inequalities in } \\
\text { one variable }\end{array}$} & 12 & 3 & 4 & 5 & & 12 & 3 & 4 & $5 \mathrm{D}$ & & 2 & 3 & 4 & 5 & D \\
\hline \multicolumn{2}{|c|}{$\begin{array}{l}\text { 45. Distinguish relevant from } \\
\text { irrelevant information, } \\
\text { identifying missing } \\
\text { information, and either } \\
\text { finding what is needed or } \\
\text { making appropriate } \\
\text { estimates. }\end{array}$} & 12 & 3 & 4 & 5 & & 12 & 3 & 4 & $5 \mathrm{D}$ & & 2 & 3 & 4 & 5 & D \\
\hline \multicolumn{2}{|c|}{$\begin{array}{l}\text { 46. Recognize whether a } \\
\text { relationship given in } \\
\text { graphical form is a function }\end{array}$} & 12 & 3 & 4 & 5 & & 12 & 3 & 4 & $5 \mathrm{D}$ & & 2 & 3 & 4 & 5 & D \\
\hline \multicolumn{2}{|c|}{$\begin{array}{l}\text { 47. Solve linear equations and } \\
\text { inequalities in one variable } \\
\text { involving the absolute value } \\
\text { of a linear function }\end{array}$} & 12 & 3 & 4 & 5 & & 12 & 3 & 4 & $5 \mathrm{D}$ & & 2 & 3 & 4 & 5 & D \\
\hline \multicolumn{2}{|c|}{$\begin{array}{l}\text { 48. Solve quadratic equations in } \\
\text { one variable }\end{array}$} & 12 & 3 & 4 & 5 & & 12 & 3 & 4 & 5 D & & 2 & 3 & 4 & 5 & D \\
\hline \multicolumn{2}{|c|}{$\begin{array}{l}\text { 49. Derive the formulas for the } \\
\text { general term and summation } \\
\text { of finite arithmetic and } \\
\text { geometric series }\end{array}$} & 12 & 3 & 4 & 5 & & 12 & 3 & 4 & $5 \mathrm{D}$ & & 2 & 3 & 4 & 5 & D \\
\hline \multicolumn{2}{|c|}{$\begin{array}{l}\text { 50. Find the sum of an infinite } \\
\text { geometric series whose } \\
\text { common ratio, } r \text {, is in the } \\
\text { interval }(-1,1)\end{array}$} & 12 & 3 & 4 & 5 & & 12 & 3 & 4 & $5 \mathrm{D}$ & & 2 & 3 & 4 & 5 & D \\
\hline \multicolumn{2}{|c|}{$\begin{array}{l}\text { 51. Use inductive and deductive } \\
\text { reasoning to arrive at valid } \\
\text { conclusions }\end{array}$} & 12 & 3 & 4 & 5 & & 12 & 3 & 4 & 5 D & & 2 & 3 & 4 & 5 & D \\
\hline \multicolumn{2}{|c|}{$\begin{array}{l}\text { 52. Demonstrate understanding } \\
\text { of the relationship between } \\
\text { the standard algebraic form } \\
\text { of ellipses and hyperbolas } \\
\text { and their graphical } \\
\text { characteristics }\end{array}$} & 12 & 3 & 4 & 5 & & 12 & 3 & 4 & 5 D & & 2 & 3 & 4 & 5 & D \\
\hline \multicolumn{2}{|c|}{$\begin{array}{l}\text { 53. Understand the properties of } \\
\text { rational exponents }\end{array}$} & 12 & 3 & 4 & 5 & & 12 & 3 & 4 & & & 2 & 3 & 4 & 5 & D \\
\hline
\end{tabular}




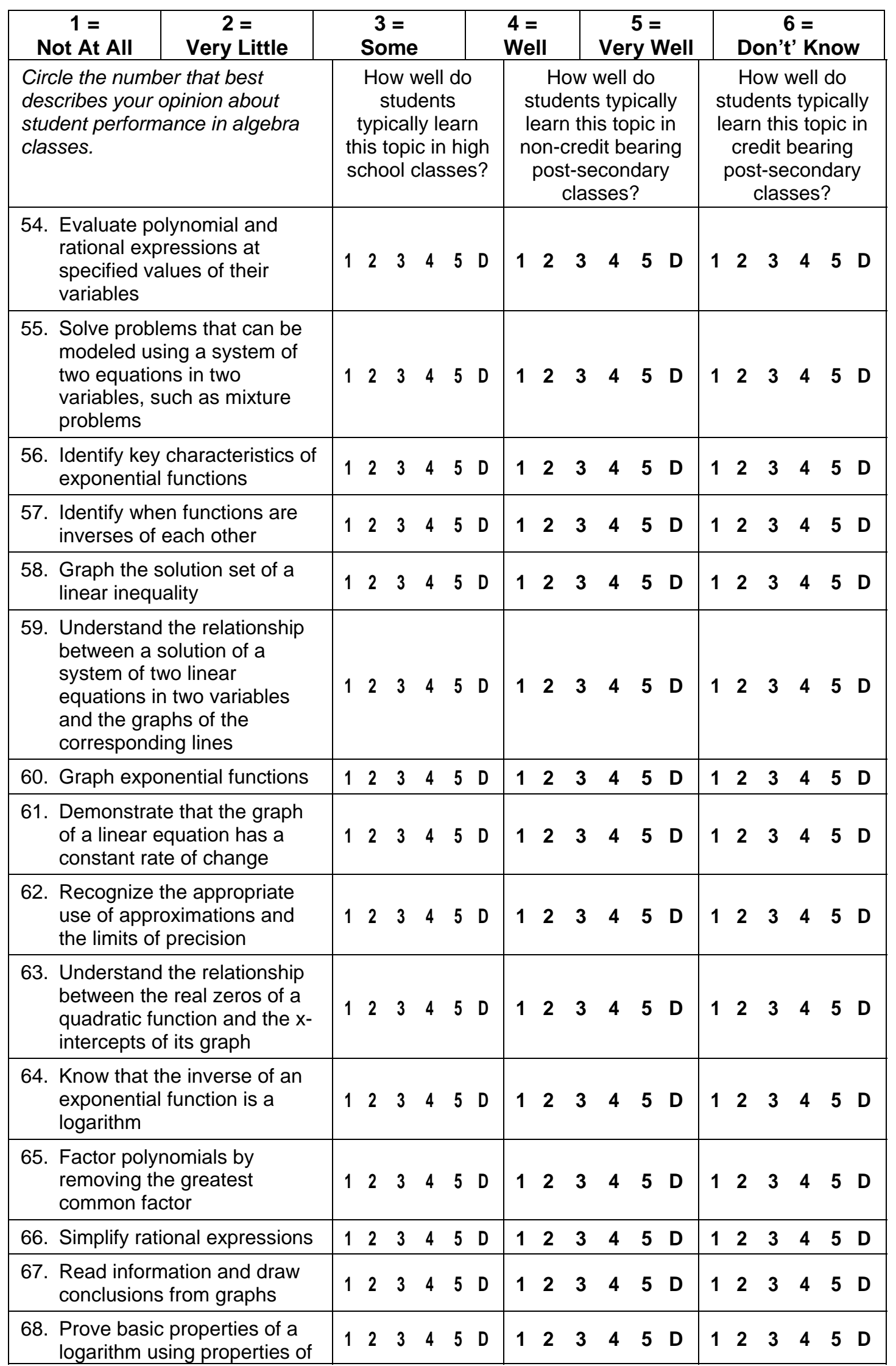




\begin{tabular}{|c|c|c|c|c|c|c|c|c|c|c|}
\hline $\begin{array}{c}1= \\
\text { Not At All }\end{array}$ & $\begin{array}{c}2= \\
\text { Very Little }\end{array}$ & & $=$ & & & & $\begin{array}{l}4= \\
\text { Well }\end{array}$ & & $\begin{array}{c}5= \\
\text { lery Well }\end{array}$ & $\begin{array}{c}6= \\
\text { Don't' Know }\end{array}$ \\
\hline \multicolumn{2}{|c|}{$\begin{array}{l}\text { Circle the number that best } \\
\text { describes your opinion about } \\
\text { student performance in algebra } \\
\text { classes. }\end{array}$} & \multicolumn{5}{|c|}{$\begin{array}{l}\text { How well do } \\
\text { students } \\
\text { typically learn } \\
\text { this topic in high } \\
\text { school classes? }\end{array}$} & \multicolumn{3}{|c|}{$\begin{array}{c}\text { How well do } \\
\text { students typically } \\
\text { learn this topic in } \\
\text { non-credit bearing } \\
\text { post-secondary } \\
\text { classes? }\end{array}$} & $\begin{array}{l}\text { How well do } \\
\text { students typically } \\
\text { learn this topic in } \\
\text { credit bearing } \\
\text { post-secondary } \\
\text { classes? }\end{array}$ \\
\hline \multicolumn{11}{|l|}{ its inverse } \\
\hline \multicolumn{2}{|c|}{$\begin{array}{l}\text { 69. Determine the domain of a } \\
\text { function in symbolic form }\end{array}$} & 1 & & & 5 & & 12 & 3 & $5 \mathrm{D}$ & $\begin{array}{lll}1 & 2 & 3\end{array}$ \\
\hline \multicolumn{2}{|c|}{$\begin{array}{l}\text { 70. Use the special symbols of } \\
\text { mathematics correctly }\end{array}$} & 1 & & & 5 & & 12 & 3 & $5 \mathrm{D}$ & $\begin{array}{llll}1 & 2 & 3 & 4\end{array}$ \\
\hline \multicolumn{2}{|c|}{$\begin{array}{l}\text { 71. Apply properties of a } \\
\text { logarithm and its inverse to } \\
\text { solve problems }\end{array}$} & 1 & & & 5 & & 12 & 3 & $5 \mathrm{D}$ & 123 \\
\hline \multicolumn{2}{|c|}{$\begin{array}{l}\text { 72. Apply the properties of } \\
\text { rational exponents to simplify } \\
\text { algebraic expressions. }\end{array}$} & & 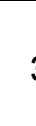 & & 5 & & 12 & 3 & $\begin{array}{lll}4 & 5 & D\end{array}$ & $\begin{array}{llll}1 & 2 & 3 & 4\end{array}$ \\
\hline
\end{tabular}

73. Additional comments? For example, share details of your experiences that influenced your responses; or share topics you think should have been addressed in the survey; or share your feelings about completing the survey.

\section{Thank you for participating in this study.}

Please return completed surveys to Jane Jones c/o Bob Ronau

College of Education \& Human Development

University of Louisville

Louisville, KY 40292 


\section{CURRICULUM VITA}

NAME: $\quad$ Jane Ann Housman Jones

ADDRESS: $\quad 6702$ Wild Fox Lane

Prospect, Kentucky 40059

DOB: $\quad$ South Bend, Indiana - March 13, 1940

EDUCATION B.A., Magna Cum Laude, Mathematics and Physics

\& TRAINING: Hanover College, Hanover, Indiana

1962

M.A.T., Mathematics Education

University of Louisville

1979

Ph.D., Curriculum and Supervision

University of Louisville

2007

\section{PROFESSIONAL EXPERIENCE:}

University of Louisville:

Research Assistant

College of Education and Human Development

Center for Research in Mathematics and Science Teacher Development

$2006-2007$

Part-Time Lecturer, Mathematics

2004-2005

Coordinator for Student Teachers in Mathematics

$2001-2002$

Graduate Assistant

College of Education and Human Development

Office of Research

$2001-2004$

Part-time Lecturer, Mathematics and Mathematics Education 
Kentucky Department of Education and Jefferson County Public Schools Region 3 Mathematics Consultant 1998-2000

High School Teaching Experience

duPont Manual High School, Louisville, Kentucky Mathematics and Computer Programming Teacher Chairperson, Computer Department School Technology Coordinator 1985-1998

Holy Cross High School, Louisville, Kentucky Mathematics and Computer Programming Teacher 1984-1985

Bishop David High School, Louisville, Kentucky Mathematics and Computer Programming Teacher 1980-1984

DuPont Manual High School, Louisville, Kentucky Mathematics Teacher 1975-1980

Westport Middle/High School Mathematics and General Science Teacher 1974-1975

AWARDS: Elected to Golden Key International Honor Society University of Louisville 2006

Samuels Fellowship University of Louisville 2003

Samuels and Grawemeyer Fellowships University of Louisville 2001, 2002

Helen Cunningham Educator Award Greater Louisville Council of Teachers of Mathematics 1997 
Presidential Award for Excellence in Mathematics and Science Teaching National Science Foundation

1996

Who's Who in America's Teachers

1996

Ashland Oil Golden Apple Achiever Award 1995

Tandy Technology Scholars Outstanding Teacher Award 1994

PROFESSIONAL Association of Mathematics Teacher Educators

SOCIETIES: $\quad$ Council of Presidential Awardees in Mathematics

Greater Louisville Council of Teachers of Mathematics

Kentucky Council of Teachers of Mathematics

Mathematical Association of America

National Council of Supervisors of Mathematics

National Council of Teachers of Mathematics

\section{REFERRED MEETING PRESENTATIONS:}

Getting Started with CAS in Calculus: Out on a Limb

International Conference of Teachers Teaching with Technology

(with P. Goins)

March 2004, New Orleans, Louisiana

Avoiding Pitfalls on the Proposal Submission Road

Society of Research Administrators International Annual Meeting (with M. Pentecost, R. Ronau)

October 2003, Pittsburgh, Pennsylvania

Lights On: Links to Achievement in Math and Science.

Annual Meeting of the Kentucky Council of Teachers of Mathematics (with G. Beswick)

September 2002, Louisville, Kentucky

Pushing Buttons or Pushing the Envelope: Using Calculators in the Math Classroom

Annual Meeting of the National Council of Supervisors of Mathematics (with K. Karp, T. Brown, G. Beswick)

April 2002, Las Vegas, Nevada 
Building Bridges to Connect High School and College Mathematics-Improving the Transitions for Students

Annual Meeting of the National Council of Supervisors of Mathematics (with R. Ronau)

April 2002, Las Vegas, Nevada

Crutch or Catalyst: Teachers Beliefs and Practices Regarding Calculator Use in Mathematics Instruction

American Educational Research Association Annual Meeting

(with K. Karp, T. Brown, G. Beswick)

April 2002, New Orleans, Louisiana

What Every New Teacher Should Know

Fall Meeting of the Kentucky Council of Teachers of Mathematics

November 2001, Owensboro, Kentucky

Connecting High School and College Mathematics

Fall Meeting of the Kentucky Council of Teachers of Mathematics

November 2001, Owensboro, Kentucky

Exploring Non-Linear Functions in Algebra

Fall Meeting of the Kentucky Council of Teachers of Mathematics

November 2000, Lexington, Kentucky

Exploring Functions in Algebra Using the TI-83 Graphing Calculator

Kentucky Learning and Technology Conference

March 2000, Louisville, Kentucky

Arithmetic and Geometric Sequences: Connections to the Real World

Annual Meeting of the Kentucky Council of Teachers of Mathematics

October 1999, Elizabethtown, Kentucky

Network Leadership that Makes a Difference

Annual Meeting of the National Council of Teachers of Mathematics

(with R. Ronau)

April 1999, San Francisco, California

Developing Technology Users and Leaders in Mathematics and Science Classrooms Through Teacher-Directed Regional Networks (with R. Ronau)

Annual Meeting of the National Council of Supervisors of Mathematics April 1998, Washington, DC 
Integrating Technology into Classroom Instruction.

Kentucky Education Technology Conference

(with S. Sidebottom)

March 1998, Louisville, Kentucky

Am I at Risk? Curve-Fitting- An Error in the Making Annual Meeting of the National Council of Teachers of Mathematics April 1997, Minneapolis, Minnesota

Matrices in the Secondary Classroom

Annual Meeting of the Kentucky Council of Teachers of Mathematics Somerset, Kentucky, October 1995

The Circle Activity

Annual Meeting of the National Council of Teachers of Mathematics (with S. Nussbaum)

April 1995, Boston, Massachusetts

Link Mathematics to Your Community Using Graph Theory

Annual Meeting of the National Council of Teachers of Mathematics April 1994, Indianapolis, Indiana

Exploratory Activities in Graph Theory

Annual Meeting of the National Council of Teachers of Mathematics

April 1992, Nashville, Tennessee

Optimizing Decision Making with Systems of Linear Inequalities, Graphs, and Matrices

Louisville Regional meeting of the National Council of Teachers of Mathematics

October 1991, Louisville, Kentucky

Probability and Statistics Activities to Integrate Into Your Classes

Annual Meeting of the National Council of Teachers of Mathematics

(with J. Austin)

April 1991, New Orleans, Louisiana

\section{REFEREED JOURNALS:}

Brown, E. T., Karp, K., Petrosko, J. M., Jones, J. H., Beswick, G., Howe, C., \& Zwanzig, K. (2007). Crutch or catalyst: Teachers beliefs and practices regarding calculator use in mathematics instruction. School Science and Mathematics. March. 


\section{NON-REFERREED PUBLICATIONS:}

Jones, J., Nickerson, L., Rising, M. Schneider, E., Schneider, G. (2002). The Physics and Mathematics of Motion. A workshop module written for a week long Kentucky Department of Education Summer Academy and presented, June, 2002, Louisville, Kentucky.

Hornbeck, C., Jones, J., Prater, P., Ryoti, D., Stamm, V., Weidemann, W..(2002). (W. Bush, Ed.) Data Analysis. A workshop module written for the Kentucky Middle Grades Mathematics Academies and presented at various week long academies throughout Kentucky, Summer, 2002.

Cantrell, A. Crowley, M., Jones, J., Manning, C., Ryoti, D., Travis, B. (2000) (W. Bush, Ed.) Functions. A workshop module written for the Kentucky Middle Grades Mathematics Academies and presented at various week long academies throughout Kentucky, Summers 2000, 2001.

\section{INVITED PRESENTATIONS:}

Statistics for High School Mathematics and Science Teachers

Technology Alliance

March 2003, Louisville, Kentucky

Graphing Calculator Activities for Advanced Users

Jefferson County Public Schools Summer Mathematics Institute (with P. Goins)

July1998, Louisville, Kentucky

Graphing Calculator Activities for High School Teachers

Jefferson County Public Schools Summer Mathematics Institute (with P. Goins, A. Herman, D. Ruggles)

August 1997, Louisville, Kentucky

Algebra Activities for Middle School Teachers

Jefferson County Public Schools workshop for middle school teachers (with A. Herman)

August 1997 and the 1997-98 school year, Louisville, Kentucky

Algebra Activities Using the Graphing Calculator

Lincoln Foundation teachers

June 1997, Louisville, Kentucky

Networks, Recursion, and Matrices in Secondary Mathematics

Jefferson County Public Schools Summer Mathematics Institute August 1995, Louisville, Kentucky 
Portfolio Ideas Using Recursion

Greater Louisville Council of Teachers of Mathematics Winter Meeting

January 1995, Louisville, Kentucky, Louisville, Kentucky

A Very Brief Introduction to Graph Theory

Greater Louisville Council of Teachers of Mathematics Winter Meeting

February 1994, Louisville, Kentucky

Topics in Discrete Mathematics

Jefferson County Public Schools Summer Mathematics Institute

August 1994, Louisville, Kentucky

Manipulatives and the Graphing Calculator

Jefferson County Public Schools Summer Mathematics Institute

(with A. Herman)

August 1994, Louisville, Kentucky

An Introduction to Topics in Discrete Mathematics

Jefferson County Public Schools Summer Mathematics Institute

August 1993, Louisville, Kentucky

Using Technology in High School Mathematics

Jefferson County Public Schools Summer Mathematics Institute

(with A. Herman, W. Mattingly)

August 1992, Louisville, Kentucky

Topics and Activities in Probability and Statistics

Jefferson County Public Schools Summer Mathematics Institute

(with J. Austin, J. Byrum, J. Greaver, M. Wesley)

August 1991, Louisville, Kentucky

Algebra for Middle School Teachers

Archdiocese of Louisville, Bellarmine University

(with J. Watts, R. Garvey, P. Green, J. Oppelt)

June 1989, Louisville, Kentucky

Probability and Statistics for Middle School Teachers

Archdiocese of Louisville, Bellarmine University

(with J. Watts, R. Garvey, P. Green, J. Oppelt)

June 1988, Louisville, Kentucky 


\section{GRANT AWARDS:}

University of Louisville/Jefferson County Public Schools Partnership Grant, $\$ 11,500$

(with R. Ronau, S. Brown, P. Goins)

2003

Institute for Advanced Studies/Park City, \$2,000

(with R. Ronau)

2003

Integrated Science and Mathematics Academy

Kentucky Department of Education, \$50,000

(with R.Ronau)

2002

University of Louisville/Jefferson County Public Schools Partnership Grant, $\$ 10,000$

(with K. Karp, G. Beswick)

(2002).

School to Work Pilot Program

Microsoft Corporation, $\$ 5000$.

(with S. Sidebottom)

1996

University of Louisville/Jefferson County Public Schools Partnership Grant, $\$ 10,000$

(with R. Ronau)

1994

Learning Tomorrow Program

National Foundation for Improvement in Education and BellSouth Foundation, $\$ 10,000$

(with B. Fendley, S. Sidebottom, B. Keepers)

1992-1994

\section{WORKSHOP/CONFERENCE LEADERSHIP:}

Building Bridges to Connect High School and College Mathematics A one-day conference for regional high school and university mathematics instructors (with R. Ronau and K. Clancey)

December 2003, University of Louisville 
The Physics and Mathematics of Motion

A one-week workshop for Jefferson County Public Schools high school mathematics and science teachers

with M. Rising, E. Schneider, G. Schneider, L. Nickerson

June 2002, Louisville, Kentucky

Connecting High School and College Mathematics

A three-day workshop for regional high school and college mathematics instructors

(with S. Seif, R. Ronau)

July 2001, University of Louisville

Kentucky Middle Grades Mathematics Academies

Three one-week workshops for local middle grades mathematics teachers (with C. Thompson, A. Herman, M. Darcy)

2000, 2001, 2002, Louisville, Kentucky

\section{SERVICE:}

Kentucky Teacher Intern Program

Teacher Educator: 2003 - 2007

Kentucky Department of Education

Grant Reviewer: 2005 - 2007

Kentucky Adult Education Benchmarks Committee: 2005

CEHD Education Graduate Student Association - Teaching and Learning

Representative: 2003 - 2004

Kentucky Core Content Advisory Committee: 1999 - 2000

Kentucky Mathematics Portfolio Advisory Committee: 1995 - 1997

LATTICE (Learning Algebra Through Technology Investigations and

Cooperative Experiences)

Steering Committee Member: 1990 - 2000

PRISM Secondary Mathematics Initiative - Teacher Consultant: 1995 - 1997

Technology Alliance

Co-chairperson (with R. Ronau): 1990 - 1998 